Igor Tona Peres

Simulação de políticas de agendamento em serviços ambulatoriais

Dissertação apresentada como requisito parcial para obtenção do grau de Mestre pelo Programa de Pós-Graduação em Engenharia de Produção do Departamento de Engenharia Industrial da PUC-Rio.

Orientador: Prof. Sílvio Hamacher

Co-orientador: Prof. Fernando Luiz Cyrino Oliveira

Rio de Janeiro

Março de 2017 
Igor Tona Peres

\section{Simulação de políticas de agendamento em serviços ambulatoriais}

Dissertação apresentada como requisito parcial para obtenção do grau de Mestre pelo Programa de Pós-Graduação em Engenharia de Produção da PUC-Rio. Aprovada pela Comissão Examinadora abaixo assinada.

Prof. Silvio Hamacher Orientador

Departamento de Engenharia Industrial - PUC-Rio

Prof. Fernando Luiz Cyrino Oliveira

Co-orientador

Departamento de Engenharia Industrial - PUC-Rio

Dr. Paulo Lísias Salomão

VITTA / SP

Prof. Thaís Spiegel

Universidade Estado do Rio de Janeiro - UERJ

Prof. Márcio da Silveira Carvalho

Coordenador Setorial do Centro Técnico Científico - PUC-Rio

Rio de Janeiro, 09 de março de 2017 
Todos os direitos reservados. É proibida a reprodução total ou parcial do trabalho sem autorização do autor, do orientador e da universidade.

\section{Igor Tona Peres}

Graduou-se em Engenharia de Produção pela Universidade Federal do Rio de Janeiro (UFRJ) em 2011. Aluno de mestrado da PUC-Rio desde março de 2015.

Ficha Catalográfica

Peres, Igor Tona

Simulação de políticas de agendamento em serviços ambulatoriais / Igor Tona Peres ; orientador: Silvio Hamacher ; co-orientador: Fernando Luiz Cyrino Oliveira. $-2017$.

130 f. : il. color. ; $30 \mathrm{~cm}$

Dissertação (mestrado)-Pontifícia Universidade Católica do Rio de Janeiro, Departamento de Engenharia Industrial, 2017.

Inclui bibliografia

1. Engenharia Industrial - Teses. 2. Agendamento de consultas. 3. Simulação de eventos discretos. 4. Sistemas de saúde. 5. Revisão sistemática. 6. Políticas de agendamento. I. Hamacher, Silvio. II. Oliveira, Fernando Luiz Cyrino. III. Pontifícia Universidade Católica do Rio de Janeiro. Departamento de Engenharia Industrial. IV. Título.

CDD: 658.5 


\section{Agradecimentos}

Aos meus pais, Sérgio e Fabíola, agradeço por todo apoio, educação, carinho, amor, torcida e confiança. Sem eles nada disso teria sido possível.

Aos meus irmãos, Gabriel e Ian, pelo suporte e companheirismo em todos os momentos que precisei, e a toda minha família pelos valores adquiridos.

À Leila, pela ajuda, paciência, incentivo e por estar sempre ao meu lado nessa jornada. Obrigado por tudo.

Aos orientadores Sílvio Hamacher e Fernando Cyrino, por todo suporte, atenção, correções, incentivos e oportunidades durante o desenvolvimento da dissertação. Obrigado por todos os ensinamentos.

Aos professores do DEI/PUC-Rio por todo conhecimento compartilhado e pelas oportunidades de aprendizado.

Aos meus colegas e amigos da PUC-Rio, obrigado por dividirem as dúvidas, experiências e por tornar toda essa trajetória um pouco mais fácil.

Ao CNPQ, FAPERJ e à PUC-Rio, pelos auxílios concedidos e pelo excelente ambiente, materiais e professores disponíveis, sem os quais este trabalho não teria sido possível.

Ao Dr. Fábio, por oferecer um excelente ambiente de estudo aplicado para o desenvolvimento desta pesquisa.

A todos aqueles que, de alguma forma, contribuíram para este trabalho, meu muito obrigado. 


\section{Resumo}

Peres, Igor Tona; Hamacher, Sílvio (Orientador); Oliveira, Fernando Luiz Cyrino (Co-Orientador). Simulação de políticas de agendamento em serviços ambulatoriais. Rio de Janeiro, 2017. 130p. Dissertação de Mestrado - Departamento de Engenharia Industrial, Pontifícia Universidade Católica do Rio de Janeiro.

Os sistemas de agendamento de consultas tradicionalmente realizam as marcações dos pacientes em intervalos fixos de tempo, sem levar em consideração diversos fatores de complexidade do sistema de saúde. Isso pode causar mão de obra ociosa em alguns períodos do dia e longas filas de espera de pacientes em outros momentos. Nesse contexto, esta dissertação tem como intuito propor uma nova política de agendamento para uma clínica especializada em cirurgia bariátrica do Rio de Janeiro, considerando os fatores desse sistema: tempos de serviços estocásticos, impontualidade do paciente, atrasos e interrupções do serviço, e presenças de no-shows. Esta dissertação analisou diversos cenários com overbooking (marcação de pacientes adicionais), e testou as principais políticas por meio de simulação, propondo a mais adequada para a clínica. As 18 políticas de agendamento aplicadas foram encontradas através de uma extensa revisão sistemática da literatura. Com a utilização da política de agendamento OFFSET, foi possível aumentar o número de atendimentos em $30 \%$ para o agendamento do principal provedor da clínica, mantendo o nível de serviço prestado. Além disto, foi proposta uma nova política de agendamento, denominada DOME CYCLE, que teve resultados superiores às demais políticas da literatura na média dos cenários realizados.

\section{Palavras-chaves}

Agendamento de consultas; simulação de eventos discretos; sistemas de saúde; revisão sistemática; políticas de agendamento. 


\section{Abstract}

Peres, Igor Tona; Hamacher, Sílvio (Advisor); Oliveira, Fernando Luiz Cyrino (Co-Advisor). Simulation of appointment-scheduling policies in outpatient services. Rio de Janeiro, 2017. 130p. Dissertação de Mestrado Departamento de Engenharia Industrial, Pontifícia Universidade Católica do Rio de Janeiro.

Appointment-scheduling systems traditionally schedule patient appointments at fixed intervals, without taking into account several complexity factors of health-care system. This schedule can make the server idle at certain times of the day and can produce long queues of patients at other times. In this context, the objective of this study is to propose a new scheduling policy for a clinic specialized in bariatric surgery in Rio de Janeiro, considering the following factors of this system: stochastic service times, patient unpunctuality, delays and interruptions of the provider and presences of no-shows. This study analyzed several scenarios with overbooking, and tested the main policies with a simulation model, proposing the most appropriate for the clinic. The 18 scheduling policies applied were found through an extensive systematic review of the literature. With the use of the OFFSET scheduling policy, it was possible to increase the number of appointments by $30 \%$ to the scheduling of the main clinic provider, maintaining the level of service provided. In addition, a new scheduling policy, called DOME CYCLE, was proposed, which has outperformed the other policies in the average of the tests performed.

\section{Keywords}

Appointment scheduling; discrete event simulation; healthcare; systematic review; scheduling policies. 


\section{Sumário}

1 Introdução 14

1.1. Contextualização da Pesquisa 14

1.2. Motivação 15

$\begin{array}{ll}\text { 1.3. Objetivo } & 17\end{array}$

1.4. Classificação da Pesquisa 18

1.5. Organização do trabalho 19

2 Revisão sistemática da literatura 20

2.1. Metodologia 20

2.2. Identificação dos estudos $\quad 24$

2.3. Síntese da literatura 28

2.3.1. Fatores de complexidade do ambiente 28

2.3.1.1. Número de serviços 34

2.3.1.2. Número de servidores 34

2.3.1.3. Número de agendamentos 34

2.3.1.4. Processo de chegada 35

$\begin{array}{ll}\text { 2.3.1.5. Tempo de serviço } & 37\end{array}$

2.3.1.6. Atraso e interrupções do serviço 38

2.3.1.7. Disciplina da fila 38

2.3.1.8. Preferências dos pacientes e dos provedores 40

2.3.2. Indicadores de desempenho 41

2.3.2.1. Indicadores de custo 42

2.3.2.2. Indicadores de tempo 43

2.3.2.3. Indicadores de congestionamento 44

2.3.2.4. Indicadores de equidade $\quad 44$

2.3.2.5. Outros indicadores 44

2.3.3. Políticas de agendamento $\quad 45$

2.3.3.1. Regras de agendamento 46

2.3.3.2. Classificação do paciente 48

2.3.3.3. Ajustes para no-shows e walk-ins $\quad 49$

2.3.4. Método para análise de Políticas de Agendamento 51 
3 Estudo de caso 55

3.1. Tempos de serviços 59

3.2. Impontualidade dos pacientes 60

3.3. Atraso e interrupções do serviço 61

3.4. No-show de pacientes 62

3.5. Disciplina da fila 64

4 Método 65

4.1. Modelo de Simulação 65

4.2. Premissas básicas 67

4.3. Cenário atual 67

4.4. Políticas de agendamento 68

4.5. Validação do modelo 70

4.6. Geração de cenários 72

4.7. Indicadores de desempenho 74

5 Resultados 76

5.1. Cenário 1 - Situação Atual 76

5.2. Cenário 2 - Cenário atual sem atraso do médico 77

5.3. Cenário 3 - Situação proposta sem atraso e com overbooking de pacientes 79

5.4. Cenário 4 - Análise de sensibilidade com redução do no-show 80

5.5. Cenário 5 - Análise de sensibilidade com aumento do no-show 82

5.6. Cenário 6 - Horário alternativo (10h-17h45min) 83

5.7. Cenário 7 - Horário alternativo (10h-16h30min) 84

5.8. Cenário 8 - Horário alternativo (13h-17h30min) 86

5.9. Comparação entre as políticas de agendamento 87

5.10. Discussão 92

6 Conclusão 98

7 Referências 102 
Apêndice A - Formulações das regras de agendamento 106

Apêndice B - Regras de sequenciamento 111

Apêndice C - Regra para ajuste de intervalo de agendamento 114

Apêndice $D$ - Descrição dos artigos analisados na revisão da literatura 115

Apêndice E - Teste estatístico do no-show por dia da semana 125

Apêndice F - Teste estatístico do no-show por classe de paciente 126

Apêndice G - Ajuste do no-show de cada horário pela proporção de pacientes

Apêndice $\mathrm{H}$ - Teste estatístico do no-show por horário do dia 128

Apêndice I - Teste estatístico do no-show por horário do dia (retirando faixa de 18h-19h)

129

Apêndice J - Formulação da regra proposta (DOME CYCLE) 130 


\section{Lista de figuras}

Figura 1 - Resultado da seleção dos artigos por etapas 23

Figura 2 - Gráfico de publicações por ano em grupos de quatro anos 26

Figura 3 - Regras de Agendamento $\quad 47$

Figura 4- Outras regras de agendamento encontradas na literatura $\quad 48$

Figura 5 - Modelo conceitual do processo de consulta 58

Figura 6 - Modelo de Simulação 66

Figura 7 - Regras de Agendamento utilizadas na aplicação 68

Figura 8 - Regra de Agendamento DOME CYCLE 69

Figura 10 - Comparação do comportamento do tempo médio de fila entre os Cenários 1 e 3 por faixa de horário agendado 95

Figura 11 - Comparação do comportamento do tempo médio de fila entre os Cenários 6, 7 e 8 por faixa de horário agendado $\quad 95$

Figura 12 - Horários do turno da tarde da política DOME CYCLE no Cenário 7

Figura 13 - Horários do turno da tarde da política DOME no Cenário 7

100

Figura 14 - Exemplo de regra IBFI sem ajuste e com ajustes nos intervalos de agendamento (IBFIA) 


\section{Lista de tabelas}

Tabela 1 - Identificação dos estudos $\quad 25$

Tabela 2- Total de artigos por fonte de publicação 27

Tabela 3- Total de publicações e citações por primeiro autor 27

Tabela 4 - Fatores de complexidade dos artigos 31

Tabela 5 - Comparação quantitativa do desempenho das regras de agendamento 53

Tabela 6 - Comparação quantitativa do desempenho das regras de sequenciamento

Tabela 7 - Classificação dos médicos por ํㅡㄹ de consultas realizadas entre 29/06/2015 a 29/06/2016 56

Tabela 8 - Resumo das estatísticas dos dados coletados 62

Tabela 9 - Média de cada indicador para o cenário atual 66

Tabela 10 - Validação do modelo $\quad 70$

Tabela 11 - Comparação do desvio do tempo de fila por horário agendado

Tabela 12 - Configurações dos fatores de complexidade de cada cenário

Tabela 13 - Resultados do Cenário $1 \quad 76$

Tabela 14 - Resultados do Cenário $2 \quad 78$

Tabela 15 - Resultados do Cenário $3 \quad 79$

Tabela 16 - Resultados do Cenário 4

Tabela 17 - Resultados do Cenário 5

Tabela 18 - Resultados do Cenário 6

Tabela 19 - Resultados do Cenário $7 \quad 85$

Tabela 20 - Resultados do Cenário $8 \quad 86$

Tabela 21 - Resultados dos desvios para o Cenário 1

Tabela 22 - Resultados dos desvios para o Cenário $3 \quad 89$

Tabela 23 - Resultados dos desvios para o Cenário $6 \quad 90$

Tabela 24 - Resultados dos desvios para o Cenário $7 \quad 90$

Tabela 25 - Resultados dos desvios para o Cenário $8 \quad 91$

Tabela 26 - Comparação entre as principais políticas de

Tabela 27 - Resultado dos cenários relevantes 93 
Tabela 28 - Resumo dos artigos

Tabela 29 - Teste de significância da variação do no-show por dia da semana

Tabela 30 - Teste de significância da variação do no-show por classe de paciente

Tabela 31 - Ajuste do no-show de cada horário pela proporção de pacientes

Tabela 32 - Teste de significância da variação do no-show por horário do dia

Tabela 33 - Teste de significância da variação do no-show por horário do dia, com exceção do horário de 18h-19h 


\section{Lista de quadros}

Quadro 1 - Testes das lógicas de busca nas bases de dados

Quadro 2 - Framework para formulação do problema

Quadro 3 - Framework de indicadores de desempenho

Quadro 4 - Framework para desenvolvimento de Políticas de Agendamento

Quadro 5 - Framework de Metodologias de análise de Políticas de Agendamento 


\section{1 Introdução}

\section{1.}

\section{Contextualização da Pesquisa}

As despesas de saúde per capita aumentaram mais de $70 \%$ desde o início da década de 1990 nos países membros da Organization for Economic Co-operation and Development (OECD). Como resultado do aumento dos gastos, a despesa total no setor de saúde, atualmente, representa, em média, mais de 9\% do PIB desses países. Entretanto, os países que gastam mais em saúde não são necessariamente os que obtêm melhores resultados, sugerindo que há espaço para obter maior valor para os investimentos em saúde (OECD, 2010).

No contexto brasileiro, segundo a World Health Organization (WHO, 2014), as despesas de saúde, somando despesas públicas e privadas, vêm crescendo nos últimos anos, de forma que, em 2014, os gastos somaram 8,3\% do total do PIB brasileiro enquanto em 2004 eram 7,1\%. Entretanto, observa-se que este crescimento não se traduziu em melhora real do sistema brasileiro, que vem sofrendo uma série de problemas nas mais diversas áreas da saúde. Ainda segundo a WHO, neste mesmo ano de 2014, as instituições privadas foram responsáveis por 54\% do total movimentado em saúde, enquanto o setor público contribuiu com os $46 \%$ restantes.

Quando se acrescentam fatores tais como o envelhecimento da população, o aumento do número de casos crônicos e os orçamentos restritos para os setores de saúde, nota-se crescente pressão sobre os prestadores de serviços de saúde para a melhoria da eficiência (Gupta e Denton, 2008; OECD, 2010; Hall, 2012). Dessa forma, os criadores de políticas de saúde têm um interesse crescente em encontrar formas de incentivar a melhora do desempenho do sistema, o qual é medido em relação a indicadores de qualidade, eficiência e equidade. Tal melhora tem o 
potencial de reduzir as tensões entre as crescentes demandas e os recursos limitados (EUROPEAN COMISSION, 2009).

Devido à complexidade dos sistemas de saúde, onde existem objetivos conflitantes, Delesie (1998) afirma que as abordagens de resolução de problemas devem-se concentrar principalmente na "solução" e "implementação" e, por isso, a aplicação de técnicas de Pesquisa Operacional (PO) é muito indicada nessa área. Segundo Hulshof et al. (2012), desde 1950, a aplicação de técnicas de PO nos serviços de saúde vem produzindo contribuições significativas na realização de ganhos de eficiência, e, portanto, vem demonstrando ser um mecanismo importante para a resolução dos problemas de planejamento em saúde.

Hans et al. (2012) definem as áreas gerenciais para o planejamento e controle dos serviços de saúde como: planejamento médico, planejamento da capacidade dos recursos, planejamento dos materiais e planejamento financeiro. Hulshof et al. (2012) definem os níveis de decisão de planejamento e controle em saúde, quais sejam: estratégico, tático, operacional (offline ou online). O presente estudo aborda o tema de agendamento de consultas, situado na área gerencial referente ao planejamento da capacidade dos recursos (Hans et al., 2012) e no nível de decisão tático (Hulshof et al., 2012).

\section{2.}

\section{Motivação}

Sistemas de agendamentos, para serviços em geral, são desenvolvidos para a atribuição de data e horário para as chegadas dos clientes em uma determinada unidade. Em um hospital, sistemas de agendamento podem ser necessários para controlar a chegada de pacientes para consultas, diagnósticos ou outros procedimentos e cirurgias (Bhattacharjee e Ray, 2016).

Esses sistemas podem ser uma fonte de insatisfação, tanto para pacientes quanto para provedores. Pacientes são afetados pela falta de disponibilidade de horários convenientes na agenda do provedor, principalmente, quando seu atendimento é de urgência, e os provedores são afetados pela incerteza do número de consultas em cada dia e pela variedade de casos que podem surgir. Esses fatores 
podem afetar tanto a remuneração dos provedores quanto os seus níveis de satisfação no trabalho (Gupta e Denton, 2008).

Dessa forma, um sistema de agendamento é projetado para garantir a disponibilidade e pontualidade do serviço de saúde, atuando para melhorar a produtividade operacional e a experiência do cliente. Com o objetivo de melhorar a relação entre capacidade e demanda, um sistema de agendamento busca suavizar a demanda e reduzir a incerteza nas chegadas de pacientes, ao mesmo tempo em que conta com a disponibilidade dos recursos, como provedores e equipamentos. Dado que estes recursos são caros, a maximização da utilização é uma questão crítica. Por outro lado, no ambiente atual cada vez mais competitivo e orientado ao consumidor, os cuidados de saúde não estão imunes à intolerância dos pacientes aos longos tempos de espera, e que segundo Huang (1994), essa espera excessiva é muitas vezes a principal razão da insatisfação dos pacientes nos ambulatórios. Portanto, o objetivo geral de um sistema de agendamento bem projetado é conseguir um equilíbrio entre os objetivos concorrentes e conflitantes, de aumentar a utilização dos recursos e de reduzir o tempo de espera dos pacientes (Bhattacharjee e Ray, 2016; Cayirli e Veral, 2003; Cayirli et al., 2012).

Sistemas de agendamentos são projetados para entregar o acesso conveniente aos serviços de saúde para todos os pacientes, tornar o fluxo de trabalho mais suave, reduzir a aglomeração nas salas de espera e respeitar as preferências dos pacientes e dos provedores (Gupta e Denton, 2008). O objetivo de um sistema de agendamento é encontrar uma política que otimize determinada medida de desempenho, considerando a incerteza do ambiente analisado (Cayirli e Veral, 2003).

As Políticas de Agendamento envolvem diferentes regras de agendamento de pacientes. O objetivo de uma regra de agendamento é definir um intervalo de tempo entre agendamentos e a quantidade de pacientes que devem ser agendados por horário (Cayirli e Veral, 2003).

Com vistas à criação de um sistema de agendamento apropriado para uma determinada clínica, é necessário considerar os fatores que afetam a eficiência do agendamento, tais como a variabilidade dos tempos de serviço do médico, a variabilidade dos intervalos entre chegadas dos pacientes (impontualidade), a taxa de 
não comparecimento dos pacientes (no-show), a presença de pacientes não agendados (walk-ins) e de urgência, e quaisquer outras interrupções com potencial de perturbar o agendamento, sendo necessário uma avaliação constante destes sistemas (Cayirli e Veral, 2003; Gupta e Denton, 2008; Bhattacharjee e Ray, 2016).

Entretanto, conforme se nota na maior parte dos hospitais e clínicas brasileiros, o agendamento de consultas normalmente é feito em intervalos fixos de tempo sem levar em consideração os fatores perturbadores tratados acima. Dessa forma, um processo eficiente de agendamento que considere esses fatores pode melhorar o nível de serviço e/ou aumentar a receita do provedor nos serviços de saúde.

Nesse contexto, este trabalho irá analisar o processo de agendamento de uma clínica especializada em cirurgia bariátrica localizada no Rio de Janeiro. Essa clínica é caracterizada por possuir mão de obra ociosa em certos horários do dia e longas filas de espera de pacientes em outros. A política de agendamento atual marca os pacientes em intervalos fixos de tempo, e não considera os fatores perturbadores do sistema, quais sejam: tempos de serviços estocásticos, impontualidade do paciente, atrasos e interrupções do serviço e presenças de no-shows.

\section{3. \\ Objetivo}

De acordo com a problemática citada acima, esta dissertação tem como objetivo realizar uma pesquisa aplicada em uma clínica de cirurgia bariátrica. O objetivo principal é desenvolver uma política de agendamento que considere os fatores estocásticos do sistema a fim de melhorar o nível de serviço prestado (diminuição do tempo de espera em filas) e incrementar a receita da clínica, com o aumento do número de atendimentos e redução da ociosidade. O objetivo secundário é apresentar as técnicas mais utilizadas na literatura e o estado da arte em termos de políticas de agendamento, envolvendo regras de agendamento e sequenciamento, através de uma extensa revisão sistemática da literatura.

A pesquisa aqui aplicada possibilita testar as principais políticas encontradas na literatura por meio de um modelo de simulação e comparar o desempenho das diversas abordagens, verificando qual gerou os melhores resultados. O presente 
trabalho também tem como objetivo verificar se é possível sugerir uma nova política de agendamento a partir do conhecimento obtido na revisão sistemática da literatura e, caso seja, pode-se testá-la no caso real da clínica em estudo. Outro objetivo é gerar cenários com diferentes horários de trabalho para diferentes períodos do ano, buscando encontrar o cenário ideal para períodos de alta, média e baixa demanda.

\section{4.}

\section{Classificação da Pesquisa}

Para a classificação da pesquisa foi utilizada a taxonomia proposta por Vergara (1997) que categoriza as pesquisas quanto aos fins e quanto aos meios.

Quanto aos fins, a pesquisa pode ser classificada como uma investigação exploratória, uma vez que está sendo realizada em um tema em que o conhecimento ainda não está totalmente sistematizado, visto que as duas revisões da literatura existentes nesse tema não são sistemáticas, além de não serem recentes. Além disso, o tema envolvendo políticas de agendamento passou a ter mais publicações recentemente. Portanto, esses fatores adicionam ainda mais valor a esta pesquisa exploratória.

Ainda quanto aos fins, como esta pesquisa visa estudar o processo de agendamento de consultas de uma clínica de cirurgia bariátrica do sistema de saúde privado brasileiro, pode-se também classificá-la como uma pesquisa aplicada, já que possui finalidade prática de resolução de um problema concreto.

No que tange a classificação quanto aos meios, também segundo a classificação de Vergara (1997), a pesquisa pode ser descrita como:

- Bibliográfica: a revisão teórica foi realizada por meio de um estudo sistematizado desenvolvido com base em material publicado em dissertações e artigos, sendo estes materiais acessíveis ao público em geral;

- Pesquisa de campo: a investigação empírica foi realizada no local do fenômeno (clínica) por meio de aplicação de entrevistas não estruturadas, observação direta e acesso a dados históricos. 
- Experimental: ocorreu a manipulação e controle de variáveis independentes e observaram-se as variações que tais manipulações e controles produziram em variáveis dependentes na etapa de Simulação de Eventos Discretos;

- Estudo de caso: o estudo foi de profundidade e detalhamento tratando da observação de uma única empresa.

Pode-se classificar também a pesquisa quanto ao seu enfoque. Nesse trabalho, o enfoque é quantitativo e qualitativo. Quantitativo pelo fato de utilizar dados e informações quantitativas para provar hipóteses com base na medição numérica e análise estatística para estabelecer padrões de comportamento, e qualitativo por utilizar as informações e dados obtidos sem medição numérica para levantar ou refinar perguntas no processo de interpretação dos fenômenos e de atribuição de significados.

\section{5.}

\section{Organização do trabalho}

A estrutura da dissertação tem a seguinte forma. Após este capítulo de introdução, o Capítulo 2 apresenta a revisão da literatura. O Capítulo 3 apresenta a problemática da clínica estudada, seguidos do Capítulo 4 que apresenta o método utilizado no estudo de caso e do Capítulo 5 que apresenta os resultados do estudo de caso. As principais conclusões e sugestões para pesquisas futuras são apresentadas no Capítulo 6. 


\section{Revisão sistemática da literatura}

Neste capítulo será apresentada uma revisão da literatura sobre políticas de agendamento de consultas, que busca encontrar políticas que foram desenvolvidas e comparadas de forma quantitativa com as principais políticas existentes. A metodologia utilizada para a execução da pesquisa considera uma análise descritiva dos artigos selecionados, uma síntese com os principais resultados encontrados na literatura e uma análise desses resultados.

\section{1.}

\section{Metodologia}

De início, foi realizada uma revisão sistemática da literatura sobre políticas de agendamento de consultas. Para a seleção dos artigos, seguiu-se uma metodologia de seis passos adaptada de Thomé et al. (2012): (i) seleção das bases de dados; (ii) identificação das palavras-chave para a pesquisa; (iii) criação de critérios de exclusão; (iv) leitura dos resumos dos artigos encontrados na pesquisa e seleção para leitura do texto completo; (v) revisão do texto completo dos artigos selecionados; e (vi) inserção de outras referências consideradas relevantes por meio de pesquisa para trás, ou seja, "varredura" às referências citadas.

Na primeira etapa, duas bases de dados foram selecionadas para a realização da pesquisa: Scopus e PubMed. A base de dados Scopus é vastamente conhecida por possibilitar a pesquisa de artigos das principais revistas de diversas áreas de conhecimento científico, enquanto que a base de dados PubMed possibilita a pesquisa na literatura biomédica.

$\mathrm{Na}$ segunda etapa, as palavras-chave foram selecionadas, com o intuito de obter resultados que fossem abrangentes o suficiente para que os artigos relevantes fossem encontrados, mas que também limitasse o número total de resultados evitando 
inviabilizar a pesquisa. Para isso, foram analisadas as palavras-chave utilizadas nos principais artigos sobre o tema, verificando quais as palavras que mais apareciam em palavras-chave o no resumo dos artigos. Dessa forma, antes de acordar a expressão de busca, muitas publicações foram analisadas e outras combinações de palavras-chave foram testadas.

Assim sendo, cinco "lógicas de busca" foram feitas a partir de combinações das palavras-chave mais encontradas nos artigos e, em seguida, testadas em ambas as bases. As lógicas de busca, o total de artigos encontrados em cada base e o total de artigos encontrados excluindo os artigos repetidos estão demonstrados no Quadro 1.

Quadro 1 - Testes das lógicas de busca nas bases de dados. Fonte: Elaboração própria.

\begin{tabular}{|cccc|}
\hline Lógicas de busca & $\begin{array}{c}\text { Total de } \\
\text { artigos na } \\
\text { Scopus }\end{array}$ & $\begin{array}{c}\text { Total de } \\
\text { artigos } \\
\text { na } \\
\text { PubMed }\end{array}$ & $\begin{array}{c}\text { Total de } \\
\text { artigos } \\
\text { excluindo } \\
\text { repetiçóes }\end{array}$ \\
\hline (a) & 324 & 194 & 353 \\
(b) $\quad \begin{array}{l}\text { \{appointment scheduling\} } \\
\text { \{appointment scheduling\} OR \{appointment } \\
\text { booking\} OR \{outpatient scheduling\} OR } \\
\text { \{appointment-scheduling\} OR \{appointment- } \\
\text { booking\} OR \{outpatient-scheduling\} }\end{array}$ & 387 & 234 & 420 \\
\hline
\end{tabular}

Analisando o Quadro 1, percebe-se que existem outras maneiras de se referir ao agendamento de consultas além da expressão "appointment scheduling”, enumerada como (a), que é sem dúvidas a tradução mais usada. Por isso, optou-se por adicionar as expressões "appointment booking" e "outpatient scheduling” para não excluir artigos indevidamente. Além disso, pelo mesmo motivo, foram adicionadas expressões semelhantes às anteriores, mas com a presença do hífen entre elas, quais sejam: "appointment-scheduling”; “appointment-booking”; e "outpatientscheduling".

Conforme pode ser visto no Quadro 1, percebe-se que a presença de todas as expressões é importante para não excluir nenhum artigo indevidamente. Por isso, foi utilizada a lógica de busca (b), que compreende todas as expressões de busca. 
A consulta às bases de dados foi realizada em julho de 2016, e dos resultados retornados foram filtrados somente artigos e revisões científicos publicados em periódicos indexados. Com o intuito de direcionar a pesquisa, as lógicas de busca foram aplicadas para title, abstracts e keywords dos artigos da base Scopus e para title e abstracts dos artigos da base PubMed, sem limitação para os tipos de journals. Dessa maneira, a pesquisa devolveu 621 artigos, sendo 201 duplicados, restando 420 para a leitura dos resumos.

Para a terceira etapa, foram criados os critérios de exclusão dos artigos, quais sejam: (i) o artigo não trata de políticas de agendamento de consultas; (ii) o artigo não é da área de saúde; e (iii) o artigo trata de programação de cirurgias. Após a leitura dos resumos e exclusão dos artigos de acordo com os critérios estabelecidos na quarta etapa, restaram 114 artigos para leitura de texto completo.

Na leitura e revisão do texto completo, que compreende a quinta etapa, somente os artigos que puderam ser encontrados via meio eletrônico foram considerados. Nessa etapa, os artigos foram excluídos seguindo os mesmos critérios citados anteriormente, adicionados a mais dois critérios observados durante as leituras, explicados a seguir.

Como o objetivo da pesquisa era encontrar trabalhos que testassem e/ou propusessem políticas de agendamento e comparassem de forma quantitativa com as principais políticas existentes, foram adicionados então os seguintes critérios de exclusão: (iv) o artigo considera apenas um dentre os diversos fatores de complexidade do ambiente de saúde (conforme fatores que serão apresentados no Quadro 2 da Seção 2.3.1); (v) o artigo não testa uma política de agendamento e compara de forma quantitativa com as principais políticas existentes na literatura.

Após a leitura do texto completo, 97 artigos foram excluídos, sendo seis no critério (i), três no critério (iv), 73 no critério (v) e 15 indisponíveis (ind.). Vale observar que, dos 73 artigos excluídos no critério (v), 58 também poderiam ser excluídos pelo critério (iv). Dessa forma, restaram 17 publicações selecionadas para o trabalho de síntese. Na sexta etapa, mais três documentos foram incluídos, totalizando 20 artigos selecionados. A Figura 1 apresenta um resumo do número de papers selecionados em cada etapa. 


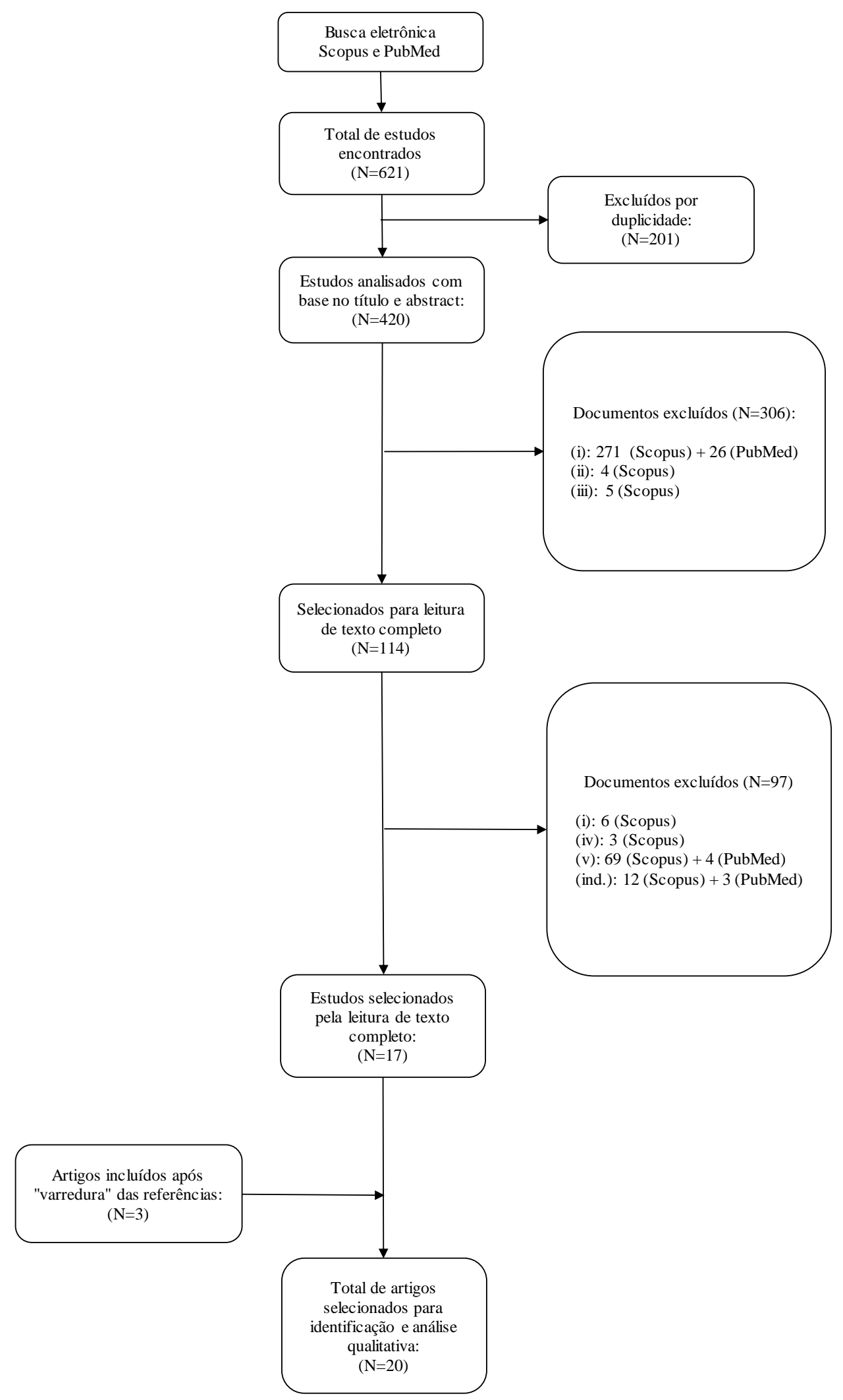

Figura 1 - Resultado da seleção dos artigos por etapas. Fonte: Elaboração própria. 
Em suma, restou um total de 20 artigos selecionados para a identificação e análise do estudo. $\mathrm{O}$ resultado desta revisão será utilizado para complementar, de forma sistemática, as análises feitas nas revisões passadas de Cayirli e Veral (2003) e de Gupta e Denton (2008), que também foram encontradas nessa pesquisa, mas que foram excluídas na quinta etapa pelo critério (v). Como a última revisão encontrada foi a de 2008, e como essas duas revisões não foram feitas de forma sistemática, há uma necessidade de sistematizar os resultados encontrados e sintetizar o estado atual da arte neste tema.

No que tange à leitura dos artigos, a seleção descrita acima e a análise do conteúdo apresentada na próxima seção respeitam os cinco itens que, segundo Khan et al. (2003), devem ser obedecidos em uma revisão sistemática da literatura, quais sejam: identificação de forma clara do problema em estudo; decidir as questões abordadas; avaliar a qualidade dos estudos e ter um nível mínimo de aceitação; sintetizar os dados apresentando as características do estudo; e interpretar a pesquisa encontrada.

A identificação dos estudos, a síntese da literatura e a análise dos resultados encontrados encontram-se nas seções $2.2,2.3$ e 2.4, respectivamente.

\section{2.}

\section{Identificação dos estudos}

Inicialmente, foi realizada a identificação dos 20 estudos encontrados na revisão da literatura. Uma lista de todos os trabalhos incluídos nesta revisão, por autores, ano, fontes de publicação e número de citações da base Scopus é apresentada na Tabela 1, ordenada por número de citações. 
Tabela 1 - Identificação dos estudos. Fonte: Elaboração própria.

\begin{tabular}{|c|c|c|c|}
\hline Autor (es) & Ano & Fonte de publicação & $\begin{array}{l}\mathrm{N}^{\circ} \text { de } \\
\text { citações }\end{array}$ \\
\hline Klassen e Rohleder & 1996 & Jornal of Operations Management & 137 \\
\hline Cayirli et al. & 2006 & Health Care Management Science & 111 \\
\hline LaGanga e Lawrence & 2007 & Decision Sciences & 105 \\
\hline Cayirli et al. & 2008 & Production and Operations Management & 62 \\
\hline Rohleder e Klassen & 2000 & Omega & 45 \\
\hline $\begin{array}{l}\text { Klassen e } \\
\text { Yoogalingam }\end{array}$ & 2009 & Production and Operations Management & 43 \\
\hline Cayirli et al. & 2012 & Production and Operations Management & 39 \\
\hline Ho e Lau & 1999 & European Journal of Operational Research & 38 \\
\hline Klassen e Rohleder & 2004 & $\begin{array}{l}\text { International Journal of Service Industry } \\
\text { Management }\end{array}$ & 36 \\
\hline White et al. & 2011 & Production and Operations Management & 19 \\
\hline $\begin{array}{l}\text { Klassen e } \\
\text { Yoogalingam }\end{array}$ & 2013 & $\begin{array}{l}\text { International Journal of Operations and } \\
\text { Production Management }\end{array}$ & 11 \\
\hline Jerbi e Kamoun & 2011 & Simulation Modelling Practice and Theory & 8 \\
\hline Salzarulo et al. & 2011 & Production and Operations Management & 7 \\
\hline $\begin{array}{l}\text { Athula Wijewickrama } \\
\text { e Takakuwa }\end{array}$ & 2012 & $\begin{array}{l}\text { International Journal of Healthcare Technology } \\
\text { and Management }\end{array}$ & 4 \\
\hline $\begin{array}{l}\text { Klassen e } \\
\text { Yoogalingam }\end{array}$ & 2014 & Decision Sciences & 4 \\
\hline Bhattacharjee e Ray & 2016 & Operations Research for Health Care & 1 \\
\hline Sepülveda e Berroeta & 2012 & Revista Medica de Chile & 0 \\
\hline Bard et al. & 2016 & Health Care Management Science & 0 \\
\hline Cayirli e Yang & 2014 & Service Science & - \\
\hline Ho e Lau & 1992 & Management Science & - \\
\hline
\end{tabular}

Percebe-se que os artigos em periódicos selecionados para esta pesquisa foram publicados em diversas fontes. Quanto ao número de citações, pode-se observar que os trabalhos de Klassen e Rohleder (1996), Cayirli et al. (2006) e LaGanga e Lawrence (2007) foram os trabalhos mais citados, com 137, 111 e 105 citações, respectivamente.

Os trabalhos de Cayirli e Yang (2014) e de Ho e Lau (1992) não foram encontrados na base Scopus e PubMed, e, por isso, estão sem o número de citações. Esses foram trabalhos inseridos após a revisão das referências dos artigos selecionados, além do trabalho de Klassen e Rohleder (1996). 
A Figura 2 apresenta a evolução dos artigos utilizados na pesquisa ao longo do tempo, em grupos de quatro anos.

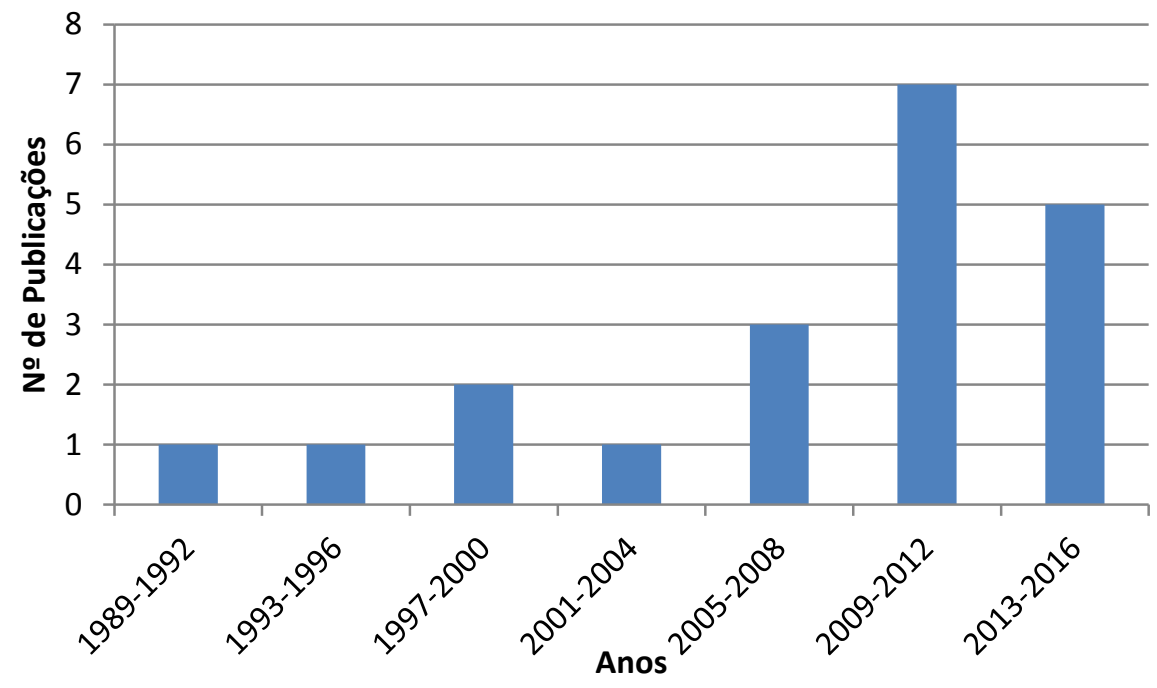

Figura 2 - Gráfico de publicações por ano em grupos de quatro anos. Fonte: Elaboração própria.

Na Tabela 2, observa-se uma análise do total de artigos selecionados em relação às fontes de publicação, na qual se pode verificar que a maioria dos trabalhos selecionados foram publicados em journals de alto fator de impacto, sendo a maior parte deles no periódico Production and Operations Management. 
Tabela 2- Total de artigos por fonte de publicação. Fonte: Elaboração própria.

\begin{tabular}{lc}
\hline Fonte de publicação & $\begin{array}{c}\text { Total de } \\
\text { Publicações }\end{array}$ \\
\hline Production and Operations Management & 5 \\
Decision Sciences & 2 \\
Health Care Management Science & 2 \\
European Journal of Operational Research & 1 \\
International Journal of Healthcare Technology and & 1 \\
Management & 1 \\
International Journal of Operations and Production & 1 \\
Management & 1 \\
International Journal of Service Industry Management & 1 \\
Management Science & 1 \\
Omega & 1 \\
Operations Research for Health Care & 1 \\
Revista Medica de Chile & 1 \\
Service Science & 1 \\
Simulation Modelling Practice and Theory & \\
Jornal of Operations Management & \\
\hline
\end{tabular}

A Tabela 3 indica o total de artigos selecionados por autor e o total de citações nesses trabalhos. Percebe-se que o autor Klassen e autora Cayirli tiveram o maior número de publicações selecionadas e o maior número de citações em seus trabalhos.

Tabela 3- Total de publicações e citações por primeiro autor. Fonte: Elaboração própria.

\begin{tabular}{lcc}
\hline Primeiro Autor & Total de Publicações & Total de Citações \\
\hline Klassen & 5 & 231 \\
Cayirli & 4 & 212 \\
LaGanga & 1 & 105 \\
Rohleder & 1 & 45 \\
Ho & 2 & 38 \\
White & 1 & 19 \\
Jerbi & 1 & 8 \\
Salzarulo & 1 & 7 \\
Athula Wijewickrama & 1 & 4 \\
Bhattacharjee & 1 & 1 \\
Bard & 1 & 0 \\
Sepülveda & 1 & 0 \\
\hline
\end{tabular}




\section{3.}

\section{Síntese da literatura}

O estudo do agendamento de pacientes em serviços ambulatoriais tem atraído o interesse de muitos acadêmicos e profissionais ao longo dos últimos 60 anos, começando com os trabalhos pioneiros de Bailey (1952) e Lindley (1952). O primeiro trabalho de revisão da literatura neste tema foi o de Cayirli e Veral (2003).

Segundo Cayirli e Veral (2003), a literatura em políticas de agendamento pode ser separada em modelos estáticos e dinâmicos. Nos modelos de agendamento estáticos, os agendamentos são definidos antes do início da seção (dia de trabalho). Nos modelos dinâmicos, os agendamentos são revisados continuamente ao longo do

dia com base no status atual do sistema, sendo aplicáveis a locais onde os pacientes já estão admitidos no hospital ou clínica e serão então encaminhados para algum serviço. Os trabalhos selecionados na revisão sistemática encontraram apenas modelos de agendamento estático, o que está alinhado com o objetivo do trabalho aplicado, que é o agendamento de pacientes que ainda não foram admitidos a uma clínica.

A síntese da literatura foi dividida em cinco subseções que serão tratadas a seguir, quais sejam: (i) fatores de complexidade do ambiente de saúde; (ii) indicadores de desempenho; (iii) políticas de agendamento; e (iv) metodologias de análise de políticas de agendamento.

\subsection{1.}

\section{Fatores de complexidade do ambiente}

Segundo Cayirli e Veral (2003), no que tange à definição e à formulação do problema de agendamento, pode-se dizer que os ambulatórios são considerados sistemas de filas. O caso mais simples é quando todos os pacientes agendados chegam pontualmente no horário marcado e apenas um único médico está atendendo com tempos de processamento estocásticos. A formulação torna-se complexa quando existem mais fatores envolvidos, tais como: a presença de múltiplos servidores; múltiplos serviços; pacientes impontuais; no-shows; walk-ins e variabilidade no tempo de serviço. Esses fatores podem acabar perturbando o desempenho do sistema, 
assim como o atraso do provedor e as interrupções no serviço. O Quadro 2 resume os fatores relacionados à formulação do problema de agendamento de consultas. Este quadro foi adaptado de Cayirli e Veral (2003), e os itens 2.(iv)(b) e 2.(v) foram aqui melhor detalhados, com o acréscimo do item 2.(viii).

Quadro 2 - Framework para formulação do problema. Fonte: Adaptado de Cayirli e Veral (2003).

\begin{tabular}{|l|}
\hline Formulação do Problema \\
\hline 1. Natureza do processo de decisão \\
(i) Estático \\
(ii) Dinâmico \\
2. Fatores de complexidade do ambiente \\
(i) Número de serviços (estágio único ou múltiplo) \\
(ii) Número de servidores (servidor único ou múltiplo) \\
(iii) Número de agendamentos por seção \\
(iv) Processo de chegada \\
(a) Pontualidade dos pacientes (pontuais ou não) \\
(b) Presença de no-shows e cancelamentos tardios \\
- No-show identicamente distribuído \\
- No-show aleatoriamente distribuído \\
- No-show individual (por característica do paciente) \\
(c) Presença de walk-ins regulares e emergenciais (preemptivos ou não) \\
(d) Presença de acompanhantes do paciente \\
(v) Tempo de serviço \\
- Determinístico \\
- Estocástico (distribuição empírica ou teórica) \\
(vi) Atraso e interrupções do serviço (preemptivas ou não) \\
(vii) Disciplina da fila (FCFS, por hora agendada, por prioridade) \\
(viii) Preferência dos pacientes e dos provedores
\end{tabular}

Nesta subseção será apresentada a síntese das características da pesquisa bibliográfica quanto aos fatores de complexidade do Quadro 2, com o objetivo de abordar todos os fatores importantes para um sistema de agendamento.

As características de cada estudo com relação aos fatores de complexidade podem ser observadas na Tabela 4 , ordenadas por ano crescente de publicação. Cada coluna corresponde a um fator, e para cada publicação, há indicação se determinado fator foi ou não abordado no estudo. Os fatores de complexidade "Número de servidores", "Presença de acompanhantes do paciente" e "Preferência dos provedores" não estão presentes na tabela, uma vez que tiveram os mesmos 
resultados em todos os artigos da revisão, quais sejam: servidor único, paciente sem acompanhantes e provedores sem preferências, respetivamente.

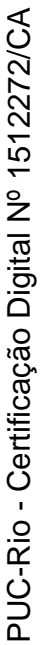


Tabela 4 - Fatores de complexidade dos artigos. Fonte: Elaboração própria.

\begin{tabular}{|c|c|c|c|c|c|c|c|c|c|c|}
\hline Artigo & $\begin{array}{l}\text { Múltiplos } \\
\text { Serviços }\end{array}$ & $\begin{array}{l}\text { Varia o } \\
\mathrm{n}^{\circ} \text { de } \\
\text { pacientes } \\
\text { por seção }\end{array}$ & $\begin{array}{l}\text { Pacientes } \\
\text { impontuais }\end{array}$ & $\begin{array}{l}\text { Processo de Che } \\
\text { Presença de No- } \\
\text { shows }(\% \text { no- } \\
\text { show) }\end{array}$ & $\begin{array}{l}\text { Over- } \\
\text { booking }\end{array}$ & $\begin{array}{l}\text { Walk- } \\
\text { ins }\end{array}$ & $\begin{array}{l}\text { Tempo de } \\
\text { serviço } \\
\text { estocástico } \\
\text { (Distribuição } \\
\text { estatística) }\end{array}$ & $\begin{array}{c}\text { Atraso e } \\
\text { interrupções } \\
\text { do serviço }\end{array}$ & $\begin{array}{l}\text { Disciplina } \\
\text { da fila } \\
\text { diferente } \\
\text { de FCFS }\end{array}$ & $\begin{array}{c}\text { Preferência } \\
\text { dos } \\
\text { pacientes }\end{array}$ \\
\hline $\begin{array}{l}\text { Ho e Lau } \\
\text { (1992) }\end{array}$ & Não & $\begin{array}{l}\text { Sim }(10 \\
20 ; 30)\end{array}$ & Não & $\begin{array}{l}\text { Sim }(0 \% ; 10 \% \\
20 \%)\end{array}$ & Não & Não & $\begin{array}{l}\text { Sim } \\
\text { (Uniforme; } \\
\text { Exponencial) }\end{array}$ & Não & Não & Não \\
\hline $\begin{array}{l}\text { Klassen e } \\
\text { Rohleder } \\
\text { (1996) }\end{array}$ & Não & $\begin{array}{l}\text { Sim (19; } \\
20 ; 21)\end{array}$ & Não & $\operatorname{Sim}(5 \%)$ & Não & Sim & $\begin{array}{l}\text { Sim } \\
\text { (Lognormal) }\end{array}$ & Não & Não & Não \\
\hline $\begin{array}{l}\text { Ho e Lau } \\
\text { (1999) }\end{array}$ & Não & $\begin{array}{l}\text { Sim }(10 \\
20 ; 30)\end{array}$ & Não & $\begin{array}{l}\operatorname{Sim}(0 \% ; 10 \% \\
20 \%)\end{array}$ & Não & Não & $\begin{array}{l}\text { Sim } \\
\text { (Uniforme; } \\
\text { Exponencial) }\end{array}$ & Não & Não & Não \\
\hline $\begin{array}{l}\text { Rohleder } \\
\text { e Klassen } \\
(2000)\end{array}$ & Não & $\begin{array}{l}\text { Sim }(19 ; \\
20 ; 21)\end{array}$ & Não & $\operatorname{Sim}(5 \%)$ & Não & Sim & $\begin{array}{l}\text { Sim } \\
\text { (Lognormal) }\end{array}$ & Não & Não & Sim \\
\hline $\begin{array}{l}\text { Klassen e } \\
\text { Rohleder } \\
\text { (2004) }\end{array}$ & Não & Não (42) & Não & $\operatorname{Sim}(5 \%)$ & Não & Sim & $\begin{array}{l}\text { Sim } \\
\text { (Lognormal) }\end{array}$ & Não & Não & Não \\
\hline $\begin{array}{l}\text { Cayirli et } \\
\text { al. (2006) }\end{array}$ & Não & $\begin{array}{l}\text { Sim }(10 \\
20)\end{array}$ & $\begin{array}{l}\text { Sim (Dist. } \\
\text { Normal) }\end{array}$ & $\operatorname{Sim}(0 \% ; 15 \%)$ & Não & Não & $\begin{array}{l}\text { Sim } \\
\text { (Lognormal) }\end{array}$ & Não & $\begin{array}{l}\text { Sim } \\
\text { (Ordem } \\
\text { da } \\
\text { agenda) } \\
\end{array}$ & Não \\
\hline $\begin{array}{l}\text { LaGanga } \\
\text { e } \\
\text { Lawrence } \\
(2007)\end{array}$ & Não & $\begin{array}{l}\text { Sim }(10 \\
30 ; 50)\end{array}$ & Não & $\begin{array}{l}\text { Sim }(10 \% ; 50 \% \\
90 \%)\end{array}$ & Sim & Não & $\begin{array}{l}\text { Sim } \\
\text { (Gamma) }\end{array}$ & Não & Não & Não \\
\hline $\begin{array}{l}\text { Cayirli et } \\
\text { al. (2008) }\end{array}$ & Não & Não (10) & $\begin{array}{l}\text { Sim (Dist. } \\
\text { Normal) }\end{array}$ & $\operatorname{Sim}(0 \% ; 15 \%)$ & Não & Sim & $\begin{array}{l}\text { Sim } \\
\text { (Lognormal) }\end{array}$ & Não & $\begin{array}{l}\text { Sim } \\
\text { (Ordem } \\
\text { da } \\
\text { agenda) } \\
\end{array}$ & Não \\
\hline
\end{tabular}




\begin{tabular}{|c|c|c|c|c|c|c|c|c|c|c|}
\hline Artigo & $\begin{array}{c}\text { Múltiplos } \\
\text { Serviços }\end{array}$ & $\begin{array}{c}\text { Varia o } \\
\mathrm{n}^{\circ} \text { de } \\
\text { pacientes } \\
\text { por seção }\end{array}$ & $\begin{array}{l}\text { Pacientes } \\
\text { impontuais }\end{array}$ & $\begin{array}{c}\text { Processo de C } \\
\text { Presença } \\
\text { de No- } \\
\text { shows (\% } \\
\text { no-show) } \\
\end{array}$ & $\begin{array}{l}\text { egada } \\
\text { Over- } \\
\text { booking }\end{array}$ & $\begin{array}{l}\text { Walk- } \\
\text { ins }\end{array}$ & $\begin{array}{l}\text { Tempo de } \\
\text { Serviço } \\
\text { Estocástico } \\
\text { (Distribuição } \\
\text { estatística) }\end{array}$ & $\begin{array}{c}\text { Atraso e } \\
\text { interrupções } \\
\text { do serviço }\end{array}$ & $\begin{array}{l}\text { Disciplina } \\
\text { da fila } \\
\text { diferente } \\
\text { de FCFS }\end{array}$ & $\begin{array}{c}\text { Preferência } \\
\text { dos } \\
\text { pacientes }\end{array}$ \\
\hline $\begin{array}{l}\text { Klassen e } \\
\text { Yoogalingam } \\
\text { (2009) }\end{array}$ & Não & Não (21) & Não & $\begin{array}{l}\text { Sim }(0 \% ; \\
10 \% ; 20 \% \text {; } \\
30 \%)\end{array}$ & Não & Não & $\begin{array}{l}\text { Sim } \\
\text { (Lognormal) }\end{array}$ & Não & Não & Não \\
\hline $\begin{array}{l}\text { White et al. } \\
\text { (2011) }\end{array}$ & Sim & Não (32) & Não & Não & Não & Não & $\begin{array}{l}\text { Sim } \\
\text { (Lognormal; } \\
\text { Gamma) }\end{array}$ & Não & Não & Não \\
\hline $\begin{array}{l}\text { Jerbi e } \\
\text { Kamoun } \\
(2011) \\
\end{array}$ & Não & Não (27) & Não & $\operatorname{Sim}(10 \%)$ & Não & Sim & $\begin{array}{l}\text { Sim } \\
\text { (Lognormal) }\end{array}$ & Não & Não & Não \\
\hline $\begin{array}{l}\text { Salzarulo et al. } \\
\text { (2011) }\end{array}$ & Não & Não (24) & $\begin{array}{l}\text { Sim (Dist. } \\
\text { Uniforme) }\end{array}$ & Não & Não & Não & Sim (Erlang) & Sim & $\begin{array}{l}\text { Sim } \\
\text { (Ordem } \\
\text { da } \\
\text { agenda) }\end{array}$ & Não \\
\hline $\begin{array}{l}\text { Cayirli et al. } \\
\text { (2012) }\end{array}$ & Não & $\begin{array}{l}\text { Sim }(5 ; \\
10 ; 15 ; \\
20 ; 25)\end{array}$ & Não & $\begin{array}{l}\operatorname{Sim}(0 \% ; \\
10 \% ; 20 \% \\
30 \% ; 40 \%)\end{array}$ & Sim & Sim & $\begin{array}{l}\text { Sim } \\
\text { (Lognormal) }\end{array}$ & Não & Não & Não \\
\hline $\begin{array}{l}\text { Athula } \\
\text { Wijewickrama } \\
\text { e Takakuwa } \\
(2012)\end{array}$ & Sim & $\begin{array}{l}\text { Sim } \\
\text { (vários) }\end{array}$ & Não & Não & Não & Não & $\begin{array}{l}\text { Sim } \\
\text { (Lognormal) }\end{array}$ & Não & Não & Não \\
\hline $\begin{array}{l}\text { Sepülveda e } \\
\text { Berroeta } \\
(2012)\end{array}$ & Não & $\begin{array}{l}\text { Sim }(10 \\
20)\end{array}$ & $\begin{array}{l}\text { Sim (Dist. } \\
\text { Normal) }\end{array}$ & $\begin{array}{l}\operatorname{Sim}(0 \% \\
15 \%)\end{array}$ & Não & Sim & $\begin{array}{l}\text { Sim } \\
\text { (Lognormal) }\end{array}$ & Não & $\begin{array}{l}\text { Sim } \\
\text { (Ordem } \\
\text { da } \\
\text { agenda) } \\
\end{array}$ & Não \\
\hline $\begin{array}{l}\text { Klassen e } \\
\text { Yoogalingam } \\
\text { (2013) }\end{array}$ & Não & $\begin{array}{l}\operatorname{Sim}(14 ; \\
21)\end{array}$ & Não & Não & Não & Não & $\begin{array}{l}\text { Sim } \\
\text { (Lognormal) }\end{array}$ & Sim & Não & Não \\
\hline
\end{tabular}




\begin{tabular}{|c|c|c|c|c|c|c|c|c|c|c|}
\hline Artigo & $\begin{array}{c}\text { Múltiplos } \\
\text { Serviços }\end{array}$ & $\begin{array}{l}\text { Varia o } \\
\mathrm{n}^{\circ} \text { de } \\
\text { pacientes } \\
\text { por seção }\end{array}$ & $\begin{array}{l}\text { Pacientes } \\
\text { impontuais }\end{array}$ & $\begin{array}{c}\text { Processo de C } \\
\text { Presença } \\
\text { de No- } \\
\text { shows (\% } \\
\text { no-show) } \\
\end{array}$ & $\begin{array}{l}\text { egada } \\
\text { Over- } \\
\text { booking }\end{array}$ & $\begin{array}{l}\text { Walk- } \\
\text { ins }\end{array}$ & $\begin{array}{l}\text { Tempo de } \\
\text { Serviço } \\
\text { Estocástico } \\
\text { (Distribuição } \\
\text { estatística) }\end{array}$ & $\begin{array}{c}\text { Atraso e } \\
\text { interrupções } \\
\text { do serviço }\end{array}$ & $\begin{array}{l}\text { Disciplina } \\
\text { da fila } \\
\text { diferente } \\
\text { de FCFS }\end{array}$ & $\begin{array}{c}\text { Preferência } \\
\text { dos } \\
\text { pacientes }\end{array}$ \\
\hline $\begin{array}{l}\text { Klassen e } \\
\text { Yoogalingam } \\
\text { (2014) }\end{array}$ & Não & Não (24) & $\begin{array}{l}\text { Sim (Dist. } \\
\text { Normal) }\end{array}$ & $\begin{array}{l}\text { Sim }(0 \% \\
12,5 \% \\
25 \%)\end{array}$ & Sim & Não & $\begin{array}{l}\text { Sim } \\
\text { (Lognormal) }\end{array}$ & Não & $\begin{array}{l}\text { Sim } \\
\text { (Ordem } \\
\text { da } \\
\text { agenda) }\end{array}$ & Não \\
\hline $\begin{array}{l}\text { Cayirli e } \\
\text { Yang (2014) }\end{array}$ & Não & Não (15) & Não & $\begin{array}{l}\text { Sim }(15 \% ; \\
30 \%)\end{array}$ & Sim & Sim & $\begin{array}{l}\text { Sim } \\
\text { (Lognormal) }\end{array}$ & Não & Não & Não \\
\hline $\begin{array}{l}\text { Bhattacharjee } \\
\text { e Ray (2016) }\end{array}$ & Não & Não (18) & $\begin{array}{l}\text { Sim (Dist. } \\
\text { Uniforme) }\end{array}$ & $\begin{array}{l}\text { Sim }(10 \% \\
20 \% ; 30 \% \\
40 \%)\end{array}$ & Não & Sim & $\begin{array}{l}\text { Sim (Beta; } \\
\text { Erlang; } \\
\text { Weibull) }\end{array}$ & Não & $\begin{array}{l}\text { Sim } \\
\text { (Ordem } \\
\text { da } \\
\text { agenda) }\end{array}$ & Não \\
\hline $\begin{array}{l}\text { Bard et al. } \\
\text { (2016) }\end{array}$ & Sim & Não (9) & $\begin{array}{l}\text { Sim (Dist. } \\
\text { Johnson) }\end{array}$ & $\begin{array}{l}\text { Sim } \\
(10,9 \% ; \\
21,8 \%)\end{array}$ & Não & Não & $\begin{array}{l}\text { Sim } \\
\text { (Lognormal; } \\
\text { Beta; } \\
\text { Gamma; } \\
\text { Erlang; } \\
\text { Weibull; } \\
\text { Exponencial) }\end{array}$ & Não & $\begin{array}{l}\text { Sim } \\
\text { (Ordem } \\
\text { da } \\
\text { agenda) }\end{array}$ & Não \\
\hline
\end{tabular}




\subsubsection{1.}

\section{Número de serviços}

Segundo Cayirli e Veral (2003), a maior parte da literatura aborda o caso de serviços de estágio único, ou seja, não aborda problemas onde o paciente percorre por diversos serviços diferentes, como consultas, exames de imagem, exames de sangue, entre outros. Nos artigos desta revisão, a maioria também aborda o caso de estágio único, com exceção dos trabalhos de White et al. (2011), Athula Wijewickrama e Takakuwa (2012) e Bard et al. (2016), que analisam o agendamento em processos com estágios múltiplos.

\subsubsection{2.}

\section{Número de servidores}

Quanto ao número de servidores, Cayirli e Veral (2003) verificaram que em clínicas especialistas costuma-se trabalhar com pacientes que são atendidos por um único servidor, visto que existe uma relação de afinidade entre o paciente com seu especialista, sendo este o tipo mais abordado na literatura. Já em clínicas de cuidado primário, costuma-se trabalhar com servidores múltiplos, uma vez que a relação de afinidade paciente-provedor é mais fraca. Nos trabalhos desta revisão, todos os artigos estudaram processos de clínicas especialistas, sendo verificado que, em todos eles, os servidores foram tratados como únicos, o que está coerente com a revisão de Cayirli e Veral (2003).

\subsubsection{3.}

\section{Número de agendamentos}

O número de agendamentos por seção é também um fator do sistema e possui, segundo Ho e Lau (1992), interação direta com o no-show e com a variabilidade do tempo de serviço, uma vez que pacientes em excesso podem sobrecarregar o sistema, o que levaria a um aumento do tempo de fila.

A maioria dos artigos encontrados varia o número de agendamentos como forma de avaliar a sensibilidade das políticas de agendamento (Ho e Lau, 1992; Klassen e Rohleder, 1996; Ho e Lau, 1999; Rohleder e Klassen, 2000; Cayirli et al., 
2006; LaGanga e Lawrence, 2007; Cayirli et al., 2012; Athula Wijewickrama e Takakuwa, 2012; Sepülveda e Berroeta, 2012; Klassen e Yoogalingam, 2013).

\subsubsection{4.}

\section{Processo de chegada}

Quanto ao processo de chegada, Cayirli e Veral (2003) dividem esse fator em quatro elementos, quais sejam: (a) pontualidade do paciente; (b) presença de noshows; (c) presença de walk-ins; e (d) presença de acompanhantes do paciente.

$\mathrm{O}$ primeiro se refere à pontualidade do paciente, ou seja, se os pacientes chegam no horário agendado ou se existe variabilidade nessa chegada, com frequentes atrasos que podem levar a ociosidade do provedor. A impontualidade do paciente é calculada pela diferença entre o horário da chegada e o horário agendado. A maioria dos artigos estudados assume que os pacientes são pontuais, com exceção dos trabalhos de Cayirli et al. (2006), Cayirli et al. (2008), Salzarulo et al. (2011), Sepülveda e Berroeta (2012), Klassen e Yoogalingam (2014), Bhattacharjee e Ray (2016) e Bard et al. (2016). Estes trabalhos consideram distribuições estatísticas para representar a impontualidade, sendo a distribuição Normal a mais utilizada, seguida da Uniforme e da Johnson, conforme foi apresentado na Tabela 4. Cayirli e Veral (2003) colocaram que evidências empíricas mostravam que pacientes chegam em média mais cedo do que mais tarde em relação ao horário agendado, o que também é verificado neste trabalho, sendo que a maioria dos estudos que consideraram a impontualidade verificaram que a média da antecipação do paciente é de 15 minutos, com desvio padrão de 25 minutos. Devido ao alto desvio padrão, apesar de, em média, pacientes chegarem mais cedo, existirá um percentual de pacientes que chegará atrasado, podendo gerar ociosidade do médico, o que torna importante considerar esse fator de complexidade em sistemas com essa caraterística. Foram encontrados os seguintes valores, respectivamente, de média e desvio em cada estudo: -17 e 27 em Cayirli et al. (2006); -15 e 25 em Cayirli et al. (2008); -7,5 e 7,2 em Salzarulo et al. (2011); -15 e 25 em Sepülveda e Berroeta (2012); e -9,39 e 13,7 em Klassen e Yoogalingam (2014). Os trabalhos de Bhattacharjee e Ray (2016) e Bard et 
al. (2016) não especificaram a média e o desvio padrão utilizados para impontualidade.

O segundo elemento do processo de chegada se refere à presença de no-show de pacientes. Esse elemento deve ser analisado uma vez que o aumento da probabilidade do paciente faltar acarreta em maior probabilidade do servidor ficar ocioso. Segundo a recente revisão sistemática da literatura nesse tema feita por Dantas (2016), a taxa média de no-show observada em 102 estudos empíricos foi de 23,0\%, tendo o menor valor igual a $4 \%$ em uma clínica de terapia venosa e o maior sendo 79,2\% em uma clínica de fisioterapia. O no-show aparece na literatura de políticas de agendamento de três formas: (i) identicamente distribuído ao longo do dia, ou seja, considera-se o no-show como uma distribuição binomial $(n, p)$ sendo $n$ o número de agendamentos no dia e $p$ a probabilidade média de no-show; (ii) aleatoriamente distribuído, em que considera-se que o no-show pode variar ao longo do dia, tendo maior chance de acontecer em alguns períodos do que em outros; (iii) individual, de forma que, segundo Dantas (2016), o no-show de cada paciente agendado pode ser predito com base nos dados históricos dos pacientes de uma determinada clínica.

Conforme apresentado na Tabela 4, a maioria dos artigos analisados considera o no-show do paciente (16 dentre os 20 estudos selecionados), sendo que todos consideram a premissa de que o no-show é identicamente distribuído ao longo do dia. Além disso, os estudos de Cayirli e Yang (2014) e Bhattacharjee e Ray (2016) reconhecem diferentes taxas de no-show por classe de paciente e o tratam dessa maneira em seus testes.

Gupta e Denton (2008) adicionam os cancelamentos tardios como fator de complexidade no processo de chegada. Segundo os autores, os cancelamentos tardios impossibilitam que outro paciente seja alocado à agenda e podem ser considerados como no-shows, podendo levar a uma redução da utilização do médico, do lucro da clínica e a um aumento do tempo de espera do paciente.

O terceiro elemento é a presença de pacientes de walk-in regulares ou de emergência. Os pacientes de walk-in regulares são aqueles que chegam para serem atendidos sem agendar uma consulta, podendo ser um paciente que estava na emergência e é encaminhado para um exame de diagnóstico. Um caso especial são os 
pacientes urgentes, que necessitam ser atendidos na hora e podem fazer com que o paciente atual tenha o seu serviço interrompido, sendo esta uma interrupção preemptiva.

Conforme Tabela 4, nove dos 20 trabalhos analisados consideram os pacientes de walk-in em seus estudos, sendo tratados normalmente como uma distribuição estatística de chegada de pacientes.

O quarto e último elemento do processo de chegada, segundo Cayirli e Veral (2003), é a presença de acompanhantes do paciente, que podem ser um problema caso não haja espaço suficiente na sala de espera. Nenhum dos estudos analisados nesta revisão sistemática verifica esse fator em suas análises. Entretanto, esse fator deve ser sempre levado em consideração em clínicas onde os pacientes precisam vir acompanhados, como é o caso de clínicas de oftalmologia, por exemplo, onde são aplicados dilatadores de pupila que afetam a visão dos pacientes, deixando-os impossibilitados de se locomover sem o auxílio do acompanhante. Deve-se considerar o acompanhante nesses casos já que ele irá utilizar o espaço da sala de espera, contribuindo para congestionar a clínica.

\subsubsection{5.}

\section{Tempo de serviço}

No que tange o tempo de serviço, segundo Cayirli e Veral (2003), a maior parte dos estudos o considera independente e identicamente distribuído para todos os pacientes. Essa premissa pode não ser verdadeira já que, em horários de pico, os médicos costumam atender mais rápido para aliviar a fila de espera (Bailey, 1952; Rockart e Hofmann, 1969; Rising et al., 1973; Babes e Sarma, 1991).

Segundo Cayirli e Veral (2003), uma variedade de distribuições de probabilidade é utilizada nos estudos de agendamento. Alguns utilizam dados empíricos coletados na clínica para encontrar a distribuição mais adequada e estudos analíticos costumam usar as distribuições Erlang e Exponencial para tornar os seus modelos tratáveis.

Conforme a Tabela 4, 15 dos 20 estudos analisados nesta revisão consideraram o tempo de serviço como uma distribuição Lognormal, o que mostra que esta 
distribuição tem apresentado boa aderência aos processos de atendimento em serviços ambulatoriais. Outras distribuições verificadas nos artigos foram a Uniforme, Exponencial, Erlang, Gamma, Beta e Weibull.

\subsubsection{6}

\section{Atraso e interrupções do serviço}

Segundo Cayirli e Veral (2003), diversos estudos consideraram a impontualidade do provedor como um fator de complexidade, sendo medida pelo atraso em relação ao primeiro agendamento da seção. Foi verificado que o atraso do provedor afeta significativamente o tempo de espera, já que todos os pacientes passam a ser atendidos mais tarde em relação ao que estava agendado.

Outro fator de complexidade são as interrupções do serviço causadas por atividades que são executadas pelo provedor durante o dia, como ligações, iterações com funcionários, entre outras (Cayirli e Veral, 2003). Rising et al. (1973) e Lehaney et al. (1999) incluíram em seus estudos as interrupções não-preemptivas, ou seja, àquelas que somente acontecem entre as consultas, e que são diferentes da preemptiva, que possibilita interromper a consulta antes do fim e depois retomá-la.

Salzarulo et al. (2011) incluíram em suas análises a interrupção nãopreemptiva, considerando que um percentual das consultas teria interrupções $(25 \%$ para uma das classes de pacientes e $50 \%$ para outra), sendo o valor da interrupção constante e igual a 4 minutos. Klassen e Yoogalingam (2013) avaliaram o efeito da impontualidade do provedor, testando diferentes valores de atraso (determinísticos e estocásticos), e também o efeito da interrupção do serviço, testando diferentes percentuais de consultas com interrupção, sendo esta regida por uma distribuição Exponencial de média igual a cinco minutos.

\subsubsection{7.}

\section{Disciplina da fila}

Segundo Cayirli e Veral (2003), estudos que consideram os pacientes sendo pontuais normalmente utilizam a disciplina de fila First-Come-First-Served (FCFS), que, nesse caso, é o mesmo que considerar a fila por ordem de agendamento, já que 
os pacientes chegam em seus horários agendados. Entretanto, estudos que consideram a impontualidade normalmente consideram a disciplina de fila por ordem de agendamento, uma vez que, como podem existir pacientes atrasados e adiantados, o atendimento deve priorizar o horário de agendamento do paciente. $\mathrm{Na}$ prática, é comum os pacientes serem chamados conforme a ordem de chegada. Entretanto, isso pode destruir o propósito de um sistema de agendamento, já que os pacientes podem passar a ignorar o horário agendado.

Conforme pode ser notado na Tabela 4, todos os artigos desta revisão que consideraram a impontualidade do paciente utilizaram como base para a regra de fila a ordem de agendamento, em vez de considerar a ordem de chegada.

Bard et al. (2016) estudaram diferentes regras de fila para um ambiente que considerava a impontualidade dos pacientes, comparando a regra FCFS com a regra de fila por ordem de agendamento. Eles propuseram duas variações de regra de fila por ordem de agendamento, tanto para o atendimento dos pacientes adiantados, como para os pacientes atrasados.

Bard et al. (2016) propõem as seguintes regras de fila por ordem de agendamento para o atendimento dos pacientes adiantados:

- Sem antecipação: Atende exatamente pela ordem de agendamento, requerendo que os pacientes adiantados aguardem por seu horário agendado, podendo até deixar o provedor ocioso caso este não esteja atendendo no momento.

- Com antecipação: Atende por ordem de agendamento, mas permite quebrar a ordem de agendamento para acomodar os pacientes adiantados, caso um slot fique disponível como resultado de um noshow ou de um atraso do paciente do horário.

Já para o atendimento dos pacientes atrasados, Bard et al. (2016) propõem as seguintes regras de fila por ordem de agendamento:

- Final da seção: Acomoda os pacientes atrasados depois do último paciente agendado para a seção.

- Final da fila: Permite atender os pacientes atrasados quando não há mais pacientes na fila. 
Segundo Cayirli e Veral (2003), clínicas que lidam com pacientes de walk-in regulares e emergenciais necessitam definir uma disciplina de fila para esses pacientes. Em geral, é mais comum dar mais prioridade aos pacientes emergenciais e menos prioridade aos walk-ins regulares em relação aos agendados.

\subsubsection{8.}

\section{Preferências dos pacientes e dos provedores}

Além dos fatores de complexidade apresentados por Cayirli e Veral (2003) e tratados nos tópicos anteriores, Gupta e Denton (2008) incluem como outro fator as preferências dos pacientes e dos provedores. Segundo os autores, os pacientes podem apresentar preferências no agendamento, desejando ser agendados no dia que ligam ou em um dia e horário específico. Além disso, os pacientes podem ter diferentes níveis de afinidade com determinado médico, devendo ser considerada caso exista mais de um médico atendendo um mesmo grupo de pacientes. Quanto aos provedores, algumas atividades podem ou não ser feitas dependendo da sua preferência, quais sejam: aumentar o tamanho da agenda fazendo overbooking, trabalhar no horário do almoço, fazer horas extras e acomodar demandas urgentes.

Segundo Gupta e Denton (2008), em serviços de cuidados primários é mais comum a preferência dos pacientes ser mais forte, enquanto que em serviços especialistas e serviços cirúrgicos, a preferência dos provedores costuma ter maior significância.

Conforme Tabela 4, o artigo de Rohleder e Klassen (2000) foi o único dos trabalhos analisados nesta revisão que incluiu em seus testes por simulação a preferência do paciente, além de considerar vários outros fatores de complexidade. Os autores testaram dois fatores de preferência, quais sejam: a proporção de pacientes com preferência por horário e a distribuição dos horários preferidos. No que tange a proporção de pacientes com preferência de horário, foram testados cenários com $10 \%, 25 \%$ e $40 \%$ de pacientes com preferência. Quanto à distribuição dos horários preferidos, foram simulados cenários sem preferência de horário, com preferência uniformemente distribuída pelos horários do dia e com preferência distribuída uniformemente apenas nos últimos cinco slots do final do período. 


\subsection{2.}

\section{Indicadores de desempenho}

Segundo Cayirli e Veral (2003), existe uma grande variedade de indicadores de desempenho usados na literatura para avaliar as políticas de agendamento. Alguns estudos listam os resultados em termos da média do tempo de espera dos pacientes $(\mathrm{E}(\mathrm{W}))$, da média do tempo em que o médico está ocioso $(\mathrm{E}(\mathrm{I}))$ e/ou da média do tempo em que o médico está fazendo horas extras $(\mathrm{E}(0))$. Ao dar pesos relativos em termos de custo do tempo de espera dos pacientes $\left(C_{p}\right)$, de custo da ociosidade $\left(C_{d}\right)$ e das horas extras do médico $\left(\mathrm{C}_{\mathrm{o}}\right)$, a maioria dos estudos analíticos utiliza a seguinte função objetivo que minimiza o custo total esperado do sistema:

$$
\operatorname{Min} \mathrm{E}(\mathrm{TC})=\mathrm{E}(\mathrm{W}) \mathrm{C}_{\mathrm{p}}+\mathrm{E}(\mathrm{I}) \mathrm{C}_{\mathrm{d}}+\mathrm{E}(0) \mathrm{C}_{\mathrm{o}}
$$

O Quadro 3 classifica os principais indicadores de desempenho utilizados na literatura que serão explicados a seguir. Este quadro foi adaptado de Cayirli e Veral (2003), de forma que dois itens do artigo original foram excluídos desta tabela por não terem sido encontrados na presente revisão da literatura, quais sejam: 4.3 (variância do tamanho das filas) e 5.6 (efetividade da clínica). 
Quadro 3 - Framework de indicadores de desempenho. Fonte: Adaptado de Cayirli e Veral (2003).

\begin{tabular}{|l|}
\hline Indicadores de desempenho utilizados na literatura \\
\hline 1. Indicadores de custo \\
Média do custo total usando a combinação dos seguintes indicadores: \\
1.1 Tempo de espera dos pacientes \\
1.2 Tempo de fluxo dos pacientes \\
1.3 Tempo de ociosidade do médico \\
1.4 Tempo de hora extra do médico \\
2. Indicadores de tempo \\
2.1 Média, máximo e comportamento da distribuição do tempo de espera do paciente \\
2.2 Média, variância e comportamento da distribuição do tempo ocioso do médico \\
2.3 Média, máximo e desvio padrão do tempo de hora extra do médico \\
2.4 Média e comportamento da distribuição do tempo de fluxo do paciente \\
2.5 Percentual de pacientes atendidos em até 30 minutos depois do horário da consulta \\
3. Indicadores de congestionamento \\
3.1 Média e comportamento da distribuição do número de pacientes na fila \\
3.2 Média e comportamento da distribuição do número de pacientes no sistema \\
4. Indicadores de equidade \\
4.1 Média do tempo de espera dos pacientes por faixa horária \\
4.2 Variância do tempo de espera \\
5. Outros indicadores \\
5.1 Produtividade do médico \\
5.2 Média da utilização do médico \\
5.3 Leadtime \\
5.4 Percentual de pacientes urgentes servidos \\
5.5 Probabilidade de o paciente receber o slot solicitado
\end{tabular}

Nesta subseção será apresentada a síntese das características da pesquisa bibliográfica quanto aos indicadores de desempenho do Quadro 3, com o objetivo de tirar conclusões acerca do que já existe no estado geral da arte.

\subsubsection{1.}

\section{Indicadores de custo}

Segundo Cayirli e Veral (2003), os estudos que usam indicadores de custo consideram variações na Equação (1), tendo em sua maioria as parcelas relacionadas ao custo de espera do paciente e de ociosidade do médico. Essa função de custo assume uma relação linear entre o custo de espera e o tempo de espera. Porém, como colocado por Klassen e Rohleder (1996), um sistema em que um paciente espera 40 
minutos na fila não é o mesmo de um em que 20 pacientes esperam, cada um, 2 minutos na fila. Além disso, o custo de espera pode não ser o mesmo para todo paciente. Quando se considera a impontualidade do paciente, a premissa de custo de espera homogêneo não é verdadeira, uma vez que pacientes atrasados tendem a aceitar um tempo maior de espera como parte da culpa sendo dele. Da mesma forma, pacientes de walk-in tendem a tolerar mais tempo de espera do que os agendados. Esses fatores dificultam a aceitabilidade da premissa de relação linear entre o custo e o tempo de espera.

Algumas pesquisas indicam que a tolerância na fila para pacientes agendados diminui após 30 minutos (Westman et al., 1987; Huang, 1994). Na Grã Bretanha, os hospitais são classificados todo o ano de acordo com um padrão nacional determinado pelo Ministério da Saúde que exige que $75 \%$ dos pacientes sejam atendidos em até 30 minutos em relação ao seu horário agendado (Department of Health, 1991). Dessa forma, Cayirli e Veral (2003) concluem que é difícil aceitar que a função de custo do paciente é homogênea e linear, recomendando-se a análise por múltiplos indicadores.

\subsubsection{2.}

\section{Indicadores de tempo}

Segundo Cayirli e Veral (2003), os indicadores de tempo normalmente utilizados nos estudos são os tempos médios de fila do paciente, de ociosidade e de horas extras do médico, assim como o tempo máximo. O tempo de fluxo é o tempo total que um paciente passa na clínica, somando o tempo em espera e em consulta. Como o paciente normalmente não se importa com o tempo gasto em consulta, a maior parte da literatura foca apenas no tempo de espera em vez de usar o tempo de fluxo.

Cayirli et al. (2008) usaram, como um dos indicadores de desempenho para comparar cenários, o percentual de pacientes que são vistos em até 30 minutos em relação ao seu horário agendado, uma importante medida de tempo que possibilita avaliar o nível de serviço do sistema. 


\subsubsection{3.}

\section{Indicadores de congestionamento}

O congestionamento do sistema pode atrapalhar a qualidade do serviço em vários sentidos, fazendo com que o provedor atenda mais rápido para aliviar a fila e que não se consiga atender todos os pacientes do dia, tendo que remarcar alguns (Cayirli e Veral, 2003; Gupta e Denton, 2008). O indicador usual para medi-lo é a média do número de pacientes na fila (Cayirli e Veral, 2003).

\subsubsection{4.}

\section{Indicadores de equidade}

Segundo Cayirli e Veral (2003), alguns estudos consideram a equidade do sistema, ou seja, a uniformidade no desempenho da política de agendamento para os pacientes de todas as faixas horárias. Dessa forma, Bailey (1952), Yang et al. (1998) e Cox et al. (1985) foram os trabalhos que estudaram o tempo de espera por faixa horária para avaliar o desempenho das políticas de agendamento.

Cayirli e Veral (2003) recomendam o uso de múltiplos indicadores de desempenho para avaliar as políticas de agendamento incluindo principalmente a equidade desses indicadores ao longo da seção.

Cayirli et al. (2008) compararam a equidade entre os resultados a partir do desvio padrão do tempo de espera dos pacientes de cada cenário, sendo esse um dos indicadores de desempenho utilizado.

\subsubsection{5.}

\section{Outros indicadores}

Segundo Cayirli e Veral (2003), também são utilizados para medir as políticas de agendamento os seguintes indicadores: produtividade do provedor (número de pacientes atendidos por seção); média da utilização do provedor (ou da ociosidade); tempo entre a solicitação de agendamento e a marcação (leadtime); percentual de pacientes urgentes atendidos; e a probabilidade do paciente em receber o slot solicitado. 


\subsection{3.}

\section{Políticas de agendamento}

O objetivo de um sistema de agendamento é encontrar uma política que otimize determinada medida de desempenho, considerando a incerteza do ambiente analisado. O desenvolvimento de uma política de agendamento pode ser separado em uma série de decisões que envolvem: (i) regras de agendamento; (ii) uso da classificação do paciente, se existir; e (iii) ajustes para reduzir o efeito deteriorador dos no-shows e dos walk-ins regulares e urgentes (Cayirli e Veral, 2003). O Quadro 4 apresenta o framework para o desenvolvimento de uma política de agendamento. Este quadro foi adaptado de Cayirli e Veral (2003), alterando apenas o item 1, de forma a torná-lo mais objetivo e a facilitar o entendimento.

Quadro 4 - Framework para desenvolvimento de Políticas de Agendamento. Fonte: Adaptado de Cayirli e Veral (2003).

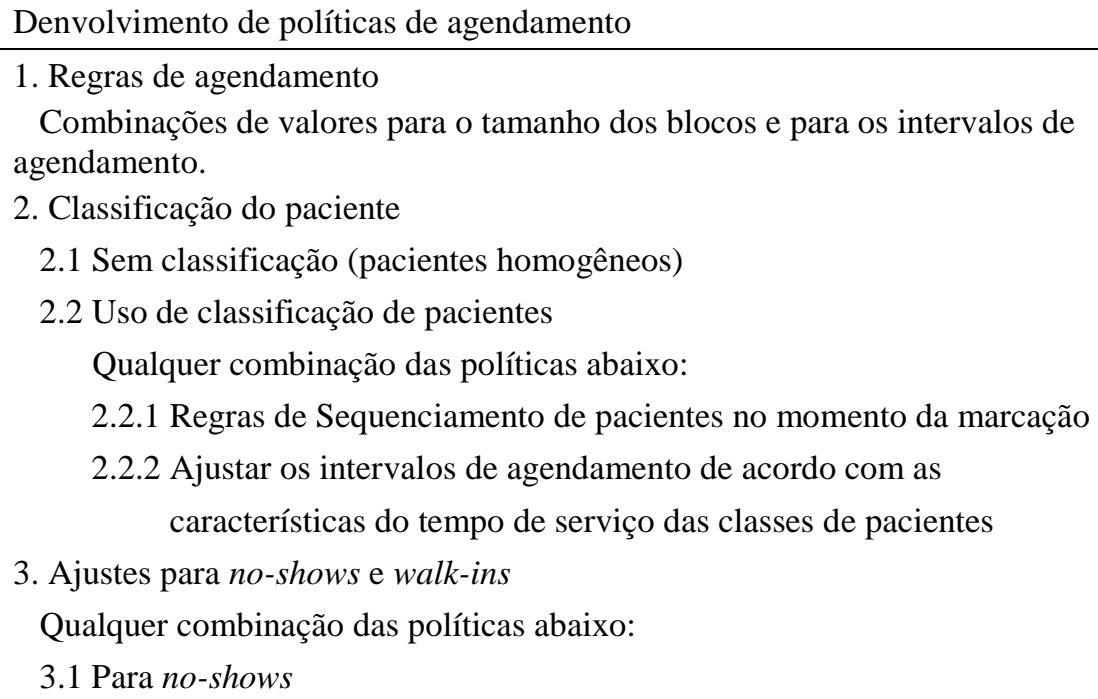

3.1.2 Overbooking agendando mais de um paciente em alguns slots, sem alterar os intervalos de agendamentos.

3.1.3 Overbooking diminuindo os intervalos de agendamento, sem alterar o número de pacientes em cada slot.

\subsection{Para walk-ins}

\subsubsection{Nenhum}

3.2.2 Deixar abertos slots pré-determinados

3.2.3 Aumentar proporcionalmente os intervalos de agendamento (diminuindo o número de pacientes) 


\subsubsection{1.}

\section{Regras de agendamento}

Segundo Cayirli e Veral (2003), uma regra de agendamento pode ser descrita em termos de três variáveis, quais sejam: (i) tamanho do bloco $\left(n_{i}\right)$, representando o número de pacientes por slot $i$; (ii) bloco inicial $\left(n_{1}\right)$, que representa o número de pacientes no primeiro slot; e (iii) intervalo entre agendamentos $\left(a_{i}\right)$, que é o tempo entre dois agendamentos sucessivos. Qualquer combinação dessas três variáveis é uma possível regra de agendamento.

Cayirli et al. (2006) propõem sete regras de agendamento que estão apresentadas na Figura 3 e serão explicadas a seguir:

- IBFI (bloco individual/intervalo fixo): regra usualmente utilizada pelas clínicas que agendam pacientes individualmente em intervalos iguais ao tempo médio de atendimento;

- OFFSET (bloco individual/intervalo variável): agenda os primeiros pacientes entre intervalos mais curtos e o restante é agendado entre intervalos mais longos, quando comparado com a regra IBFI;

- DOME (bloco individual/intervalo variável): agenda os primeiros pacientes entre intervalos mais curtos, pacientes no meio do turno são agendados entre intervalos mais longos, e o restante é agendado entre intervalos mais curtos, quando comparado com a regra IBFI;

- 2BEG (bloco individual/intervalo fixo): igual a regra IBFI, mas com bloco inicial de dois pacientes;

- MBFI (bloco múltiplo/intervalo fixo): agenda dois pacientes por vez em intervalos iguais ao dobro do tempo médio de atendimento;

- 2BGDM (bloco individual/intervalo variável): Combinação da regra 2BEG com a regra DOME;

- MBDM (bloco múltiplo/intervalo variável): Combinação da regra MBFI com a regra DOME; 


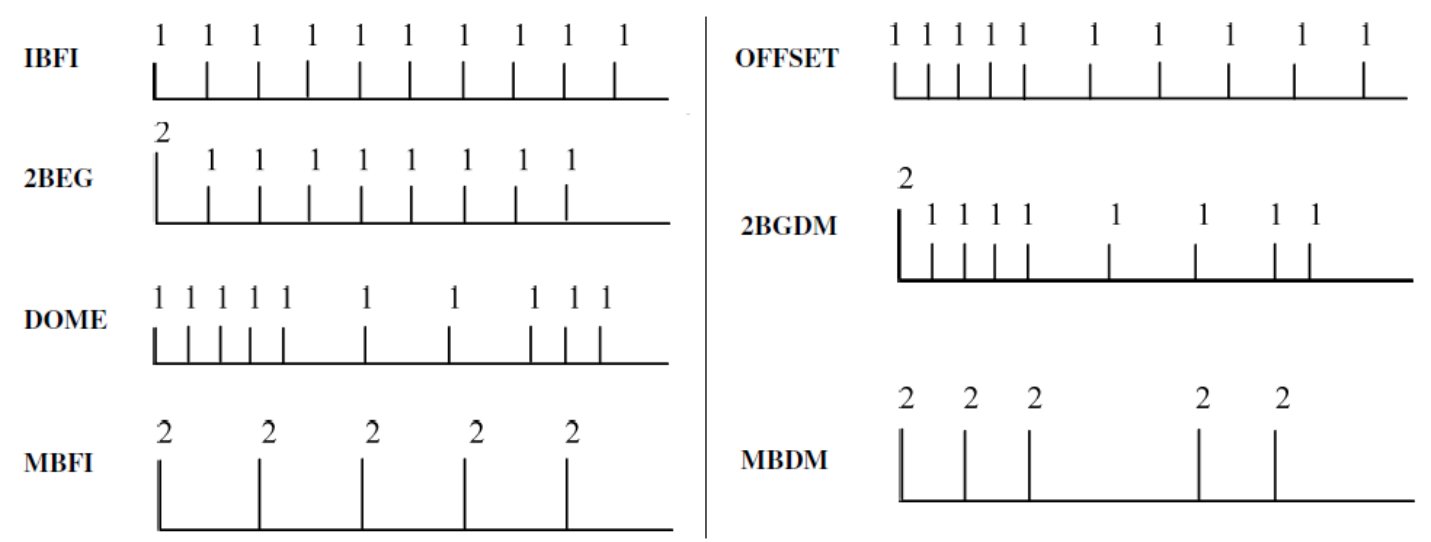

Figura 3- Regras de Agendamento. Fonte: Adaptada de Cayirli et al. (2006).

Além destas, outros autores também propuseram regras de agendamento, como será abordado a seguir. Klassen e Yoogalingam (2009) verificaram que os intervalos de agendamento ótimos tinham a forma PLATÔ-DOME e propuseram uma alteração da DOME para facilitar a implementação, tornando-a em forma platô, ou seja, os intervalos de agendamento no meio do dia são iguais em vez de diferirem um do outro, enquanto que os do começo e final são menores. Porém, eles não indicaram uma formulação para tal. Salzarulo et al. (2011) propuseram uma formulação para o cálculo da PLATÔ-DOME e testaram 36 configurações diferentes, concluindo que dez configurações apresentaram os melhores resultados dependendo da razão entre o custo do provedor e o custo do paciente.

Cayirli et al. (2012) propuseram uma nova regra de agendamento que tem como comportamento o mesmo padrão da regra DOME, mas que busca uma parametrização melhor do que a tradicional. Para isso, a regra DOME UNIVERSAL considera em seu cálculo diversos fatores de complexidade, quais sejam: número de pacientes agendados ajustado $\left(N^{\prime}\right)$, coeficiente de variação do tempo de serviço $(C V)$, probabilidade de no-shows $\left(P_{n}\right)$, probabilidade de walk-ins $\left(P_{w}\right)$ e a razão entre os custos do provedor e do paciente $(C R)$. Além disso, o número de pacientes agendados, a média $(\mu)$ e a variância $\left(\sigma^{2}\right)$ do tempo de serviço têm seus valores revisados para calcular os intervalos entre agendamentos, que serão tratados na Seção 2.3.3.3. 
Klassen e Yoogalingam (2014) testaram um ambiente com diversos fatores de complexidade (impontualidade e no-show do paciente, atraso do provedor e interrupções entre consultas) e propuseram uma nova regra, a IICR, que teve desempenho melhor em seus testes do que a PLATÔ-DOME. A IICR alterna consecutivamente intervalos pequenos e grandes, sendo que, à medida que a seção prossegue, a diferença de intervalos vai aumentando chegando a ficar com dois ou três agendamentos por seção (double, triple-booking). Os autores não propõem uma formulação específica para seu cálculo, apenas mostram os intervalos testados.

Cayirli e Yang (2014) propuseram uma adaptação na regra de agendamento DOME UNIVERSAL, de Cayirli et al. (2012), para considerar a classificação de pacientes, permitindo assim o ajuste de intervalo e o sequenciamento.

Athula Wijewickrama e Takakuwa (2012) e Bhattacharjee e Ray (2016) testaram regras de agendamento ajustando os intervalos por classe e definiram novas formulações para auxiliar seus cálculos.

A Figura 4 ilustra o funcionamento das outras regras de agendamento encontradas na literatura propostas após o trabalho de Cayirli et al. (2006).

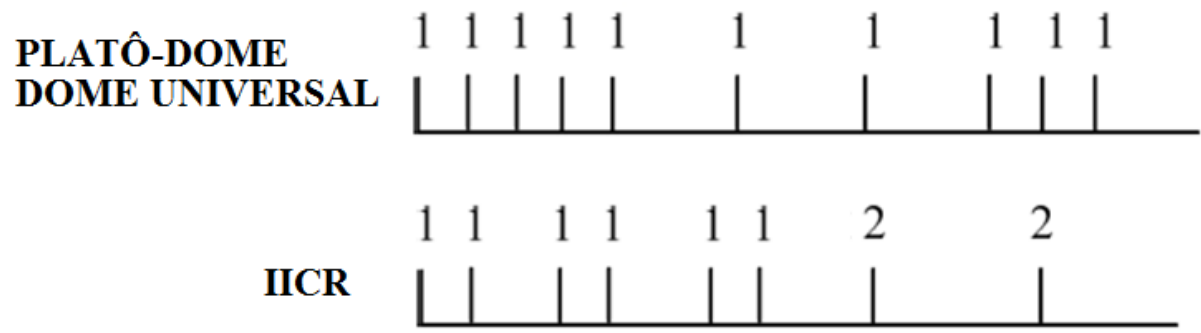

Figura 4- Outras regras de agendamento encontradas na literatura. Fonte: Elaboração própria.

As formulações detalhadas das regras de agendamento apresentadas nessa seção podem ser encontradas no Apêndice A.

\subsubsection{2.}

\section{Classificação do paciente}

Na maioria dos estudos encontrados por Cayirli e Veral (2003), os pacientes são considerados homogêneos e agendados conforme a ordem de ligação (FCFA). 
Quando existem grupos de pacientes que são conhecidos por serem diferentes em diversos atributos, como características do tempo de serviço, processo de chegada, custo de espera, entre outros, deve-se pensar em como melhorar o desempenho de uma política de agendamento reconhecendo essas diferenças.

Em agendamento de consultas, a classificação do paciente pode ser usada para dois propósitos, quais sejam: (i) sequenciar os pacientes no momento da marcação; e/ou (ii) ajustar os intervalos de agendamento de acordo com as distintas características dos tempos de serviço das diferentes classes de pacientes (Cayirli e Veral, 2003).

Segundo Cayirli e Veral (2003), uma classificação realística requer que se separem os pacientes em um número gerenciável de classes e que se atribua para cada classe um grupo pré-determinado de slots para estarem disponíveis no momento da ligação. $\mathrm{Na}$ literatura, algumas características identificadas para classificar pacientes foram: (1) o tipo de paciente (pacientes de retorno ou de primeira vez); (2) a variabilidade do tempo de serviço (alta ou baixa); e (3) o tipo de procedimento.

O Apêndice B apresenta as regras de sequenciamento propostas pelos artigos encontrados nesta revisão sistemática da literatura e o Apêndice C apresenta a regra para ajuste de intervalo de agendamento por classe de paciente.

\subsubsection{3.}

\section{Ajustes para no-shows e walk-ins}

Uma política de agendamento deve antecipar os efeitos dos no-shows e walk-ins de modo a reduzir o impacto negativo causado por estes fatores (Cayirli e Veral, 2003).

No trabalho de Cayirli e Veral (2003), os ajustes para no-shows são feitos colocando mais pacientes na agenda (overbooking) de forma a compensar os pacientes que faltarem. Os autores colocam que existem duas maneiras de se fazer overbooking, quais sejam: (i) agendando mais de um paciente em determinados slots, mantendo os intervalos de agendamentos fixos; ou (ii) diminuindo os intervalos de agendamento de forma a aumentar o número de pacientes na agenda, sem agendar mais de um paciente por horário. 
Já para os ajustes para walk-ins, Cayirli e Veral (2003) afirmam que eles são feitos reduzindo o número de pacientes agendados de forma a compensar os pacientes que chegarem sem estar agendados. Os autores colocam que existem duas maneiras de se fazer o ajuste, quais sejam: (i) deixar slots pré-reservados para esses pacientes; ou (ii) aumentar os intervalos de agendamento de forma a reduzir o número de pacientes na agenda.

LaGanga e Lawrence (2007) desenvolveram uma regra simples de overbooking baseada na redução dos intervalos de agendamento. Essa regra considera que o número de agendamentos ajustado $\left(N^{\prime}\right)$ é igual à capacidade diária de atendimento de pacientes $(N)$ dividido por um menos a taxa média de no-show $\left(P_{n}\right)$ e que o intervalo entre agendamentos é igual à duração do dia $(C)$ dividido pelo número de agendamentos $\left(N^{\prime}\right)$. Dessa maneira, os intervalos de agendamento são reduzidos proporcionalmente com o aumento da taxa de no-show. A partir dessas definições, LaGanga e Lawrence (2007) simularam cenários com alterações do no-show e na variabilidade do serviço, e verificam que essa regra de ajuste pode ser usada no sentido de aumentar a utilização do médico, recomendando como estudos futuros a combinação da mesma com outras regras de agendamento. Além disso, os autores também recomendam a inclusão de testes com outros valores de número de pacientes agendados, próximos ao valor calculado analiticamente pela regra.

Cayirli et al. (2012) e Cayirli e Yang (2014) também fizeram um ajuste do número de pacientes agendados $(N)$, considerando as probabilidades de no-shows $\left(P_{n}\right)$ e walk-ins $\left(P_{w}\right)$, e também propuseram ajustes para a média $(\mu)$ e variância $\left(\sigma^{2}\right)$ do tempo de serviço, que são utilizados para recalcular os intervalos entre agendamentos. Os autores consideram para esses ajustes as análises de Vissers e Wijngaard (1979), que derivaram as fórmulas da média e variância, considerando o impacto de no-shows e walk-ins, interpretando um no-show como um paciente com um tempo de consulta igual a zero e um walk-in como dois pacientes atendidos consecutivamente em um único slot. Segundo os autores, esse ajuste de média e a variância do serviço devem ser feitos para todas as regras, sendo que a variância apenas será ajustada nas regras que a possuem em sua formulação, que é o caso da DOME e da OFFSET. Klassen e Yoogalingam (2014) também recalcularam o 
número de pacientes agendados, considerando o no-show, de forma que, em média, o mesmo número de pacientes chegue para ser atendido.

\title{
2.3.4.
}

\section{Método para análise de Políticas de Agendamento}

O método de análise das políticas de agendamento pode ser classificado em analítico, por simulação ou estudo de caso (Cayirli e Veral, 2003), conforme apresentado no Quadro 5.

Quadro 5-Framework de Metodologias de análise de Políticas de Agendamento. Fonte: Adaptado de Cayirli e Veral (2003).

\author{
Metologias de análise das Políticas de Agendamento \\ 1. Estudos Analíticos \\ 1.1 Teoria de Filas \\ 1.2 Programação Matemática \\ 2. Estudos de Simulação \\ 2.1 Análise Fatores x Ambiente (que fatores afetam mais que medida de desempenho) \\ 2.2 Comparação do desempenho entre diferentes políticas de agendamento \\ 3. Estudos de Caso \\ 3.1 Por observação do ambiente \\ 3.2 Experimentação de uma política alternativa de agendamento \\ 3.3 Modelo quantitativo (Simulação, Teoria de Filas, etc.) para o desenvolvimento de uma política \\ alternativa de agendamento com ou sem análise de implementação posterior
}

Cayirli et al. (2006) concluíram que a maioria dos estudos de simulação existentes na literatura analisam o ambiente específico de determinada clínica, tornando os resultados desses estudos difíceis de serem generalizados. Por isso, como sugerido por Shafer e Smunt (2004), combinar o poder e a flexibilidade da simulação com a utilização de dados empíricos passa a ser uma das maneiras mais efetivas de solucionar essa lacuna existente entre o rigor acadêmico e a aplicabilidade gerencial. Em serviços de saúde, o uso de Simulação de Eventos Discretos (SED) ganhou força por causa de três vantagens principais: a capacidade de incluir atributos individuais, a flexibilidade para expressar a dinâmica e a lógica do processo, e o desenvolvimento avançado de pacotes de software (Brailsford, 2007). 


\section{4.}

\section{Análise dos resultados dos artigos selecionados na revisão}

As análises dos 20 artigos selecionados neste trabalho foram apresentadas nas subseções anteriores, e destas análises é possível obter as principais conclusões, descritas nesta subseção e apresentadas no Apêndice D.

Este Apêndice D apresenta a descrição dos artigos analisados na revisão da literatura, incluindo quais regras de agendamento e sequenciamento, análises de sensibilidade, método, número de fatores de complexidade e indicadores de desempenho foram utilizados por cada artigo, como também quais as regras que obtiveram os melhores resultados.

A partir das análises de cada artigo, foi possível fazer uma comparação quantitativa do desempenho de cada regra de agendamento e sequenciamento. A Tabela 5 mostra o número total de testes feitos com cada regra de agendamento, o número de vezes que cada uma apareceu com resultado superior e com resultado inferior, comparada com as outras regras. 
Tabela 5 - Comparação quantitativa do desempenho das regras de agendamento. Fonte: Elaboração própria.

\begin{tabular}{lccc}
\hline Regra de agendamento & $\begin{array}{c}\text { Total } \\
\text { de } \\
\text { testes }\end{array}$ & $\begin{array}{c}\text { Resultado } \\
\text { superior }\end{array}$ & $\begin{array}{c}\text { Resultado } \\
\text { inferior }\end{array}$ \\
\hline IBFI & 13 & 7 & 6 \\
2BEG & 13 & 4 & 9 \\
OFFSET & 9 & 4 & 5 \\
MBFI & 9 & 2 & 7 \\
DOME & 5 & 2 & 3 \\
IBFIA & 4 & 3 & 1 \\
2BEGA & 4 & 3 & 1 \\
4BEG & 4 & 2 & 2 \\
PLATÔ-DOME & 3 & 3 & 0 \\
MBFIA & 3 & 2 & 1 \\
DOME UNIVERSAL & 2 & 1 & 1 \\
3BEG & 2 & 0 & 2 \\
MBDM & 2 & 0 & 2 \\
IICR & 1 & 1 & 0 \\
OFFSETA & 1 & 1 & 0 \\
DOME UNIVERSAL A & 1 & 1 & 0 \\
2BGDM & 1 & 0 & 1 \\
\hline
\end{tabular}

Pela análise da Tabela 5, pode-se perceber que as regras IBFI com e sem ajuste, 2BEG com e sem ajuste, OFFSET, MBFI e DOME foram as mais analisadas nos artigos.

As regras IBFI, 2BEG e OFFSET, com e sem ajustes, e a regra DOME são as que tiveram os melhores desempenhos nos artigos selecionados, e que deveriam ser incluídas e simuladas para o ambiente específico de cada clínica. As recentes regras PLATÔ-DOME, DOME UNIVERSAL com e sem ajuste e IICR ainda foram pouco estudadas, mas mostraram resultados de desempenho bem superiores, o que revela a importância de serem incluídas em estudos futuros para validação.

A Tabela 6 indica o número total de testes realizados com cada regra de sequenciamento, o número de vezes que cada uma apareceu como um dos melhores desempenhos e que não apareceu entre as melhores. 
Tabela 6 - Comparação quantitativa do desempenho das regras de sequenciamento. Fonte: Elaboração própria.

\begin{tabular}{lrrr}
\hline \multicolumn{1}{c}{ Regra de } & $\begin{array}{c}\text { Total } \\
\text { de } \\
\text { sequenciamento }\end{array}$ & $\begin{array}{c}\text { Resultado } \\
\text { superior }\end{array}$ & $\begin{array}{c}\text { Resultado } \\
\text { inferior }\end{array}$ \\
\hline ALTER1 & 8 & 3 & 5 \\
LVBEG & 6 & 5 & 1 \\
HMBEG & 6 & 3 & 3 \\
LMBEG & 6 & 4 & 2 \\
FCFA & 6 & 0 & 6 \\
HVBEG & 2 & 0 & 2 \\
ALTER5 & 2 & 0 & 2 \\
LMBND & 2 & 0 & 2 \\
HMBND & 2 & 0 & 2 \\
ALTER-B & 2 & 0 & 2 \\
HVBND & 1 & 0 & 1 \\
LVBND & 1 & 0 & 1 \\
LCVBEG & 1 & 1 & 0 \\
HPBEG & 1 & 1 & 0 \\
LCVBEG' & 1 & 1 & 0 \\
ALTER-A & 1 & 0 & 1 \\
LVBEG' & 1 & 0 & 1 \\
LMVBEG' & 1 & 0 & 1 \\
\hline
\end{tabular}

Pela análise da Tabela 6, pode-se verificar que as regras ALTER1, LVBEG, LMBEG, HMBEG e FCFA foram as mais testadas nos artigos selecionados. Apesar de ter sido muito estudada, a regra ALTER1 apenas apresentou bons resultados em três dos oito trabalhos que a testaram.

As regras ALTER1 e LVBEG são as regras de sequenciamento que tiveram os melhores desempenhos nos artigos selecionados, e deveriam ser incluídas e simuladas para o ambiente específico de cada clínica. As recentes regras LCVBEG e LCVBEG' foram ainda pouco estudadas, mas também apresentaram bons resultados, o que demonstra a importância em avalia-las em estudos futuros. 


\section{3}

\section{Estudo de caso}

O estudo aplicado foi elaborado por meio da coleta de dados em uma clínica de cirurgia bariátrica localizada no estado do Rio de Janeiro. A clínica em questão possui cinco cirurgiões bariátricos, além de provedores de outras especialidades que fazem consultas de suporte à cirurgia bariátrica, sendo quatro nutricionistas, três psicólogos, dois fisioterapeutas, dois endocrinologistas e um anestesiologista.

A Tabela 7 mostra a classificação dos médicos de acordo com o número de consultas realizadas de 29/06/2015 a 29/06/2016, considerando todos os dias da semana e todas as classes de pacientes atendidos. A partir dessa classificação, pode-se notar que o cirurgião bariátrico de código "1" é o médico que realiza mais atendimentos na clínica, representando $21 \%$ dos atendimentos, quase o dobro de atendimentos do médico com segundo maior número. Portanto, optou-se por realizar o estudo no processo de consulta desse cirurgião, que é o proprietário e principal médico da clínica. 
Tabela 7 - Classificação dos médicos por no de consultas realizadas entre 29/06/2015 a 29/06/2016. Fonte: Elaboração própria.

\begin{tabular}{clcc}
\hline $\begin{array}{c}\text { Código } \\
\text { do } \\
\text { médico }\end{array}$ & Especialidade & $\begin{array}{c}\mathrm{N}^{\mathrm{o}} \text { de } \\
\text { consultas } \\
\text { realizadas }\end{array}$ & $\begin{array}{c}\% \text { do } \\
\text { total }\end{array}$ \\
\hline 1 & Cirurgião bariátrico & 1468 & $21.0 \%$ \\
9 & Psicólogo & 826 & $11.8 \%$ \\
3 & Anestesiologista & 807 & $11.5 \%$ \\
2 & Nutricionista & 786 & $11.2 \%$ \\
5 & Endocrinologista & 717 & $10.2 \%$ \\
12 & Cirurgião bariátrico & 374 & $5.3 \%$ \\
13 & Psicólogo & 291 & $4.2 \%$ \\
8 & Cirurgião bariátrico & 272 & $3.9 \%$ \\
14 & Nutricionista & 217 & $3.1 \%$ \\
10 & Nutricionista & 213 & $3.0 \%$ \\
6 & Endocrinologista & 197 & $2.8 \%$ \\
7 & Psicólogo & 174 & $2.5 \%$ \\
11 & Cirurgião bariátrico & 171 & $2.4 \%$ \\
4 & Fisioterapeuta & 157 & $2.2 \%$ \\
19 & Cirurgião bariátrico & 118 & $1.7 \%$ \\
22 & Fisioterapeuta & 115 & $1.6 \%$ \\
20 & Nutricionista & 96 & $1.4 \%$ \\
\hline
\end{tabular}

Foram coletados do sistema corporativo os dados de comparecimento ou não comparecimento, horário agendado, horários de início e de término do atendimento. Os dados extraídos eram relativos aos atendimentos do ano de 2014 a 2016, mas optou-se por desconsiderar os dados de 2014 até meados de 2015. Isso foi realizado uma vez que o sistema foi implementado em meados de 2014, optando-se por não considerar os dados do primeiro ano de uso do sistema, uma vez que estes não estavam fidedignos. Portanto, foi considerado o período de um ano, de 29/06/2015 a 29/06/2016, excluindo apenas os pacientes de encaixe, já que não era possível saber qual era a classe de paciente agendado por restrições da base de dados. A classe de paciente se refere ao tipo de agendamento, ou seja, se o paciente está sendo atendido pela primeira vez ou se ele é um retorno.

Além disso, foi necessário fazer medições in loco para o entendimento do processo atual e para coleta dos tempos de chegada dos pacientes, que não eram cadastrados no sistema. Também foram coletados os dados de tempos de atendimento da secretária e tempo de preenchimento de fichas por parte dos pacientes, e como o 
número de dados era insuficiente para a realização de testes de aderência, o tempo de duração desses processos foram assumidos como distribuições triangulares. Além da coleta dos dados, foram feitas entrevistas com a secretária e com o médico para auxiliar no entendimento do processo, apresentado na Figura 5. 


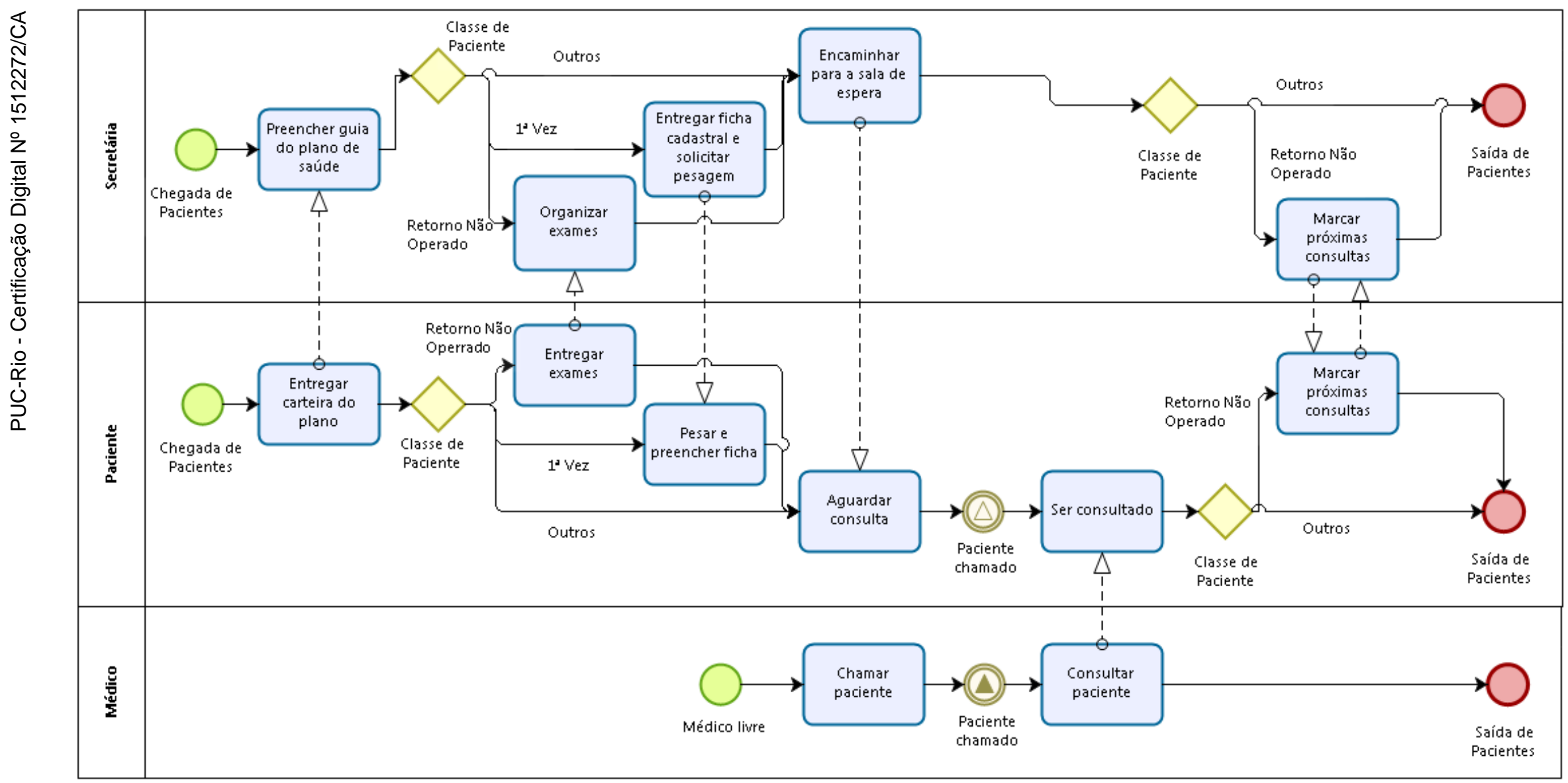

Figura 5 - Modelo conceitual do processo de consulta. Fonte: Elaboração própria. 
No que tange ao no-show dos pacientes, foi realizada uma análise estatística para saber se o não comparecimento variava entre os dias da semana, entre os horários do dia e entre as classes de paciente. Para cada uma dessas análises, foi utilizado o teste qui-quadrado com um nível de significância de 5\%.

Após análise das informações obtidas nas entrevistas e do tratamento dos dados, foi possível obter as características da clínica com relação aos fatores de complexidade existentes no sistema. Portanto, o processo em estudo pode ser caracterizado pelos seguintes fatores de complexidade (conforme Quadro 2 da Seção 2.3.1) que serão apresentados nas próximas subseções: tempos de serviços estocásticos, pacientes impontuais, com atraso e interrupções do serviço, presença de no-shows e com disciplina de fila por ordem da agenda. Além disso, o processo também é caracterizado como de agendamento estático, serviço único, servidor único, com 23 agendamentos por seção (no cenário atual) e com testes de outros cenários (conforme será apresentado na Seção 4.6), sem walk-ins e sem acompanhantes.

\section{1.}

\section{Tempos de serviços}

Conforme pode ser notado na Figura 5, o processo de atendimento da clínica tem algumas diferenças de acordo com a classe de paciente que chega. A classificação principal de pacientes na clínica é feita pelo tipo de agendamento, quais sejam: agendamento de primeira vez, de retorno antes da cirurgia (retorno não operado), de marcação de cirurgia ou de retorno após cirurgia (retorno operado).

Após a chegada do paciente, o processo da clínica se inicia pelo primeiro atendimento da secretária, que solicita o documento de identidade, para identificação do agendamento, e, caso o paciente possua, solicita a carteira do plano de saúde para preenchimento da guia do plano, que deve ser assinada pelo paciente. Esse processo compreende um tempo Triangular $(1,1.5,2)$, em minutos.

Depois desse primeiro atendimento, se o paciente for de marcação de cirurgia ou de retorno operado, a secretária solicita que aguardem o atendimento na sala de espera. Caso seja um paciente de primeira vez, antes de ser encaminhado para a sala de espera, ele deve se pesar e preencher uma ficha cadastral, que tem um tempo 
Triangular $(5,6,8)$, em minutos, sendo esse processo feito sem a necessidade de acompanhamento da secretária. Caso seja um paciente de retorno não operado, antes de se dirigir à sala de espera, ele deve esperar a secretária organizar e conferir os exames recebidos, processo que tem um tempo Triangular $(1,2,3)$, em minutos.

Após ser chamado pelo médico, o processo de consulta possui tempos diferentes entre as classes de paciente, e essa diferença foi estatisticamente significativa para um nível de significância de 5\%. As consultas de primeira vez costumam ser mais demoradas do que as de retorno, como também foi observado na literatura, levando um tempo de distribuição estatística Weibull, com média de 22,3 minutos e desvio padrão de 9,27 minutos. As consultas de retorno acontecem antes da cirurgia, para avaliar os exames pré-operatórios, e depois da cirurgia, para avaliar o paciente pós-cirurgia. Não foi encontrada diferença significativa ( $\alpha=5 \%)$ entre os tempos de consulta dos pacientes de retorno não operados e operados, e, por isso, no que tange ao tempo de consulta, os pacientes de retorno foram considerados como um grupo homogêneo de pacientes, com um tempo de distribuição Weibull, com média de 15,3 minutos e desvio padrão de 8,42 minutos. A marcação de cirurgia é uma consulta mais rápida e tem um tempo de distribuição Lognormal com média de 11,7 minutos e desvio padrão de 6,34 minutos.

Após a consulta, os pacientes são liberados pelo médico e saem do consultório, com exceção dos pacientes de retorno não operado, que antes devem marcar as consultas de suporte com os outros médicos da clínica. Esse processo de marcação é feito pela secretária e tem um tempo Triangular $(3,3.5,4)$, minutos.

\section{2.}

\section{Impontualidade dos pacientes}

Foi observado que, em média, os pacientes do consultório são pontuais, mas existe uma grande variabilidade e incerteza no processo de chegada. Esse processo é regido por uma distribuição Normal $(-11.7,29.6)$, em minutos, que representa a impontualidade do paciente. Nota-se que, em média, os pacientes são pontuais chegando 11,7 minutos antes do horário agendado da consulta. Porém, como o desvio padrão é de 29,6 minutos, sabe-se que alguns pacientes chegam atrasado, o que acaba 
interferindo negativamente no desempenho do sistema. Esse valor está coerente com o encontrado nos estudos da literatura que encontraram na maioria dos estudos a distribuição Normal com valores de média e desvio padrão próximos de -15 e 25 minutos, respectivamente (Cayirli et al., 2006; Cayirli et al, 2008; Juan Pedro Sepülveda e Berroeta, 2012).

3.3.

Atraso e interrupções do serviço

Foi verificado pelos dados obtidos que 26,8\% das consultas apresentam uma interrupção após o seu término, ou seja, nesses casos há uma parada do médico entre o fim da consulta atual e o início da próxima (não-preemptiva). Essas interrupções estão relacionadas a momentos em que o médico interrompe o próximo atendimento para responder a e-mails ou ir ao banheiro, sendo regidas pela distribuição estatística Weibull, com média 5,55 e desvio padrão 4,94. Foi considerado como intervalo sem interrupção àquele que tinha até 1 minuto de duração.

Quanto à pontualidade do médico, foi verificado pelos dados que o médico chega em média 57 minutos atrasado em relação à primeira consulta agendada do dia, com desvio padrão de 17 minutos, processo que é regido pela distribuição Beta. Como os dados de atraso disponíveis eram poucos, foi necessário validar esses valores empiricamente, observando a chegada do médico e fazendo perguntas à secretária e ao próprio médico. Segundo eles, o atraso realmente é grande, visto que o próprio médico diz preferir chegar ao consultório e já ter pacientes aguardando pela consulta, para minimizar seu tempo ocioso. Entretanto, essa atitude tende a aumentar as filas no início do dia, prejudicando o nível de serviço prestado ao paciente, conforme será apresentado na Seção 4.5. Além disso, verificou-se que o médico nem sempre almoça dentro do intervalo de uma hora, que seria o correto para voltar para o consultório antes do início do segundo turno agendado. Por isso, o tempo de almoço foi considerado como outro fator estocástico e, a partir dos dados extraídos do sistema, pôde-se concluir que o médico leva 84 minutos para almoço, com desvio padrão de 18 minutos, processo regido pela distribuição Normal. 
No que tange às distribuições estatísticas do tempo de consulta, da impontualidade do paciente, das interrupções entre consultas, do atraso do médico e do tempo de almoço, foram selecionadas àquelas aceitas e com menor erro quadrático médio no teste de aderência Kolmogorov-smirnov ao nível de significância de 5\%, sendo estas apresentadas na Tabela 8.

Tabela 8 - Resumo das estatísticas dos dados coletados. Fonte: Elaboração própria.

\begin{tabular}{|c|c|c|c|c|c|}
\hline $\begin{array}{c}\text { Fator de } \\
\text { complexidade }\end{array}$ & $\begin{array}{c}\text { Tamanho } \\
\text { da } \\
\text { amostra }\end{array}$ & $\begin{array}{c}\% \text { da } \\
\text { Agenda }\end{array}$ & $\begin{array}{l}\text { Classe do } \\
\text { Paciente }\end{array}$ & $\begin{array}{c}\text { Melhor } \\
\text { Distribuição } \\
\text { (média, } \\
\text { desvio) } \\
\text { (min.) }\end{array}$ & $\begin{array}{l}\text { Expressão } \\
\text { (minutos) }\end{array}$ \\
\hline \multirow{4}{*}{$\begin{array}{l}\text { Tempo de } \\
\text { consulta do } \\
\text { médico }\end{array}$} & 349 & $51.8 \%$ & $1^{\mathrm{a}} \mathrm{Vez}$ & $\begin{array}{c}\text { Weibull } \\
(22.3,9.27)\end{array}$ & $4+\mathrm{W}(2.04,20.6)$ \\
\hline & \multirow[t]{2}{*}{393} & $29.3 \%$ & $\begin{array}{l}\text { Retorno } \\
\text { Não } \\
\text { Operado }\end{array}$ & \multirow{2}{*}{$\begin{array}{c}\text { Weibull } \\
(15.3,8.42)\end{array}$} & \multirow{2}{*}{$1+\mathrm{W}(1.78,16.1)$} \\
\hline & & $14.4 \%$ & $\begin{array}{l}\text { Retorno } \\
\text { Operado }\end{array}$ & & \\
\hline & 127 & $4.5 \%$ & $\begin{array}{c}\text { Marcação } \\
\text { de } \\
\text { Cirurgia }\end{array}$ & $\begin{array}{c}\text { Lognormal } \\
(11.7,6.34)\end{array}$ & $2+\mathrm{L}(9.91,7.76)$ \\
\hline $\begin{array}{l}\text { Impontualidade } \\
\text { do paciente }\end{array}$ & 86 & - & - & $\begin{array}{c}\text { Normal } \\
(-11.7 \text {, } \\
29.6) \\
\end{array}$ & $\mathrm{N}(-9.91,27.3)$ \\
\hline $\begin{array}{c}\text { Interrupção } \\
\text { entre consultas }\end{array}$ & 153 & - & - & $\begin{array}{c}\text { Weibull } \\
(5.55,4.94)\end{array}$ & $\begin{array}{c}0.999+\mathrm{W}(0.863 \\
4.24)\end{array}$ \\
\hline Atraso médico & 21 & - & - & $\begin{array}{c}\text { Normal } \\
(57.1,16.9)\end{array}$ & $\mathrm{N}(57.1,16.9)$ \\
\hline $\begin{array}{c}\text { Tempo de } \\
\text { almoço }\end{array}$ & 39 & - & - & $\begin{array}{c}\text { Beta }(84.3, \\
18.3)\end{array}$ & $\begin{array}{c}54+65 * \mathrm{~B}(0.998 \\
1.14)\end{array}$ \\
\hline
\end{tabular}

\section{4 .}

\section{No-show de pacientes}

A taxa média de no-show do paciente foi de $26,13 \%$, obtida pela relação entre o número de pacientes que não compareceram à consulta agendada e o número total de pacientes agendados. Ao avaliar a variação do no-show por dia da semana, verificou-se uma taxa de no-show de $27,95 \%$ na segunda-feira e de $23,67 \%$ na quartafeira, sendo estes os dois únicos dias de atendimento na semana. Após a análise por meio do teste estatístico qui-quadrado, a diferença do no-show entre os dias da 
semana não foi significativa para um $\alpha=5 \%$, conforme pode ser visto no Apêndice E.

Outra análise realizada foi se o no-show era identicamente distribuído entre as classes de pacientes. Após o teste de significância, concluiu-se que a hipótese de noshow homogêneo entre as classes foi rejeitada ao nível de significância de 5\% (Apêndice F). A taxa de no-show por classe foi de 30,38\% para os pacientes de $1^{\text {a }}$ vez, 20,97\% para os de marcação de cirurgia, 19,59\% para os de retorno não operado e $25,84 \%$ para os de retorno operado. A taxa de no-show mais alta para os pacientes de primeira vez ocorre uma vez que estes pacientes ainda não conhecem o médico, não ocorrendo assim a fidelização do paciente. No caso do no-show alto para os pacientes de retorno operado, este pode ser explicado por uma característica cultural da população brasileira de não fazer o acompanhamento correto após as cirurgias, não fazendo as consultas pós-operatórias que previnem o paciente de não voltar a sofrer do mesmo problema.

Para avaliar se o no-show é identicamente distribuído ao longo do dia, foi feito novamente um teste qui-quadrado, mas com intuito de avaliar se a diferença do noshow entre os horários do dia era significativa. Como a classe de pacientes se mostrou um fator relevante para o no-show, ajustou-se inicialmente o no-show esperado de cada horário do dia de acordo com a sua devida proporção de pacientes em cada classe (Apêndice G). Após esse ajuste, a hipótese de no-show ser homogêneo entre os horários do dia foi rejeitada ao nível de significância de 5\% (Apêndice H). Entretanto, ao retirar o período de período de $18 \mathrm{~h}-19 \mathrm{~h}$ dessa análise, que possui poucos pacientes agendados já que não faz parte do turno normal, nota-se que a premissa de homogeneidade do no-show ao longo do dia torna-se verdadeira para os outros horários do dia na clínica em questão, com nível de significância de 5\% (Apêndice I).

Portanto, esse estudo considerou o no-show diferente para cada classe de paciente, sendo o comportamento do no-show de cada classe identicamente distribuído ao longo do dia. 


\section{5 .}

\section{Disciplina da fila}

A disciplina de fila do atendimento utilizada pela clínica é por ordem da agenda. Para representar com clareza o comportamento do sistema real, não foi adicionada nenhuma complexidade quanto à disciplina de fila para os pacientes atrasados, ou seja, os pacientes que estão na fila são atendidos pela ordem em que estão agendados, independente do horário da chegada. Para os pacientes adiantados, esses podem ser atendidos antes, caso a fila esteja vazia, evitando a ociosidade do médico (disciplina com antecipação).

Portanto, o modelo que será desenvolvido irá considerar todos os fatores de complexidade apresentados, quais sejam: pacientes impontuais, presença de no-shows diferentes por cada classe de paciente, tempos de serviços estocásticos, com atraso e interrupções do médico e com disciplina de fila por ordem da agenda. 
O método utilizado para modelar o sistema descrito na seção anterior foi a Simulação de Eventos Discretos, conforme as orientações de Cayirli e Veral (2003), Robinson (2005) e Brailsford (2007).

Nos subtópicos a seguir, serão apresentados o modelo de simulação desenvolvido, as premissas do sistema e as políticas de agendamento utilizadas. Em seguida, será apresentada a simulação do cenário atual e a validação do modelo desenvolvido. Após essa validação, serão apresentados os cenários gerados e os indicadores de desempenho utilizados para avaliar cada política de agendamento.

\section{1.}

\section{Modelo de Simulação}

A partir das características observadas na Seção 3, construiu-se um modelo de simulação no software ProModel® versão 8.6 para representar o processo do consultório em questão (Figura 8). Este tem como característica ser um modelo de simulação terminal, uma vez que possui horário de início e fim para cada turno, e contempla dois turnos de trabalho (manhã e tarde). Além disso, como o sistema começa vazio em ambos os turnos, ou seja, fora do horário de trabalho não há pacientes na sala de espera nem pacientes sendo atendidos, logo, não há necessidade da utilização de um tempo para o aquecimento da simulação. 


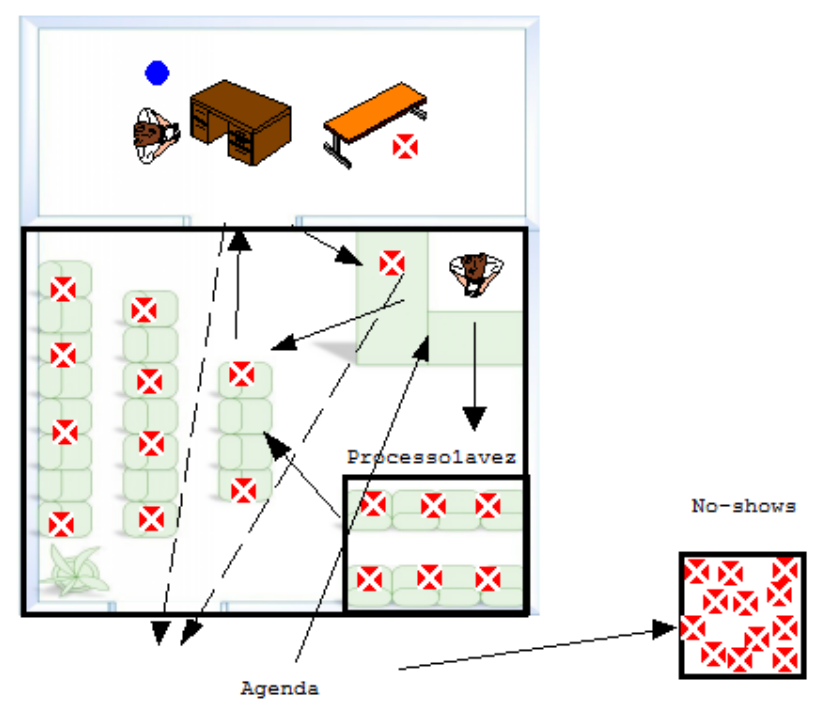

Figura 6 - Modelo de Simulação. Fonte: Elaboração própria.

O modelo foi desenvolvido de forma que representasse da melhor forma possível o caso em estudo e, para que fosse atribuída maior confiabilidade a ele, cada simulação foi replicada 500 vezes, sendo cada replicação responsável por representar um dia de funcionamento do sistema. Para verificar se o número de replicações estava adequado, foi feito um estudo em que o número de replicações variava entre 100 e 999 replicações, e percebeu-se que, a partir do cenário com 500 replicações, o resultado de cada indicador já estava bem próximo comparado ao cenário com 999 replicações, conforme Tabela 9. Portanto, escolheu-se utilizar 500 replicações para facilitar a geração dos resultados, dado que foram simuladas 114 combinações de cenários diferentes.

Tabela 9 - Média de cada indicador para o cenário atual. Fonte: Elaboração própria.

\begin{tabular}{ccccccc}
\hline $\begin{array}{c}\mathbf{N}^{\mathbf{o}} \text { de } \\
\text { Replicações } \\
(\boldsymbol{n})\end{array}$ & $\begin{array}{c}\text { Tempo } \\
\text { Médio } \\
\text { de Fila } \\
(\mathbf{m i n})\end{array}$ & $\begin{array}{c}\text { Tempo } \\
\text { Máximo } \\
\text { de Fila } \\
(\mathbf{m i n})\end{array}$ & $\begin{array}{c}\text { Utilização } \\
\text { da Sala } \\
\text { de } \\
\text { Consulta } \\
(\%)\end{array}$ & $\begin{array}{c}\text { \% } \\
\text { Pacientes } \\
\text { até } \\
\text { 30min na } \\
\text { Fila }\end{array}$ & $\begin{array}{c}\text { Horário } \\
\text { de fim } \\
\text { do dia } \\
(\mathbf{h})\end{array}$ & $\begin{array}{c}\mathbf{N}^{\mathbf{o}} \text { de } \\
\text { pacientes } \\
\text { atendidos }\end{array}$ \\
\hline 100 & 24.41 & 72.16 & $73.00 \%$ & $67.31 \%$ & 18.40 & 17.01 \\
200 & 23.40 & 70.22 & $72.30 \%$ & $68.36 \%$ & 18.46 & 16.91 \\
300 & 23.85 & 69.82 & $72.80 \%$ & $67.26 \%$ & 18.44 & 16.98 \\
400 & 22.77 & 67.30 & $72.15 \%$ & $68.76 \%$ & 18.44 & 16.87 \\
500 & 22.73 & 66.45 & $72.33 \%$ & $68.93 \%$ & 18.45 & 16.93 \\
999 & 23.06 & 67.01 & $72.02 \%$ & $68.07 \%$ & 18.45 & 16.85 \\
\hline
\end{tabular}




\section{2.}

\section{Premissas básicas}

Com o intuito de tornar o estudo possível, foi feita uma série de premissas. Primeiramente, o modelo parte da premissa que a recepcionista está sempre disponível durante os dois turnos de trabalho, e assume-se que a pontualidade do paciente independe do horário de consulta. O estudo também assume que os tempos de serviço são independentes e identicamente distribuídos, de forma que o tempo de um serviço não dependa do tamanho da fila no momento e nem de outro atendimento. Por último, assume-se que cada paciente somente é atendido uma única vez por visita.

Após a definição das premissas, o primeiro cenário simulado teve como objetivo representar o funcionamento atual do consultório, conforme descrito na Seção 3, considerando as distribuições encontradas para os tempos de serviço da secretária e do médico, para a impontualidade do paciente, para o atraso do médico e para as interrupções entre consultas, além da presença de no-shows por classe de paciente e com disciplina de fila por ordem da agenda.

\section{3.}

\section{Cenário atual}

No cenário atual da clínica os pacientes de primeira vez e de retorno são agendados em slots de 20 minutos e os de marcação em slots de 10 minutos. Essa regra de agendamento utilizada se assemelha a regra IBFIA, porém os intervalos definidos para cada classe não são os intervalos exatos dessa regra, em que os pacientes de retorno deveriam ser agendados em slots de 15 minutos, em vez de 20, já que seu tempo médio de atendimento é de 15 minutos. Por isso, decidiu-se chamar essa regra de ATUAL.

Quanto à configuração da agenda, o agendamento é feito de $9 \mathrm{~h}$ às $11 \mathrm{~h} 40 \mathrm{~min} \mathrm{e}$ de $13 \mathrm{~h} 40 \mathrm{~min}$ às $18 \mathrm{~h}$, e o atendimento é feito duas vezes por semana, às segundas e quartas-feiras. Nove pacientes são agendados na parte da manhã e 14 pacientes na parte da tarde, sendo um total de 23 pacientes agendados por dia. Como o médico agenda os pacientes até às $18 \mathrm{~h}$, o turno normal considerado por ele é até às $18 \mathrm{~h} 30 \mathrm{~min}$. 
4.4.

\section{Políticas de agendamento}

Em cada cenário testado, serão consideradas as políticas de agendamento de melhor desempenho encontradas na literatura (IBFI, 2BEG, IBFIA, 2BEGA, OFFSET e DOME), como também as que obtiveram bons resultados recentemente, mas que foram pouco testadas (PLATÔ-DOME, DOME UNIVERSAL, DOME UNIVERSAL A, OFFSETA e IICR). No que tange ao sequenciamento, em todas as regras, com exceção da DOME UNIVERSAL A e OFFSETA, os pacientes de cada classe serão sequenciados pela ordem da ligação (FCFA), ou seja, as classes serão agendadas aleatoriamente respeitando as proporções de pacientes de cada classe, que é o sequenciamento mais prático entre os existentes, não necessitando de slots dedicados por classe.

No que tange às regras de agendamento, a Figura 6 resume o funcionamento das regras que serão testadas na clínica em estudo.

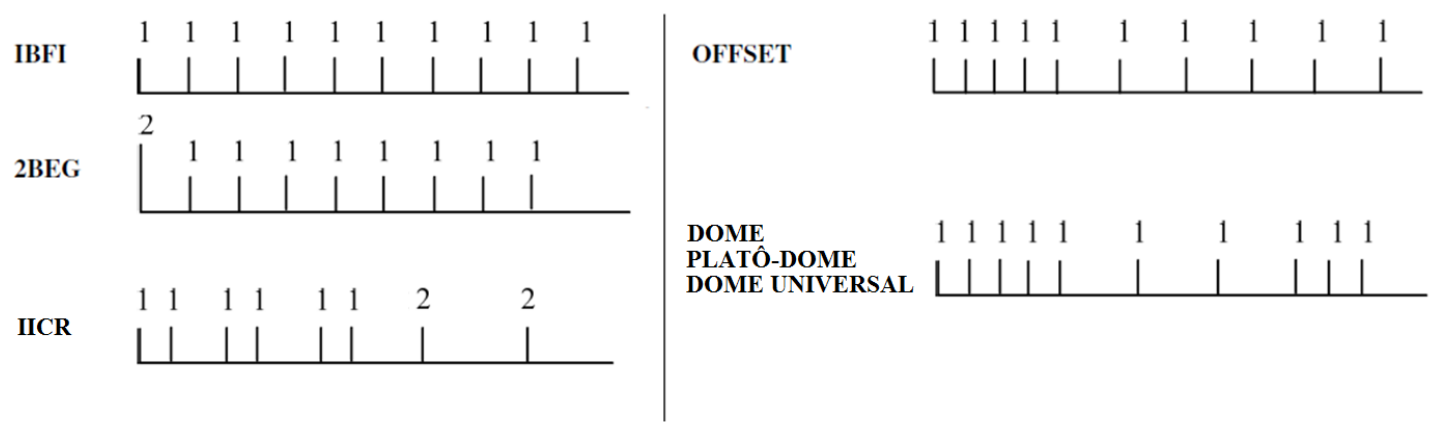

Figura 7 - Regras de Agendamento utilizadas na aplicação. Fonte: Elaboração própria

Além disso, as regras IBFI, 2BEG, OFFSET e DOME UNIVERSAL serão também testadas utilizando ajustes de horários por classe de paciente (IBFIA, 2BEGA, OFFSET A e DOME UNIVERSAL A), conforme explicação apresentada no Apêndice C. Portanto, nas políticas de intervalos ajustados pela classe IBFIA e 2BEGA, os pacientes foram separados em três classes ("Primeira Vez", "Retorno" e "Marcação de Cirurgia") e sequenciados pela ordem da ligação (FCFA). No caso da OFFSET A e da DOME UNIVERSAL A, os pacientes serão agrupados em apenas duas classes ("Primeira Vez" e "Retorno + Marcação de Cirurgia”), uma vez que as 
formulações dessas políticas preveem apenas duas classes de pacientes. Dessa forma, os horários de agendamento foram ajustados por essas classes e os pacientes foram sequenciados de duas formas: com a classe de paciente de maior média de tempo de serviço no inicio do dia e a de menor no final (HMBEG); e o inverso, ou seja, com a de menor média no início (LMBEG). Dessa forma, nesse caso, devido à exigência da formulação, foi feito uma separação de slots por classe de paciente, não sendo possível sequenciar por ordem da ligação (FCFA).

Durante a configuração inicial de cada política de agendamento, foram feitos testes de diversas configurações diferentes. Nesses testes, notou-se que a utilização da política DOME de forma periódica dentro de um mesmo turno gerava resultados superiores aos da DOME tradicional quando havia um maior número de pacientes agendados em um mesmo período. Essa política, denominada aqui de DOME CYCLE, foi acrescentada aos testes, e sua formulação encontra-se no Apêndice J. A Figura 7 ilustra o funcionamento dessa regra de agendamento para um turno com 15 agendamentos.

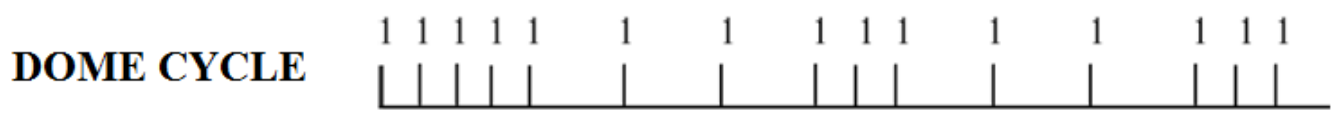

Figura 8 - Regra de Agendamento DOME CYCLE.

Portanto, foram testadas as seguintes políticas de agendamento com seus respectivos parâmetros: IBFI, 2BEG, IBFIA - FCFA, 2BEGA - FCFA, OFFSET 1 $\left(\beta_{1}=0.15 ; \beta_{2}=0.3\right)$, OFFSET $2\left(\beta_{1}=0.25 ; \beta_{2}=0.5\right)$, DOME $\left(\beta_{1}=0.15 ; \beta_{2}=\right.$ $\left.0.02 ; \beta_{3}=0.05\right)$, DOME CYCLE $\left(\beta_{1}=0.15 ; \beta_{2}=0.02 ; \beta_{3}=0.05, P=N / 2\right)$, PLATÔ-DOME $1(S=0.3, Z=-0.15)$, PLATÔ-DOME $2(S=0.45, Z=-0.15)$, PLATÔ-DOME $3 \quad(S=0.9, Z=-0.15), \quad$ DOME UNIVERSAL, DOME UNIVERSAL A - HMBEG, DOME UNIVERSAL A - LMBEG, OFFSETA HMBEG, OFFSETA - LMBEG e IICR, além da regra ATUAL. Todas as políticas tiveram os horários ajustados para intervalos proporcionais a cinco minutos para torná-las factíveis de serem implementadas na prática, ou seja, se a formulação 
retornou que um paciente deve ser agendado às $10 \mathrm{~h} 14 \mathrm{~min}$, ele na verdade será agendado às $10 \mathrm{~h} 15 \mathrm{~min}$.

\section{5 .}

\section{Validação do modelo}

Ao simular o cenário, com as características observadas anteriormente na Seção 3 e utilizando a regra ATUAL, pôde-se comparar os resultados encontrados na simulação com os indicadores de desempenho do sistema atual que foram calculados por meio dos dados do sistema corporativo (Tabela 10). Percebe-se que os resultados da simulação estão coerentes com os indicadores empíricos.

Tabela 10 - Validação do modelo. Fonte: Elaboração própria.

\begin{tabular}{lccccc}
\hline Modelo & $\begin{array}{c}\text { Tempo } \\
\text { Médio } \\
\text { de Fila } \\
\text { (min) }\end{array}$ & $\begin{array}{c}\text { Tempo Máximo } \\
\text { de Fila (min) }\end{array}$ & $\begin{array}{c}\text { Pacientes } \\
\text { até } \\
\text { 30min na } \\
\text { Fila }\end{array}$ & $\begin{array}{c}\text { Horário } \\
\text { de fim } \\
\text { do dia } \\
\text { (h) }\end{array}$ & $\begin{array}{c}\mathbf{N}^{\mathbf{0}} \text { de } \\
\text { pacientes } \\
\text { atendidos }\end{array}$ \\
\hline Simulado & 22.73 & 66.45 & $68.93 \%$ & 18.45 & 16.93 \\
Empírico & 18.14 & 67.82 & $72.90 \%$ & 18.40 & 16.99 \\
\hline
\end{tabular}

Pode-se comparar também o comportamento da fila ao longo do dia para avaliar se o modelo de simulação está representado a realidade da clínica. Dessa forma, a Figura 9 mostra o tempo que o paciente fica na fila por faixa de horário agendado, tanto para o modelo simulado quanto para os dados coletados. 


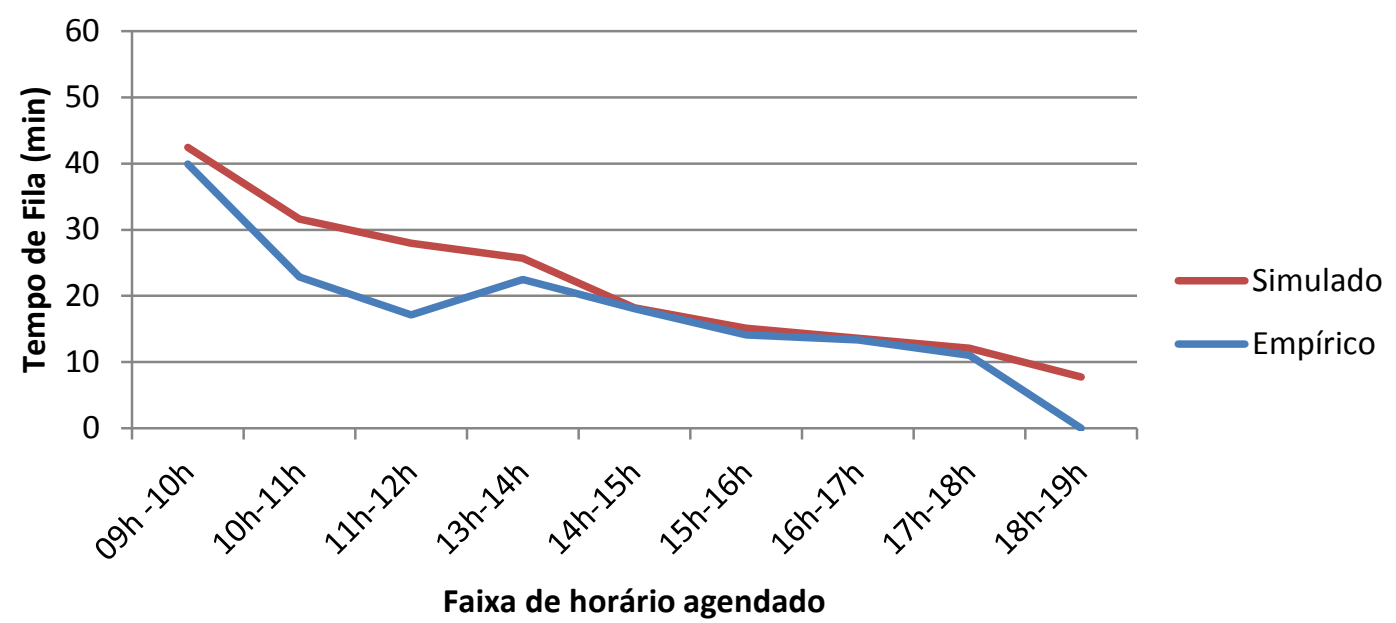

Figura 9 - Comparação do comportamento do tempo de fila por faixa de horário agendado. Fonte: Elaboração própria.

Primeiramente, percebe-se que os comportamentos estão bem parecidos, o que mostra que o modelo está coerente com a realidade da clínica. Os desvios entre o tempo de fila dos dois modelos por horário agendado estão apresentados na Tabela 11. Nota-se que a média do desvio foi de apenas $18,9 \%$.

Tabela 11 - Comparação do desvio do tempo de fila por horário agendado. Fonte: Elaboração própria.

\begin{tabular}{|c|c|c|c|c|}
\hline \multirow{2}{*}{$\begin{array}{c}\text { Faixa de } \\
\text { Horário } \\
\text { Agendado }\end{array}$} & \multicolumn{2}{|c|}{$\begin{array}{l}\text { Média de Tempo de } \\
\text { Fila (min) }\end{array}$} & \multirow[t]{2}{*}{ |Diferença| } & \multirow[t]{2}{*}{$\begin{array}{c}\text { Desvio } \\
\text { |Diferença//Maiol }\end{array}$} \\
\hline & Empírico & Simulado & & \\
\hline $09 \mathrm{~h}-10 \mathrm{~h}$ & 39.91 & 42.42 & 2.51 & $5.9 \%$ \\
\hline $10 \mathrm{~h}-11 \mathrm{~h}$ & 22.87 & 31.61 & 8.73 & $27.6 \%$ \\
\hline $11 \mathrm{~h}-12 \mathrm{~h}$ & 17.14 & 27.98 & 10.85 & $38.8 \%$ \\
\hline $13 \mathrm{~h}-14 \mathrm{~h}$ & 22.51 & 25.68 & 3.17 & $12.4 \%$ \\
\hline $14 \mathrm{~h}-15 \mathrm{~h}$ & 18.05 & 18.18 & 0.13 & $0.7 \%$ \\
\hline $15 \mathrm{~h}-16 \mathrm{~h}$ & 14.13 & 15.10 & 0.97 & $6.4 \%$ \\
\hline $16 \mathrm{~h}-17 \mathrm{~h}$ & 13.35 & 13.62 & 0.26 & $1.9 \%$ \\
\hline $17 \mathrm{~h}-18 \mathrm{~h}$ & 11.04 & 12.12 & 1.08 & $8.9 \%$ \\
\hline $18 \mathrm{~h}-19 \mathrm{~h}$ & 0.00 & 7.76 & 7.76 & $100.0 \%$ \\
\hline Média Geral & 18.44 & 22.73 & 4.29 & $18.9 \%$ \\
\hline
\end{tabular}


Além disso, percebe-se que, devido ao atraso do médico no início do dia (em média $57 \mathrm{~min}$ ), a fila tem seu pico no primeiro horário de agendamento e vai diminuindo ao longo da manhã. Na parte da tarde, a fila tem seu pico novamente no primeiro horário devido ao longo tempo que o médico leva para almoço (84 min em média), voltando a diminuir ao longo da tarde.

\section{6.}

\section{Geração de cenários}

Após a validação do cenário atual, foram desenvolvidos outros cenários de forma a considerar diferentes turnos de trabalho possíveis, conforme está apresentado na Tabela 12 e será explicado em seguida.

Tabela 12 - Configurações dos fatores de complexidade de cada cenário. Fonte: Elaboração própria.

\begin{tabular}{|c|c|c|c|c|c|c|c|}
\hline & \multicolumn{7}{|c|}{ Cenário } \\
\hline Fator de complexidade & 1 & 3 & 4 & 5 & 6 & 7 & 8 \\
\hline $\begin{array}{l}\text { Número de pacientes na } \\
\text { seção }\end{array}$ & $\mathrm{N}=23$ & & $N^{\prime}=30$ & & $N^{\prime}=27$ & $\mathrm{~N}^{\prime}=22$ & $N^{\prime}=19$ \\
\hline $\begin{array}{c}\text { Horário de } \\
\text { Agendamento }\end{array}$ & $9 \mathrm{~h}-18 \mathrm{~h}$ & & $9 \mathrm{~h}-18 \mathrm{~h}$ & & $\begin{array}{l}10 \mathrm{~h}- \\
17: 45\end{array}$ & $\begin{array}{l}10 \mathrm{~h}- \\
16: 30\end{array}$ & $\begin{array}{l}13 \mathrm{~h}- \\
17: 30\end{array}$ \\
\hline Horário de Almoço & $\begin{array}{l}12: 30- \\
13: 40\end{array}$ & & 2:30-13: & & $\begin{array}{l}12: 30- \\
13: 30\end{array}$ & $\begin{array}{l}12: 30- \\
13: 30\end{array}$ & $\begin{array}{l}12: 30- \\
13: 30\end{array}$ \\
\hline $\begin{array}{l}\text { Probabilidade de no- } \\
\quad \text { show por classe }\end{array}$ & Atual & Atual & $\begin{array}{l}20 \% \\
\text { maior }\end{array}$ & $\begin{array}{l}20 \% \\
\text { menor }\end{array}$ & Atual & Atual & Atual \\
\hline $\begin{array}{l}\text { Médico impontual } \\
\text { (chegada e no almoço) }\end{array}$ & Sim Não & & Não & & Não & Não & Não \\
\hline$\%$ de interrupções & $26,8 \%$ & & $26,8 \%$ & & $26,8 \%$ & $26,8 \%$ & $26,8 \%$ \\
\hline
\end{tabular}

O Cenário 1 é o cenário atual com médico impontual e agendamento de $9 \mathrm{~h}$ às $18 \mathrm{~h}$, que foi validado e será testado para todas as outras políticas de agendamento. O Cenário 2 mantém as mesmas características do sistema atual, mas considerando o médico sendo pontual. Essa comparação serve para avaliar o desempenho do mesmo sistema contando que o médico se empenhasse para ser pontual. 
A partir do Cenário 2, pôde-se perceber que o sistema atual, com o médico pontual, gerou uma grande ociosidade do médico devido à alta taxa de no-show. Como proposta para que não aconteça essa ociosidade do médico e para aumentar o número de atendimentos por dia, o Cenário 3 considera o overbooking para compensar o no-show de pacientes, seguindo a regra descrita na Equação 26 do Apêndice A, que aumenta o número de pacientes agendados reduzindo o tamanho dos intervalos de agendamento. Esse cenário considera o médico como pontual.

$$
N^{\prime}=\frac{N}{1-P_{n}+P_{w}}
$$

Com objetivo de verificar se as melhores regras de agendamento do Cenário 3 se mantinham com bom desempenho, foi feita uma análise de sensibilidade variando a taxa de no-show em 20\% para mais e para menos (Cenário 4 e 5).

Os Cenários 6, 7 e 8 são cenários com horários de agendamento alternativos que possuem um menor turno de trabalho diário. Esses cenários foram gerados para atender a uma necessidade do médico que gostaria de ter flexibilidade em sua agenda para determinados períodos de menor demanda. Esses três cenários consideram turnos menores e possuem overbooking para compensar o no-show de pacientes (conforme Equação 26), sendo que o Cenário 6 agenda de 10h às 17h45min, o Cenário 7 de 10h às 16h30min e o Cenário 8 de 13h às 17h30min.

Nos Cenários 1 e 2, todas as políticas de agendamento foram testadas com exceção da DOME UNIVERSAL e DOME UNIVERSAL A, uma vez que suas formulações consideram o no-show para fazer overbooking, ou seja, aumentam o número de pacientes agendados e reduzem o tamanho dos intervalos entre agendamentos. No Cenário 3, 4 e 5, todas as políticas de agendamento foram testadas. Nos Cenários 6, 7 e 8, apenas as melhores políticas dos cenários anteriores foram testadas.

A partir das 114 simulações feitas, relacionando cada cenário a cada política de agendamento, foram obtidos os resultados a partir da ferramenta Output Viewer do software ProModel ${ }^{\circledR}$ versão 8.6, sendo que alguns dados foram exportados para uma planilha para obter resultados mais específicos, visando os objetivos desse estudo. 


\section{7.}

\section{Indicadores de desempenho}

Para cada cenário, a política de agendamento escolhida para o consultório será aquela que apresentar o melhor desempenho conjunto nos seguintes indicadores: (1) tempo médio de fila de pacientes; (2) horário de fim do dia; e (3) percentual de pacientes que aguardam até 30 minutos na fila. Para auxiliar possíveis desempates entre políticas, também serão analisados os indicadores: (4) tempo máximo de fila; e (5) percentual de ociosidade do médico. Dessa forma, este estudo utilizou quatro tipos de indicadores de tempo da literatura, conforme classificação feita no Quadro 3 da Seção 2.3.2. Os indicadores (1) e (4) correspondem ao item 2.1 do Quadro 3, relacionado ao tempo de espera do paciente, o indicador (2) se enquadra no item $2.3 \mathrm{e}$ o indicador (3) tem a mesma definição do item 2.5. Além dos indicadores de tempo, o indicador (5) corresponde ao item 5.2, relacionado ao percentual de utilização do médico.

Para auxiliar na validação de cada política, foi utilizado o indicador (6) número de pacientes atendidos, de forma que, em cada cenário, o número de pacientes atendidos deve ser igual para todas as políticas. $\mathrm{O}$ número de pacientes atendidos também será utilizado para fazer uma comparação entre os cenários.

Considera-se como um bom desempenho no indicador de percentual de pacientes até 30 minutos na fila, um percentual maior do que 70\%, para ficar próximo do padrão estabelecido por alguns países europeus, conforme mencionado na Seção 2.3.2.1. (Department of Health, 1991). Em relação ao indicador de horário de fim do dia, recomenda-se que esse horário não ultrapasse o fim do turno. Por exemplo, no cenário atual, que possui agendamentos até $18 \mathrm{~h}$, o turno deveria terminar às $18 \mathrm{~h} 30 \mathrm{~min}$.

Com o objetivo de comparar as principais políticas de agendamento da literatura, foi realizada uma análise quantitativa dos indicadores de desempenho de cada política em cada cenário. Em primeiro lugar, procurou-se encontrar, para cada indicador de desempenho, o desvio entre o resultado de cada política e o resultado da melhor política nesse indicador. Portanto, busca-se encontrar a política que minimiza o somatório dos desvios de cada indicador de desempenho. 
Para os indicadores de tempo médio e máximo de fila e de percentual de ociosidade, o desvio representa a diferença entre o resultado da política analisada e o resultado da melhor política, dividido pelo resultado da melhor política. Para o indicador de percentual de pacientes até 30min na fila, o desvio representa a diferença entre o resultado da melhor política e o resultado da política analisada, dividido pelo resultado da melhor política.

No caso do indicador de horário de final do dia, o desvio representa a diferença entre o horário de fim do dia da política analisada e o horário do último agendamento, dividido pela diferença entre o horário de fim do turno e o horário do último agendamento, subtraído de uma unidade ao final da operação. Por exemplo, no caso de uma política em que o horário de fim do dia é às $19 \mathrm{~h}$, que o horário do fím do turno é às $18 \mathrm{~h} 30$ min e que o horário de último agendamento é às $18 \mathrm{~h}$, nota-se que o dia acaba 60min após o último horário agendado, sendo que se tolera que ele termine em até 30min após o último horário agendado. Dessa forma, o desvio é de $100 \%$ em relação ao tolerado, que é o mesmo que dividir 60 por 30 e diminuir uma unidade. Quando o horário de fim do dia for anterior ao horário tolerado, o desvio será considerado igual a zero.

Para cada política em cada cenário, foi feito o somatório dos desvios para cada indicador de desempenho, considerando um peso dobrado para os indicadores de tempo médio de fila, de horário de fim do dia e de percentual de pacientes até 30min na fila, que são os principais indicadores de desempenho adotados neste trabalho, e um peso normal para os indicadores de tempo máximo de fila e ociosidade percentual, que são os indicadores complementares.

Na próxima seção serão apresentados os resultados dos cenários gerados, a comparação entre as políticas e a discussão dos resultados. 


\section{Resultados}

Nesta seção estão apresentados os resultados dos cenários testados, respeitando as definições de cada cenário, conforme foi ilustrado na Tabela 12 da Seção 4.6.

5.1.

Cenário 1 - Situação Atual

Ao simular o cenário atual para cada política de agendamento, obtiveram-se os resultados para os indicadores de desempenho, conforme apresentados na Tabela 13 para uma média de 500 replicações.

Tabela 13 - Resultados do Cenário 1. Fonte: Elaboração própria.

\begin{tabular}{ccccccc}
\hline $\begin{array}{c}\text { Política de } \\
\text { Agendamento }\end{array}$ & $\begin{array}{c}\text { Tempo } \\
\text { Médio } \\
\text { de Fila } \\
\text { (min) }\end{array}$ & $\begin{array}{c}\text { Horário } \\
\text { de fim } \\
\text { do dia } \\
\text { (h) }\end{array}$ & $\begin{array}{c}\text { Tempo } \\
\text { Máximo } \\
\text { de Fila } \\
(\mathbf{m i n})\end{array}$ & $\begin{array}{c}\text { \% } \\
\text { Pacientes } \\
\text { até } \\
\text { 30min na } \\
\text { Fila }\end{array}$ & $\begin{array}{c}\text { Ociosidade } \\
(\%)\end{array}$ & $\begin{array}{c}\mathbf{N}^{\mathbf{d}} \text { de } \\
\text { pacientes } \\
\text { atendidos }\end{array}$ \\
\hline IBFI & 21.11 & $18: 29$ & 61.48 & $69.88 \%$ & $29.46 \%$ & 16.90 \\
PLATO-DOME 1 & 21.75 & $18: 26$ & 63.85 & $69.47 \%$ & $29.59 \%$ & 16.77 \\
ATUAL & 22.73 & $18: 27$ & 66.45 & $68.93 \%$ & $29.07 \%$ & 16.93 \\
PLATO-DOME 3 & 23.15 & $18: 14$ & 65.90 & $67.30 \%$ & $26.73 \%$ & 16.94 \\
OFFSETA-HMBEG & 23.22 & $18: 21$ & 68.52 & $67.93 \%$ & $28.42 \%$ & 16.84 \\
PLATO-DOME 2 & 23.55 & $18: 15$ & 66.41 & $66.90 \%$ & $26.58 \%$ & 17.04 \\
DOME & 24.02 & $18: 13$ & 66.49 & $65.48 \%$ & $26.76 \%$ & 16.89 \\
OFFSET 1 & 24.05 & $18: 20$ & 66.73 & $65.61 \%$ & $28.52 \%$ & 16.78 \\
IICR & 24.56 & $18: 22$ & 71.45 & $65.09 \%$ & $28.21 \%$ & 16.93 \\
DOME CYCLE & 25.38 & $18: 10$ & 68.00 & $63.72 \%$ & $26.46 \%$ & 16.84 \\
OFFSETA-LMBEG & 26.37 & $18: 25$ & 68.27 & $61.58 \%$ & $29.16 \%$ & 16.84 \\
OFFSET 2 & 27.32 & $18: 16$ & 71.39 & $60.85 \%$ & $27.77 \%$ & 16.78 \\
IBFIA-FCFA & 28.26 & $18: 06$ & 72.83 & $59.95 \%$ & $25.10 \%$ & 16.98 \\
2BEG & 29.04 & $18: 14$ & 74.50 & $58.40 \%$ & $26.57 \%$ & 16.97 \\
2BEGA-FCFA & 32.63 & $17: 53$ & 79.01 & $51.81 \%$ & $23.31 \%$ & 16.83 \\
\hline
\end{tabular}


Nota-se que todas as regras respeitaram o mesmo número de pacientes atendidos, cerca de 17 pacientes, o que era esperado já que a taxa média de no-show utilizada foi a mesma em todas elas $(26,13 \%)$, e foram agendados 23 pacientes. Para o cenário atual, percebe-se que a política IBFI teve o melhor resultado em termos de tempo de fila ( 21min), com o horário de fim do dia às $18 \mathrm{~h} 29 \mathrm{~min}$, o que está adequado ao turno até às 18h30min. As políticas ATUAL e PLATO-DOME 1 também possuíram resultados bem próximos em ambos os indicadores, o que mostra que a política utilizada pelo médico funciona bem para o cenário em que o sistema se encontra atualmente. A política PLATO-DOME 3 apresentou um resultado bem próximo em termos de tempo de fila (23min.) e teve um horário de fim do dia mais cedo (18h14min), sendo também uma boa alternativa.

Percebe-se que a ociosidade do médico na melhor política do cenário atual está alta $(29,46 \%)$. Isso é gerado devido à alta taxa de no-show, que faz com que o médico fique sem pacientes para atender em diversos momentos do dia.

Percebe-se que o percentual de pacientes até 30min na fila está próximo dos $70 \%$ para as políticas com melhor desempenho, o que é um bom resultado no que diz respeito à satisfação do paciente.

\section{2.}

Cenário 2 - Cenário atual sem atraso do médico

Ao simular o cenário sem atraso para cada política de agendamento, obtiveramse os resultados demonstrados na Tabela 14. 
Tabela 14 - Resultados do Cenário 2. Fonte: Elaboração própria.

\begin{tabular}{|c|c|c|c|c|c|c|}
\hline Política & $\begin{array}{c}\text { Tempo } \\
\text { Médio de } \\
\text { Fila (min) }\end{array}$ & $\begin{array}{l}\text { Horário } \\
\text { de fim } \\
\text { do dia } \\
\text { (h) }\end{array}$ & $\begin{array}{c}\text { Tempo } \\
\text { Máximo } \\
\text { de Fila } \\
\text { (min) }\end{array}$ & $\begin{array}{c}\% \\
\text { Pacientes } \\
\text { até } \\
\text { 30min na } \\
\text { Fila }\end{array}$ & $\begin{array}{c}\text { Ociosidade } \\
(\%)\end{array}$ & $\begin{array}{c}\mathbf{N}^{0} \text { de } \\
\text { pacientes } \\
\text { atendidos }\end{array}$ \\
\hline PLATO-DOME 1 & 7.49 & $18: 27$ & 30.86 & $93.62 \%$ & $39.76 \%$ & 16.78 \\
\hline IBFI & 7.69 & $18: 26$ & 32.17 & $93.42 \%$ & $39.30 \%$ & 16.87 \\
\hline OFFSETA-LMBEG & 7.78 & $18: 20$ & 32.16 & $93.52 \%$ & $38.78 \%$ & 16.82 \\
\hline ATUAL & 8.53 & $18: 30$ & 34.65 & $92.28 \%$ & $39.98 \%$ & 16.83 \\
\hline PLATO-DOME 2 & 8.59 & $18: 13$ & 34.37 & $92.13 \%$ & $37.60 \%$ & 16.91 \\
\hline IICR & 8.84 & $18: 21$ & 38.67 & $91.12 \%$ & $38.59 \%$ & 16.90 \\
\hline OFFSET 2 & 8.93 & $18: 14$ & 34.59 & $91.49 \%$ & $37.62 \%$ & 16.93 \\
\hline DOME & 8.95 & $18: 12$ & 35.73 & $91.38 \%$ & $37.31 \%$ & 16.94 \\
\hline OFFSET 1 & 9.11 & $18: 17$ & 35.04 & $91.36 \%$ & $37.69 \%$ & 17.02 \\
\hline PLATO-DOME 3 & 9.18 & $18: 12$ & 35.89 & $90.59 \%$ & $37.54 \%$ & 16.89 \\
\hline $\begin{array}{c}\text { OFFSETA- } \\
\text { HMBEG }\end{array}$ & 9.55 & 18:16 & 36.06 & $89.83 \%$ & $37.97 \%$ & 16.92 \\
\hline DOME CYCLE & 9.75 & 18:06 & 36.97 & $90.30 \%$ & $36.25 \%$ & 17.01 \\
\hline IBFIA-FCFA & 10.14 & $17: 59$ & 38.05 & $88.84 \%$ & $35.99 \%$ & 16.85 \\
\hline 2BEG & 10.37 & $18: 10$ & 37.59 & $88.87 \%$ & $36.89 \%$ & 16.98 \\
\hline 2BEGA-FCFA & 12.60 & $17: 46$ & 41.99 & $85.73 \%$ & $33.90 \%$ & 16.89 \\
\hline
\end{tabular}

Percebe-se que todas as políticas obtiveram bons desempenhos em termos de tempo de fila (entre sete e 12 minutos). Isso acontece devido ao aumento da ociosidade do médico nesse cenário, que é em média $40 \%$ nas melhores políticas em termos de tempo de fila. Essa ociosidade é causada pela alta taxa de no-show e pelo fato do médico estar chegando pontualmente nesse cenário, tendo assim mais tempo ocioso durante o dia. Dessa maneira, como o horário do último paciente marcado é às 18h (na maioria das políticas), ele é obrigado a aguardar até esse horário sem poder ir embora para poder atender o paciente caso ele venha, o que mantém a alta ociosidade.

Com o intuito de reduzir a ociosidade do médico, percebe-se que é adequado adotar uma política de overbooking para esse cenário, uma vez que os indicadores de tempo de fila estão com resultados melhores do que os aceitáveis para o sistema, como é o caso do percentual de pacientes até 30min na fila de espera, que está acima de $90 \%$ para as melhores políticas. Isso será feito no Cenário 3 da seção seguinte. 
5.3.

Cenário 3 - Situação proposta sem atraso e com overbooking de pacientes

Para simular o cenário proposto (sem atraso do médico) incluindo o overbooking para cada política de agendamento, o número de pacientes agendados passou de 23 para 30, e obtiveram-se os resultados demonstrados na Tabela 15.

Tabela 15 - Resultados do Cenário 3. Fonte: Elaboração própria.

\begin{tabular}{|c|c|c|c|c|c|c|}
\hline $\begin{array}{c}\text { Política de } \\
\text { Agendamento }\end{array}$ & $\begin{array}{c}\text { Tempo } \\
\text { Médio } \\
\text { de Fila } \\
\text { (min) }\end{array}$ & $\begin{array}{l}\text { Horário } \\
\text { de fim } \\
\text { do dia } \\
\text { (h) }\end{array}$ & $\begin{array}{c}\text { Tempo } \\
\text { Máximo } \\
\text { de Fila } \\
\text { (min) }\end{array}$ & $\begin{array}{c}\% \\
\text { Pacientes } \\
\text { até 30min } \\
\text { na Fila }\end{array}$ & $\begin{array}{l}\text { Ociosidade } \\
(\%)\end{array}$ & $\begin{array}{c}\mathrm{N}^{\mathbf{o}} \mathrm{de} \\
\text { pacientes } \\
\text { atendidos }\end{array}$ \\
\hline $\begin{array}{c}\text { DOME UNIVERSAL } \\
\text { A - LMBEG }\end{array}$ & 14.95 & $19: 03$ & 50.66 & $81.84 \%$ & $26.26 \%$ & 22.03 \\
\hline OFFSETA-LMBEG & 15.26 & $18: 48$ & 51.83 & $80.79 \%$ & $24.31 \%$ & 21.97 \\
\hline $\begin{array}{c}\text { DOME UNIVERSAL } \\
\text { A - HMBEG }\end{array}$ & 16.94 & 19:00 & 53.38 & $78.66 \%$ & $25.99 \%$ & 21.98 \\
\hline OFFSET 2 & 17.13 & $18: 55$ & 54.01 & $78.05 \%$ & $25.06 \%$ & 22.05 \\
\hline PLATO-DOME 1 & 17.89 & $18: 47$ & 57.44 & $77.43 \%$ & $23.73 \%$ & 22.11 \\
\hline IBFI & 18.51 & $18: 48$ & 59.53 & $76.28 \%$ & $24.56 \%$ & 21.92 \\
\hline OFFSETA-HMBEG & 19.78 & $18: 45$ & 59.13 & $74.22 \%$ & $22.58 \%$ & 22.34 \\
\hline DOME UNIVERSAL & 19.82 & $18: 37$ & 59.88 & $73.65 \%$ & $22.56 \%$ & 22.01 \\
\hline ATUAL & 19.94 & $18: 50$ & 62.11 & $73.82 \%$ & $24.94 \%$ & 21.89 \\
\hline OFFSET 1 & 20.72 & $18: 33$ & 60.59 & $72.58 \%$ & $21.91 \%$ & 22.03 \\
\hline PLATO-DOME 2 & 21.32 & $18: 38$ & 65.81 & $72.40 \%$ & $22.46 \%$ & 22.10 \\
\hline DOME CYCLE & 21.48 & $18: 34$ & 67.31 & $72.09 \%$ & $22.46 \%$ & 21.93 \\
\hline DOME & 21.59 & $18: 35$ & 66.38 & $71.87 \%$ & $21.62 \%$ & 22.18 \\
\hline 2BEG & 21.61 & $18: 33$ & 61.07 & $71.40 \%$ & $21.66 \%$ & 22.10 \\
\hline PLATO-DOME 3 & 21.71 & $18: 32$ & 70.66 & $72.27 \%$ & $21.15 \%$ & 22.18 \\
\hline IICR & 23.17 & $18: 25$ & 77.38 & $69.94 \%$ & $20.83 \%$ & 21.99 \\
\hline IBFIA-FCFA & 27.06 & $18: 28$ & 77.42 & $64.56 \%$ & $21.92 \%$ & 21.81 \\
\hline 2BEGA-FCFA & 27.85 & $18: 21$ & 76.62 & $62.79 \%$ & $20.34 \%$ & 21.93 \\
\hline
\end{tabular}

Nota-se que o overbooking faz com que o número de pacientes atendidos aumente de 17 para 22 pacientes, o que permitiu reduzir a ociosidade do sistema de forma considerável, saindo de uma taxa que estava em média $40 \%$ nas melhores políticas do Cenário 2 para $22 \%$ nas melhores políticas deste cenário. Percebe-se 
também que os resultados em termos de tempo de fila e horário de fim do dia variaram muito entre as políticas testadas.

Pela análise dos indicadores, pode-se notar que as políticas OFFSET 1 e DOME UNIVERSAL foram as que tiveram os melhores resultados em termos de tempos médio e máximo de fila e percentual de pacientes até 30 min na fila, dentre as políticas que terminam o dia em horário próximo das $18 \mathrm{~h} 30 \mathrm{~min}$, sendo recomendado a utilização das mesmas.

Para auxiliar na definição da melhor regra entre as duas encontradas para o cenário proposto, os Cenários 4 e 5 a seguir fazem análises de sensibilidade com aumento e redução do no-show.

\section{4 .}

Cenário 4 - Análise de sensibilidade com redução do no-show

Para analisar a sensibilidade do cenário proposto (Cenário 3), foi realizado primeiramente uma redução de $20 \%$ na taxa de no-show de cada classe, passando para uma taxa média de $20,9 \%$ de não comparecimento. O número de pacientes agendados e todos os outros fatores de complexidade do Cenário 3 foram mantidos com mesmo valor nesse cenário. Os resultados estão demonstrados na Tabela 16. 
Tabela 16 - Resultados do Cenário 4. Fonte: Elaboração própria.

\begin{tabular}{|c|c|c|c|c|c|c|}
\hline $\begin{array}{c}\text { Política de } \\
\text { Agendamento }\end{array}$ & $\begin{array}{c}\text { Tempo } \\
\text { Médio } \\
\text { de Fila } \\
(\mathrm{min})\end{array}$ & $\begin{array}{c}\text { Horário } \\
\text { de fim } \\
\text { do dia } \\
\text { (h) }\end{array}$ & $\begin{array}{c}\text { Tempo } \\
\text { Máximo } \\
\text { de Fila } \\
\text { (min) }\end{array}$ & $\begin{array}{c}\% \\
\text { Pacientes } \\
\text { até } \\
\text { 30min na } \\
\text { Fila }\end{array}$ & $\begin{array}{c}\text { Ociosidade } \\
(\%)\end{array}$ & $\begin{array}{c}\mathrm{N}^{\mathbf{o}} \text { de } \\
\text { pacientes } \\
\text { atendidos }\end{array}$ \\
\hline $\begin{array}{c}\text { DOME UNIVERSAL A } \\
\text { - LMBEG }\end{array}$ & 17.54 & 19:10 & 57.37 & $78.09 \%$ & $21.66 \%$ & 23.73 \\
\hline OFFSETA-LMBEG & 18.66 & $18: 58$ & 60.23 & $75.61 \%$ & $20.07 \%$ & 23.66 \\
\hline PLATO-DOME 1 & 21.58 & $18: 53$ & 66.50 & $72.39 \%$ & $20.17 \%$ & 23.40 \\
\hline $\begin{array}{c}\text { DOME UNIVERSAL A } \\
\text { - HMBEG }\end{array}$ & 21.86 & 19:07 & 63.57 & $71.31 \%$ & $21.57 \%$ & 23.60 \\
\hline IBFI & 23.04 & 18:56 & 68.42 & $69.71 \%$ & $20.15 \%$ & 23.57 \\
\hline OFFSET 2 & 24.06 & 19:06 & 66.39 & $68.69 \%$ & $21.60 \%$ & 23.57 \\
\hline ATUAL & 25.12 & $18: 59$ & 72.91 & $67.41 \%$ & $21.31 \%$ & 23.35 \\
\hline PLATO-DOME 2 & 25.50 & $18: 46$ & 74.37 & $66.72 \%$ & $18.73 \%$ & 23.53 \\
\hline OFFSETA-HMBEG & 25.56 & 18:52 & 70.82 & $66.98 \%$ & $19.24 \%$ & 23.65 \\
\hline OFFSET 1 & 26.39 & $18: 44$ & 71.61 & $64.11 \%$ & $18.59 \%$ & 23.46 \\
\hline DOME CYCLE & 26.60 & $18: 45$ & 75.77 & $64.75 \%$ & $18.73 \%$ & 23.46 \\
\hline DOME UNIVERSAL & 27.08 & $18: 51$ & 74.87 & $64.80 \%$ & $19.40 \%$ & 23.55 \\
\hline PLATO-DOME 3 & 27.35 & $18: 44$ & 81.16 & $65.12 \%$ & $18.30 \%$ & 23.54 \\
\hline DOME & 27.78 & $18: 46$ & 79.39 & $63.18 \%$ & $18.62 \%$ & 23.55 \\
\hline 2BEG & 28.07 & $18: 47$ & 75.89 & $62.78 \%$ & $19.14 \%$ & 23.43 \\
\hline IICR & 29.41 & $18: 42$ & 92.52 & $62.22 \%$ & $18.02 \%$ & 23.53 \\
\hline IBFIA-FCFA & 31.98 & $18: 41$ & 85.56 & $59.02 \%$ & $17.78 \%$ & 23.55 \\
\hline 2BEGA-FCFA & 35.79 & $18: 36$ & 90.38 & $53.05 \%$ & $16.79 \%$ & 23.62 \\
\hline
\end{tabular}

Nota-se que, como esperado, a redução do no-show fez com que o número de pacientes atendidos aumentasse ainda mais, passando para em média 23,5 pacientes atendidos. Percebe-se que esse aumento no número de pacientes no sistema fez com que o desempenho do mesmo piorasse em todos os outros indicadores para todas as políticas. Comparando as duas melhores políticas do Cenário 3 (OFFSET 1 e DOME UNIVERSAL), observa-se que, no caso de haver essa redução no no-show, a OFFSET 1 passa a ser superior à DOME UNIVERSAL em todos os indicadores, com exceção apenas do indicador de percentual de pacientes até 30min na fila, cujo resultado da OFFSET 1 foi um pouco inferior $(64,1 \%)$, mas bem próximo do resultado da DOME UNIVERSAL (64,8\%). 


\section{5 .}

\section{Cenário 5 - Análise de sensibilidade com aumento do no-show}

Na segunda análise de sensibilidade, foi realizado um aumento de $20 \%$ na taxa de no-show, passando para uma taxa média de 31,4\% de não comparecimento. Da mesma maneira, todos os outros fatores de complexidade dos Cenários 3 e 4 foram mantidos com mesmo valor nesse cenário. Os resultados estão demonstrados na Tabela 17.

Tabela 17 - Resultados do Cenário 5. Fonte: Elaboração própria.

\begin{tabular}{ccccccc}
\hline $\begin{array}{c}\text { Política de } \\
\text { Agendamento }\end{array}$ & $\begin{array}{c}\text { Tempo } \\
\text { Médio } \\
\text { de Fila } \\
\text { (min) }\end{array}$ & $\begin{array}{c}\text { Horário } \\
\text { de fim } \\
\text { do dia } \\
\text { (h) }\end{array}$ & $\begin{array}{c}\text { Tempo } \\
\text { Máximo } \\
\text { de Fila } \\
\text { (min) }\end{array}$ & $\begin{array}{c}\text { \% } \\
\text { Pacientes } \\
\text { até } \\
\text { 30min na } \\
\text { Fila }\end{array}$ & $\begin{array}{c}\text { Ociosidade } \\
(\%)\end{array}$ & $\begin{array}{c}\mathbf{N}^{\mathbf{0}} \text { de } \\
\text { pacientes } \\
\text { atendidos }\end{array}$ \\
\hline $\begin{array}{c}\text { DOME UNIVERSAL } \\
\text { A - LMBEG }\end{array}$ & 11.34 & $18: 54$ & 43.12 & $87.65 \%$ & $30.55 \%$ & 20.40 \\
DOME UNIVERSAL & 12.23 & $18: 52$ & 44.86 & $85.71 \%$ & $29.72 \%$ & 20.58 \\
A - HMBEG & & & & & & \\
OFFSETA-LMBEG & 13.51 & $18: 41$ & 47.30 & $84.04 \%$ & $28.28 \%$ & 20.55 \\
IBFI & 14.26 & $18: 35$ & 50.15 & $82.44 \%$ & $28.28 \%$ & 20.33 \\
OFFSET 2 & 14.47 & $18: 52$ & 49.34 & $82.76 \%$ & $30.08 \%$ & 20.48 \\
PLATO-DOME 1 & 15.26 & $18: 35$ & 53.60 & $80.94 \%$ & $28.37 \%$ & 20.30 \\
OFFSETA-HMBEG & 15.45 & $18: 31$ & 50.48 & $80.56 \%$ & $27.32 \%$ & 20.42 \\
ATUAL & 15.52 & $18: 40$ & 52.42 & $80.58 \%$ & $28.33 \%$ & 20.49 \\
DOME UNIVERSAL & 16.03 & $18: 28$ & 52.95 & $80.01 \%$ & $26.88 \%$ & 20.41 \\
PLATO-DOME 2 & 16.83 & $18: 26$ & 54.57 & $78.83 \%$ & $26.17 \%$ & 20.55 \\
DOME & 16.98 & $18: 24$ & 56.07 & $78.66 \%$ & $26.07 \%$ & 20.48 \\
2BEG & 17.56 & $18: 26$ & 53.80 & $76.85 \%$ & $25.62 \%$ & 20.69 \\
PLATO-DOME 3 & 17.60 & $18: 22$ & 60.58 & $77.47 \%$ & $25.97 \%$ & 20.42 \\
DOME CYCLE & 17.65 & $18: 21$ & 57.90 & $77.15 \%$ & $25.94 \%$ & 20.39 \\
OFFSET 1 & 17.85 & $18: 24$ & 56.52 & $76.93 \%$ & $26.35 \%$ & 20.42 \\
IICR & 19.85 & $18: 16$ & 67.42 & $74.96 \%$ & $24.59 \%$ & 20.57 \\
IBFIA-FCFA & 21.72 & $18: 15$ & 65.02 & $72.18 \%$ & $25.07 \%$ & 20.38 \\
2BEGA-FCFA & 24.69 & $18: 08$ & 69.93 & $65.98 \%$ & $23.50 \%$ & 20.52 \\
\hline & & & & & & \\
\hline
\end{tabular}

Nota-se que o aumento do no-show fez com que o número de pacientes atendidos fosse reduzido, passando para uma média de 20,5 pacientes. Comparando novamente as políticas OFFSET 1 e DOME UNIVERSAL, percebe-se que no caso de haver esse aumento no no-show, ambas as políticas passam a ter bons resultados 
em todos os indicadores, já que o sistema fica menos congestionado. Como os resultados são bem próximos para todos os indicadores, a escolha de uma ou outra não afeta o desempenho do sistema nesse cenário.

Portanto, pela análise dos Cenários 3, 4 e 5, recomenda-se a utilização da política OFFSET 1, para o cenário proposto com agendamento de $9 \mathrm{~h}$ às $18 \mathrm{~h}$ com overbooking. Essa política possui resultado semelhante à DOME UNIVERSAL no Cenário 3 e 5, mas apresenta resultado superior no Cenário 4.

5.6.

\section{Cenário 6 - Horário alternativo (10h-17h45min)}

$\mathrm{O}$ primeiro cenário de horário alternativo foi com agendamento de $10 \mathrm{~h}$ às 17h45min. Nesse cenário, o horário de almoço foi reduzido em 10 minutos, sendo de 12h30min às 13h30min, com o objetivo de aumentar o turno, já que o horário de trabalho é menor. Isso é factível, uma vez que o médico está chegando mais tarde e saindo mais cedo do consultório, o que lhe permite mais tempo do dia para realizar outras atividades externas à clínica. Quanto aos outros fatores, eles foram considerados iguais aos do Cenário 3. O overbooking foi considerado para cada política de agendamento, o que resultou em 27 pacientes agendados.

Nesses cenários alternativos, as políticas com horário ajustado por classe, que não obtiveram bons resultados nos cenários anteriores, foram desconsideradas da simulação para reduzir o número de testes e tornar possível a análise em tempo viável. Dessa forma, obtiveram-se os seguintes resultados para as políticas, demonstrados na Tabela 18. 
Tabela 18 - Resultados do Cenário 6. Fonte: Elaboração própria.

\begin{tabular}{ccccccc}
\hline $\begin{array}{c}\text { Política de } \\
\text { Agendamento }\end{array}$ & $\begin{array}{c}\text { Tempo } \\
\text { Médio } \\
\text { de Fila } \\
\text { (min) }\end{array}$ & $\begin{array}{c}\text { Horário } \\
\text { de fim } \\
\text { do dia } \\
\text { (h) }\end{array}$ & $\begin{array}{c}\text { Tempo } \\
\text { Máximo } \\
\text { de Fila } \\
\text { (min) }\end{array}$ & $\begin{array}{c}\text { \% } \\
\text { Pacientes } \\
\text { até } \\
\text { 30min na } \\
\text { Fila }\end{array}$ & $\begin{array}{c}\mathbf{N}^{\mathbf{0}} \text { de } \\
\text { pacientes } \\
\text { atendidos }\end{array}$ & $\begin{array}{c}\text { Ociosi- } \\
\text { dade } \\
(\%)\end{array}$ \\
\hline PLATO-DOME 1 & 19.86 & $18: 35$ & 59.60 & $74.71 \%$ & 19.89 & $21.99 \%$ \\
DOME UNIVERSAL & 20.08 & $18: 36$ & 58.69 & $72.83 \%$ & 19.91 & $22.13 \%$ \\
DOME CYCLE & 20.09 & $18: 37$ & 59.65 & $73.95 \%$ & 19.77 & $22.85 \%$ \\
DOME & 20.40 & $18: 40$ & 61.25 & $73.66 \%$ & 19.93 & $22.82 \%$ \\
IBFI & 20.68 & $18: 39$ & 61.01 & $73.25 \%$ & 19.70 & $23.43 \%$ \\
PLATO-DOME 2 & 21.43 & $18: 32$ & 65.10 & $71.33 \%$ & 19.78 & $21.94 \%$ \\
2BEG & 21.63 & $18: 23$ & 59.21 & $71.23 \%$ & 19.71 & $20.59 \%$ \\
PLATO-DOME 3 & 21.67 & $18: 26$ & 65.51 & $72.77 \%$ & 19.65 & $21.40 \%$ \\
OFFSET 1 & 21.68 & $18: 29$ & 58.75 & $70.65 \%$ & 19.83 & $21.26 \%$ \\
IICR & 23.97 & $18: 21$ & 75.80 & $69.55 \%$ & 19.64 & $20.66 \%$ \\
\hline
\end{tabular}

Nota-se que o número de pacientes atendidos é em média igual a 20, o que está próximo do Cenário 3 (22 pacientes), e maior do que o Cenário 1 (17 pacientes). Além disso, o overbooking fez com que a ociosidade do sistema se mantivesse baixa, comparado com o Cenário 3, sendo 20\% nas melhores políticas. Quanto ao desempenho das políticas, pode-se verificar que a PLATO-DOME 1 teve um resultado superior em termos de tempo médio e máximo de fila, e de percentual de pacientes até 30min na fila, sendo que o horário de fim do dia termina apenas 14 minutos mais tarde do que a política que possui fim do dia mais cedo (IICR), o que, na visão do médico em estudo, não é tão significativo comparado com a melhoria proporcionada no nível de serviço, reduzindo, por exemplo, o tempo médio de fila de 24min na pior política (IICR) para 20min na PLATO-DOME 1, ou seja, quatro minutos a menos por paciente atendido. Dessa forma, recomenda-se a sua utilização nesse cenário.

\section{7.}

\section{Cenário 7 - Horário alternativo (10h-16h30min)}

O segundo cenário de horário alternativo para períodos de menor demanda foi o com agendamento de $10 \mathrm{~h}$ às $16 \mathrm{~h} 30 \mathrm{~min}$. Nesse cenário, o horário de almoço também 
foi considerado entre $12 \mathrm{~h} 30 \mathrm{~min}$ e $13 \mathrm{~h} 30 \mathrm{~min}$, e os outros fatores iguais aos do Cenário 3. O overbooking foi utilizado para cada política de agendamento, o que resultou em 22 pacientes agendados. Dessa forma, obtiveram-se os resultados indicados na Tabela 19.

Tabela 19 - Resultados do Cenário 7. Fonte: Elaboração própria.

\begin{tabular}{ccccccc}
\hline $\begin{array}{c}\text { Política de } \\
\text { Agendamento }\end{array}$ & $\begin{array}{c}\text { Tempo } \\
\text { Médio } \\
\text { de Fila } \\
\text { (min) }\end{array}$ & $\begin{array}{c}\text { Horário } \\
\text { de fim } \\
\text { do dia } \\
\text { (h) }\end{array}$ & $\begin{array}{c}\text { Tempo } \\
\text { Máximo } \\
\text { de Fila } \\
\text { (min) }\end{array}$ & $\begin{array}{c}\text { \%acientes } \\
\text { até } \\
\text { 30min na } \\
\text { Fila }\end{array}$ & $\begin{array}{c}\text { Ociosidade } \\
(\%)\end{array}$ & $\begin{array}{c}\mathbf{N}^{\mathbf{0}} \text { de } \\
\text { pacientes } \\
\text { atendidos }\end{array}$ \\
\hline DOME CYCLE & 16.85 & $17: 15$ & 51.09 & $78.72 \%$ & $23.43 \%$ & 16.12 \\
DOME & 17.63 & $17: 20$ & 51.25 & $76.41 \%$ & $24.43 \%$ & 16.11 \\
IBFI & 17.85 & $17: 18$ & 52.85 & $76.94 \%$ & $23.99 \%$ & 16.13 \\
OFFSET 1 & 17.95 & $17: 22$ & 50.89 & $76.68 \%$ & $24.30 \%$ & 16.21 \\
DOME & 18.83 & $17: 18$ & 53.57 & $75.52 \%$ & $23.58 \%$ & 16.22 \\
UNIVERSAL & 19.50 & $17: 05$ & 61.53 & $74.89 \%$ & $20.77 \%$ & 16.21 \\
IICR & 20.68 & $17: 08$ & 58.22 & $72.48 \%$ & $21.57 \%$ & 16.17 \\
PLATO-DOME 1 & 20.76 & $17: 09$ & 58.98 & $72.63 \%$ & $22.05 \%$ & 16.15 \\
PLATO-DOME 2 & 21.61 & $17: 05$ & 58.27 & $70.36 \%$ & $20.61 \%$ & 16.26 \\
2BEG & 22.73 & $17: 02$ & 68.73 & $69.98 \%$ & $20.28 \%$ & 16.19 \\
PLATO-DOME 3 & 22.73 & & & \\
\hline
\end{tabular}

Nota-se, na Tabela 19, que devido à redução do turno, o número de pacientes atendidos reduz comparado com o do Cenário 3, atendendo em média 16 pacientes. Ainda comparando com o Cenário 3, percebe-se que, mesmo com a redução do número de pacientes atendidos, a utilização do overbooking fez com que a ociosidade continue menor, sendo em média 24\% nas melhores políticas. Quanto ao desempenho das políticas, pode-se verificar que a DOME CYCLE teve um resultado superior em termos de tempo médio e máximo de fila, como também de percentual de pacientes até 30min na fila. Quanto ao horário de fim do dia, novamente percebe-se que a melhor política termina um pouco mais tarde do que outras, como a PLATO-DOME 3, que termina 13 minutos mais cedo. Entretanto, pela visão do médico esse valor não é significativo comparado com a melhoria proporcionada no nível de serviço, reduzindo, por exemplo, o tempo de fila de 23min (PLATO-DOME 3) para 17min na DOME CYCLE, recomendando-se à sua utilização. 
5.8.

\section{Cenário 8 - Horário alternativo (13h-17h30min)}

O terceiro cenário de horário alternativo para períodos de menor demanda foi o com agendamento de $13 \mathrm{~h}$ às $17 \mathrm{~h} 30$ min. Nesse cenário, não existe horário de almoço, já que o turno começa 13 h e os outros fatores foram novamente iguais aos do Cenário 3. O overbooking foi considerado para cada política de agendamento, o que resultou em 19 pacientes agendados. Dessa forma, obtiveram-se os seguintes resultados, demonstrados na Tabela 20.

Tabela 20 - Resultados do Cenário 8. Fonte: Elaboração própria.

\begin{tabular}{ccccccc}
\hline $\begin{array}{c}\text { Política de } \\
\text { Agendamento }\end{array}$ & $\begin{array}{c}\text { Tempo } \\
\text { Médio } \\
\text { de Fila } \\
(\mathbf{m i n})\end{array}$ & $\begin{array}{c}\text { Horário } \\
\text { de fim } \\
\text { do dia } \\
\text { (h) }\end{array}$ & $\begin{array}{c}\text { Tempo } \\
\text { Máximo } \\
\text { de Fila } \\
\text { (min) }\end{array}$ & $\begin{array}{c}\text { \%acientes } \\
\text { até } \\
\text { 30min na } \\
\text { Fila }\end{array}$ & $\begin{array}{c}\text { Ociosidade } \\
(\%)\end{array}$ & $\begin{array}{c}\mathbf{N}^{\mathbf{o} \text { de }} \\
\text { pacientes } \\
\text { atendidos }\end{array}$ \\
\hline DOME & 15.92 & $18: 22$ & 45.30 & $79.24 \%$ & $23.11 \%$ & 13.87 \\
OFFSET 1 & 16.49 & $18: 30$ & 42.98 & $77.91 \%$ & $24.97 \%$ & 13.90 \\
DOME UNIVERSAL & 16.95 & $18: 23$ & 46.52 & $77.83 \%$ & $23.48 \%$ & 13.85 \\
DOME CYCLE & 17.36 & $18: 24$ & 47.01 & $76.88 \%$ & $23.35 \%$ & 13.93 \\
IBFI & 18.34 & $18: 22$ & 48.31 & $75.39 \%$ & $22.62 \%$ & 13.98 \\
2BEG & 20.47 & $18: 06$ & 49.75 & $72.11 \%$ & $18.91 \%$ & 13.91 \\
PLATO-DOME 1 & 21.48 & $18: 03$ & 53.11 & $70.08 \%$ & $18.40 \%$ & 13.87 \\
IICR & 23.52 & $18: 05$ & 61.53 & $69.46 \%$ & $18.96 \%$ & 13.85 \\
PLATO-DOME 2 & 25.36 & $17: 57$ & 62.20 & $64.76 \%$ & $17.01 \%$ & 13.82 \\
PLATO-DOME 3 & 30.98 & $17: 50$ & 73.48 & $58.18 \%$ & $14.21 \%$ & 13.94 \\
\hline
\end{tabular}

Nota-se que o número de pacientes atendidos foi reduzido, comparado com o Cenário 3, 6 e 7, sendo em média igual a 14 pacientes. Ainda comparando com esses cenários, novamente o overbooking fez com que a ociosidade do sistema se mantivesse baixa, sendo em média $24 \%$ nas melhores políticas. Quanto ao desempenho das políticas, pode-se verificar que a DOME teve um resultado superior em termos de tempo médio e máximo de fila, e de percentual de pacientes até 30min na fila, sendo recomendado à sua utilização. 
5.9.

\section{Comparação entre as políticas de agendamento}

Com o objetivo de comparar as principais políticas de agendamento da literatura, foi realizada uma análise quantitativa dos indicadores de desempenho de cada política em cada cenário. Os Cenários 2, 4 e 5 não serão apresentados, já que estes cenários não serão propostos para a clínica. O Cenário 2 não é proposto, uma vez que é o único cenário testado, além do cenário atual, que não possui overbooking, sendo o cenário que apresenta o pior desempenho em termos de utilização do médico (maior ociosidade). Além disso, os Cenários 4 e 5 também não serão propostos, já que estes são apenas análises de sensibilidade do Cenário 3, em que a taxa de noshow foi variada, não representando o estado atual do sistema.

Procurou-se encontrar, para cada indicador de desempenho, o desvio entre o resultado de cada política e o resultado da melhor política nesse indicador. Para cada política em cada cenário, foi feito o somatório dos desvios para cada indicador de desempenho. As Tabelas 21, 22, 23, 24 e 25 apresentam os cálculos dos desvios do resultado de cada política de agendamento comparado com o resultado da melhor política para cada indicador, ordenados pelo valor do somatório dos desvios para cada política. 
Tabela 21 - Resultados dos desvios para o Cenário 1. Fonte: Elaboração própria.

\begin{tabular}{ccccccc}
\hline Política de & $\begin{array}{c}\text { Desvio } \\
\text { do } \\
\text { Agendamento } \\
\text { Médio }\end{array}$ & $\begin{array}{c}\text { Desvio } \\
\text { do } \\
\text { Ho Fila } \\
\text { de fim } \\
\text { do dia }\end{array}$ & $\begin{array}{c}\text { Desvio } \\
\text { do } \\
\text { Tempo } \\
\text { Máximo } \\
\text { de Fila }\end{array}$ & $\begin{array}{c}\text { Desvio } \\
\text { do \% } \\
\text { Pacientes } \\
\text { até } \\
\text { 30min na } \\
\text { Fila }\end{array}$ & $\begin{array}{c}\text { Desvio da } \\
\text { Ociosidade }\end{array}$ & Somatório \\
\hline IBFI & 0.00 & 0.00 & 0.00 & 0.00 & 0.26 & \\
PLATO-DOME 1 & 0.03 & 0.00 & 0.04 & 0.01 & 0.27 & 0.26 \\
PLATO-DOME 3 & 0.10 & 0.00 & 0.07 & 0.04 & 0.15 & 0.49 \\
ATUAL & 0.08 & 0.00 & 0.08 & 0.01 & 0.25 & 0.51 \\
PLATO-DOME 2 & 0.12 & 0.00 & 0.08 & 0.04 & 0.14 & 0.54 \\
OFFSETA-HMBEG & 0.10 & 0.00 & 0.11 & 0.03 & 0.22 & 0.59 \\
DOME & 0.14 & 0.00 & 0.08 & 0.06 & 0.15 & 0.63 \\
OFFSET 1 & 0.14 & 0.00 & 0.09 & 0.06 & 0.22 & 0.71 \\
DOME CYCLE & 0.20 & 0.00 & 0.11 & 0.09 & 0.14 & 0.82 \\
IICR & 0.16 & 0.00 & 0.16 & 0.07 & 0.21 & 0.84 \\
OFFSETA-LMBEG & 0.25 & 0.00 & 0.11 & 0.12 & 0.25 & 1.10 \\
OFFSET 2 & 0.29 & 0.00 & 0.16 & 0.13 & 0.19 & 1.20 \\
IBFIA-FCFA & 0.34 & 0.00 & 0.18 & 0.14 & 0.08 & 1.22 \\
2BEG & 0.38 & 0.00 & 0.21 & 0.16 & 0.14 & 1.43 \\
2BEGA-FCFA & 0.55 & 0.00 & 0.29 & 0.26 & 0.00 & 1.89 \\
\hline
\end{tabular}


Tabela 22 - Resultados dos desvios para o Cenário 3. Fonte: Elaboração própria.

\begin{tabular}{|c|c|c|c|c|c|c|}
\hline $\begin{array}{c}\text { Política de } \\
\text { Agendamento }\end{array}$ & $\begin{array}{c}\text { Desvio } \\
\text { do } \\
\text { Tempo } \\
\text { Médio } \\
\text { de Fila }\end{array}$ & $\begin{array}{c}\text { Desvio } \\
\text { do } \\
\text { Horário } \\
\text { de fim } \\
\text { do dia }\end{array}$ & $\begin{array}{c}\text { Desvio } \\
\text { do } \\
\text { Tempo } \\
\text { Máximo } \\
\text { de Fila }\end{array}$ & $\begin{array}{c}\text { Desvio } \\
\text { do \% } \\
\text { Pacientes } \\
\text { até } \\
\text { 30min na } \\
\text { Fila } \\
\end{array}$ & $\begin{array}{l}\text { Desvio da } \\
\text { Ociosidade }\end{array}$ & Somatório \\
\hline OFFSET 1 & 0.39 & 0.10 & 0.20 & 0.11 & 0.08 & 1.47 \\
\hline OFFSETA-LMBEG & 0.02 & 0.60 & 0.02 & 0.01 & 0.20 & 1.49 \\
\hline DOME UNIVERSAL & 0.33 & 0.23 & 0.18 & 0.10 & 0.11 & 1.61 \\
\hline 2BEG & 0.45 & 0.10 & 0.21 & 0.13 & 0.06 & 1.62 \\
\hline PLATO-DOME 3 & 0.45 & 0.07 & 0.39 & 0.12 & 0.04 & 1.71 \\
\hline DOME CYCLE & 0.44 & 0.13 & 0.33 & 0.12 & 0.10 & 1.81 \\
\hline DOME & 0.44 & 0.17 & 0.31 & 0.12 & 0.06 & 1.84 \\
\hline PLATO-DOME 1 & 0.20 & 0.57 & 0.13 & 0.05 & 0.17 & 1.93 \\
\hline IICR & 0.55 & 0.00 & 0.53 & 0.15 & 0.02 & 1.94 \\
\hline PLATO-DOME 2 & 0.43 & 0.27 & 0.30 & 0.12 & 0.10 & 2.02 \\
\hline OFFSETA-HMBEG & 0.32 & 0.50 & 0.17 & 0.09 & 0.11 & 2.11 \\
\hline IBFI & 0.24 & 0.60 & 0.18 & 0.07 & 0.21 & 2.20 \\
\hline OFFSET 2 & 0.15 & 0.83 & 0.07 & 0.05 & 0.23 & 2.35 \\
\hline $\begin{array}{l}\text { DOME UNIVERSAL } \\
\text { A - LMBEG }\end{array}$ & 0.00 & 1.10 & 0.00 & 0.00 & 0.29 & 2.49 \\
\hline IBFIA-FCFA & 0.81 & 0.00 & 0.53 & 0.21 & 0.08 & 2.65 \\
\hline ATUAL & 0.33 & 0.67 & 0.23 & 0.10 & 0.23 & 2.65 \\
\hline $\begin{array}{l}\text { DOME UNIVERSAL } \\
\text { A - HMBEG }\end{array}$ & 0.13 & 1.00 & 0.05 & 0.04 & 0.28 & 2.68 \\
\hline 2BEGA-FCFA & 0.86 & 0.00 & 0.51 & 0.23 & 0.00 & 2.70 \\
\hline
\end{tabular}


Tabela 23 - Resultados dos desvios para o Cenário 6. Fonte: Elaboração própria.

\begin{tabular}{|c|c|c|c|c|c|c|}
\hline $\begin{array}{c}\text { Política de } \\
\text { Agendamento }\end{array}$ & $\begin{array}{l}\text { Desvio } \\
\text { do } \\
\text { Tempo } \\
\text { Médio } \\
\text { de Fila }\end{array}$ & $\begin{array}{c}\text { Desvio } \\
\text { do } \\
\text { Horário } \\
\text { de fim } \\
\text { do dia }\end{array}$ & $\begin{array}{c}\text { Desvio } \\
\text { do } \\
\text { Tempo } \\
\text { Máximo } \\
\text { de Fila }\end{array}$ & $\begin{array}{c}\text { Desvio } \\
\text { do \% } \\
\text { Pacientes } \\
\text { até } \\
\text { 30min na } \\
\text { Fila } \\
\end{array}$ & $\begin{array}{l}\text { Desvio da } \\
\text { Ociosidade }\end{array}$ & Somatório \\
\hline 2BEG & 0.09 & 0.00 & 0.01 & 0.05 & 0.00 & 0.28 \\
\hline PLATO-DOME 1 & 0.00 & 0.11 & 0.02 & 0.00 & 0.06 & 0.30 \\
\hline OFFSET 1 & 0.09 & 0.00 & 0.00 & 0.05 & 0.03 & 0.32 \\
\hline PLATO-DOME 3 & 0.09 & 0.00 & 0.12 & 0.03 & 0.04 & 0.39 \\
\hline DOME UNIVERSAL & 0.01 & 0.13 & 0.00 & 0.03 & 0.07 & 0.41 \\
\hline DOME CYCLE & 0.01 & 0.16 & 0.02 & 0.01 & 0.11 & 0.48 \\
\hline PLATO-DOME 2 & 0.08 & 0.04 & 0.11 & 0.05 & 0.06 & 0.51 \\
\hline DOME & 0.03 & 0.22 & 0.04 & 0.01 & 0.10 & 0.68 \\
\hline IBFI & 0.04 & 0.20 & 0.04 & 0.02 & 0.13 & 0.70 \\
\hline IICR & 0.21 & 0.00 & 0.29 & 0.07 & 0.00 & 0.84 \\
\hline
\end{tabular}

Tabela 24 - Resultados dos desvios para o Cenário 7. Fonte: Elaboração própria.

\begin{tabular}{|c|c|c|c|c|c|c|}
\hline $\begin{array}{c}\text { Política de } \\
\text { Agendamento }\end{array}$ & $\begin{array}{l}\text { Desvio } \\
\text { do } \\
\text { Tempo } \\
\text { Médio } \\
\text { de Fila }\end{array}$ & $\begin{array}{c}\text { Desvio } \\
\text { do } \\
\text { Horário } \\
\text { de fim } \\
\text { do dia }\end{array}$ & $\begin{array}{c}\text { Desvio } \\
\text { do } \\
\text { Tempo } \\
\text { Máximo } \\
\text { de Fila }\end{array}$ & $\begin{array}{c}\text { Desvio } \\
\text { do \% } \\
\text { Pacientes } \\
\text { até } \\
\text { 30min na } \\
\text { Fila }\end{array}$ & $\begin{array}{l}\text { Desvio da } \\
\text { Ociosidade }\end{array}$ & Somatório \\
\hline DOME CYCLE & 0.00 & 0.00 & 0.00 & 0.00 & 0.16 & 0.16 \\
\hline IBFI & 0.06 & 0.07 & 0.04 & 0.02 & 0.18 & 0.52 \\
\hline DOME & 0.05 & 0.11 & 0.01 & 0.03 & 0.20 & 0.59 \\
\hline IICR & 0.16 & 0.00 & 0.21 & 0.05 & 0.02 & 0.64 \\
\hline $\begin{array}{c}\text { DOME } \\
\text { UNIVERSAL }\end{array}$ & 0.12 & 0.07 & 0.05 & 0.04 & 0.16 & 0.66 \\
\hline OFFSET 1 & 0.07 & 0.16 & 0.00 & 0.03 & 0.20 & 0.69 \\
\hline PLATO-DOME 1 & 0.23 & 0.00 & 0.14 & 0.08 & 0.06 & 0.82 \\
\hline PLATO-DOME 2 & 0.23 & 0.00 & 0.16 & 0.08 & 0.09 & 0.86 \\
\hline 2BEG & 0.28 & 0.00 & 0.15 & 0.11 & 0.02 & 0.94 \\
\hline PLATO-DOME 3 & 0.35 & 0.00 & 0.35 & 0.11 & 0.00 & 1.27 \\
\hline
\end{tabular}


Tabela 25 - Resultados dos desvios para o Cenário 8. Fonte: Elaboração própria.

\begin{tabular}{|c|c|c|c|c|c|c|}
\hline $\begin{array}{c}\text { Política de } \\
\text { Agendamento }\end{array}$ & $\begin{array}{l}\text { Desvio } \\
\text { do } \\
\text { Tempo } \\
\text { Médio } \\
\text { de Fila }\end{array}$ & $\begin{array}{c}\text { Desvio } \\
\text { do } \\
\text { Horário } \\
\text { de fím } \\
\text { do dia }\end{array}$ & $\begin{array}{c}\text { Desvio } \\
\text { do } \\
\text { Tempo } \\
\text { Máximo } \\
\text { de Fila }\end{array}$ & $\begin{array}{c}\text { Desvio } \\
\text { do \% } \\
\text { Pacientes } \\
\text { até } \\
\text { 30min na } \\
\text { Fila } \\
\end{array}$ & $\begin{array}{l}\text { Desvio da } \\
\text { Ociosidade }\end{array}$ & Somatório \\
\hline DOME & 0.00 & 0.16 & 0.05 & 0.00 & 0.63 & 0.99 \\
\hline 2BEG & 0.29 & 0.00 & 0.16 & 0.09 & 0.33 & 1.24 \\
\hline $\begin{array}{c}\text { DOME } \\
\text { UNIVERSAL }\end{array}$ & 0.06 & 0.18 & 0.08 & 0.02 & 0.65 & 1.26 \\
\hline DOME CYCLE & 0.09 & 0.20 & 0.09 & 0.03 & 0.64 & 1.38 \\
\hline IBFI & 0.15 & 0.16 & 0.12 & 0.05 & 0.59 & 1.43 \\
\hline PLATO-DOME 1 & 0.35 & 0.00 & 0.24 & 0.12 & 0.29 & 1.46 \\
\hline OFFSET 1 & 0.04 & 0.33 & 0.00 & 0.02 & 0.76 & 1.53 \\
\hline IICR & 0.48 & 0.00 & 0.43 & 0.12 & 0.33 & 1.97 \\
\hline PLATO-DOME 2 & 0.59 & 0.00 & 0.45 & 0.18 & 0.20 & 2.20 \\
\hline PLATO-DOME 3 & 0.95 & 0.00 & 0.71 & 0.27 & 0.00 & 3.13 \\
\hline
\end{tabular}

A partir dos valores do somatório do desvio de cada política em cada cenário, pode-se apresentar o resultado consolidado de todos os cenários analisados, conforme Tabela 26. Essa tabela apresenta apenas as políticas que foram testadas em todos os cenários propostos (Cenários 3, 6, 7 e 8), para possibilitar a comparação entre elas.

Tabela 26 - Comparação entre as principais políticas de agendamento. Fonte: Elaboração própria.

\begin{tabular}{c|ccccc|ccc|cc}
\hline Política de & \multicolumn{4}{c|}{ Soma dos desvios por Cenário } & \multicolumn{3}{c|}{ Cenários 1 a 8 } & \multicolumn{2}{c}{ Cenários 3 a 8} \\
Agendamento & 1 & 3 & 6 & 7 & 8 & Média & Soma & Média & Soma \\
\hline DOME CYCLE & 0.82 & 1.81 & 0.48 & 0.16 & 1.38 & 0.93 & 4.65 & 0.96 & 3.82 \\
DOME UNIVERSAL & - & 1.61 & 0.41 & 0.66 & 1.26 & - & - & 0.99 & 3.94 \\
DOME & 0.63 & 1.84 & 0.68 & 0.59 & 0.99 & 0.94 & 4.72 & 1.02 & 4.09 \\
OFFSET 1 & 0.71 & 1.47 & 0.32 & 0.69 & 1.53 & 0.94 & 4.72 & 1.00 & 4.01 \\
PLATO-DOME 1 & 0.38 & 1.93 & 0.30 & 0.82 & 1.46 & 0.98 & 4.90 & 1.13 & 4.52 \\
IBFI & 0.26 & 2.20 & 0.70 & 0.52 & 1.43 & 1.02 & 5.10 & 1.21 & 4.84 \\
2BEG & 1.43 & 1.62 & 0.28 & 0.94 & 1.24 & 1.10 & 5.50 & 1.02 & 4.07 \\
PLATO-DOME 2 & 0.54 & 2.02 & 0.51 & 0.86 & 2.20 & 1.23 & 6.13 & 1.40 & 5.59 \\
IICR & 0.84 & 1.94 & 0.84 & 0.64 & 1.97 & 1.25 & 6.23 & 1.35 & 5.40 \\
PLATO-DOME 3 & 0.49 & 1.71 & 0.39 & 1.27 & 3.13 & 1.40 & 6.98 & 1.62 & 6.50 \\
\hline
\end{tabular}

Pode-se perceber que a política DOME CYCLE apresentou o melhor resultado entre as políticas testadas, uma vez que possui o menor valor de média e também de soma dos desvios nos cenários. Essa política não teve bom desempenho apenas no 
cenário atual (Cenário 1). Em todos os cenários propostos (Cenários 3, 6, 7 e 8), a política DOME CYCLE apresenta um bom desempenho, sendo a melhor entre todas as políticas no Cenário 7 .

\subsection{0 .}

\section{Discussão}

Após a apresentação dos resultados de cada cenário, torna-se importante comparar os cenários testados e indicar qual a melhor opção para o consultório, tanto para períodos de alta, média e baixa demanda por agendamentos, de acordo com os indicadores de desempenho.

A Tabela 27 apresenta o resultado das melhores políticas para cada cenário, além do resultado da política ATUAL no cenário atual como base de comparação. Assim como na comparação das políticas feita na Seção 5.9, os Cenários 2, 4 e 5 também não serão apresentados nessa tabela, já que estes cenários não serão propostos para a clínica. 
Tabela 27 - Resultado dos cenários relevantes. Fonte: Elaboração própria.

\begin{tabular}{|c|c|c|c|c|c|c|c|}
\hline $\begin{array}{c}\text { Cenário } \\
\text { (Agenda) }\end{array}$ & $\begin{array}{c}\text { Política } \\
\text { de } \\
\text { Agenda- } \\
\text { mento }\end{array}$ & $\begin{array}{c}\text { Tempo } \\
\text { Médio } \\
\text { de Fila } \\
\text { (min) }\end{array}$ & $\begin{array}{l}\text { Horário } \\
\text { de fim } \\
\text { do dia } \\
\text { (h) }\end{array}$ & $\begin{array}{c}\text { Tempo } \\
\text { Máximo } \\
\text { de Fila } \\
\text { (min) }\end{array}$ & $\begin{array}{c}\% \\
\text { Pacientes } \\
\text { até } \\
\text { 30min na } \\
\text { Fila }\end{array}$ & $\begin{array}{c}\text { Ociosidade } \\
(\%)\end{array}$ & $\begin{array}{c}\quad \mathbf{N}^{0} \text { de } \\
\text { pacientes } \\
\text { atendidos }\end{array}$ \\
\hline \multicolumn{8}{|l|}{ Atual } \\
\hline \multirow{2}{*}{$\begin{array}{c}1 \\
\text { (9h-18h) }\end{array}$} & ATUAL & 22.73 & $18: 27$ & 66.45 & $68.93 \%$ & $29.07 \%$ & 16.93 \\
\hline & IBFI & 21.11 & $18: 29$ & 61.48 & $69.88 \%$ & $29.46 \%$ & 16.90 \\
\hline \multicolumn{8}{|l|}{ Proposto } \\
\hline $\begin{array}{c}3 \\
\text { (9h-18h) }\end{array}$ & $\begin{array}{c}\text { OFFSET } \\
1\end{array}$ & 20.72 & $18: 33$ & 60.59 & $72.58 \%$ & $21.91 \%$ & 22.03 \\
\hline \multicolumn{8}{|l|}{ Alternativos } \\
\hline $\begin{array}{c}6 \\
(10 \mathrm{~h}- \\
17 \mathrm{~h} 45 \mathrm{~min})\end{array}$ & $\begin{array}{c}\text { PLATO- } \\
\text { DOME } \\
1\end{array}$ & 19.86 & $18: 35$ & 59.60 & $74.71 \%$ & $21.99 \%$ & 19.89 \\
\hline $\begin{array}{c}7 \\
(10 \mathrm{~h}- \\
16 \mathrm{~h} 30 \mathrm{~min})\end{array}$ & $\begin{array}{l}\text { DOME } \\
\text { CYCLE }\end{array}$ & 16.85 & $17: 15$ & 51.09 & $78.72 \%$ & $23.43 \%$ & 16.12 \\
\hline $\begin{array}{c}8 \\
(13 \mathrm{~h}- \\
17 \mathrm{~h} 30 \mathrm{~min})\end{array}$ & DOME & 15.92 & $18: 22$ & 45.30 & $79.24 \%$ & $23.11 \%$ & 13.87 \\
\hline
\end{tabular}

Ao comparar o Cenário 3 com o Cenário 1, percebe-se que o overbooking proporcionou um aumento de 30\% no número de pacientes atendidos, de 17 para 22 pacientes. Apesar desse aumento, o horário de fim do dia se manteve próximo de 18h30min e o nível de serviço melhorou, com a redução do tempo médio de fila. $\mathrm{O}$ Cenário 3 trouxe uma melhoria em todos os indicadores, quando comparados com a política ATUAL e com a IBFI do Cenário 1. Além disso, todos os indicadores ficaram com valores satisfatórios no ponto de vista do paciente. Entretanto, vale ressaltar que esse resultado, assim como os resultados dos Cenários 6, 7 e 8, dependem do comprometimento do médico quanto à sua pontualidade, já que consideram o médico pontual.

Comparando o Cenário 6 com o Cenário 1, percebe-se que, mesmo com um turno de trabalho menor para o cenário 6, em que o dia começa uma hora mais tarde, o overbooking possibilitou um número de pacientes atendidos $17 \%$ maior do que o cenário atual, aumentando de 17 para 20 pacientes. Esse cenário alternativo trouxe novamente uma melhoria em todos os indicadores comparados tanto com a política 
ATUAL quanto com a IBFI do Cenário 1, mantendo o horário de fim do dia próximo das $18 \mathrm{~h} 30 \mathrm{~min}$. Além disso, todos os indicadores ficaram com valores satisfatórios.

Na comparação do Cenário 7 com o Cenário 1, percebe-se que, mesmo com um horário de agendamento menor, de $10 \mathrm{~h}$ às $16 \mathrm{~h} 30 \mathrm{~min}$, o número de atendimentos foi bem semelhante ao cenário atual devido ao overbooking, tendo em média 16 pacientes atendidos. Além de começar mais cedo, nesse cenário o dia também termina cerca de 1h15min mais cedo do que o cenário atual, às 17h15min. Além disso, esse cenário alternativo teve um dos melhores desempenhos em termos de nível de serviço, com um dos menores valores de tempo médio de fila entre os cenários.

Na comparação do Cenário 8 com o Cenário 1, percebe-se que esse cenário com horário de agendamento de $13 \mathrm{~h}$ às $17 \mathrm{~h} 30 \mathrm{~min}$, teve um número de atendimentos menor do que o cenário atual, com uma média de 14 pacientes. Isso acontece uma vez que o horário de agendamento é muito curto nesse Cenário 8. Além disso, esse cenário alternativo teve o melhor desempenho em termos de nível de serviço, em todos os indicadores de fila.

Portanto, pelos resultados apresentados anteriormente, recomenda-se para o agendamento a utilização da melhor política do Cenário 3 (9h-18h), a OFFSET 1, para períodos de alta demanda, da PLATO-DOME 1 do Cenário 6 (10h-17h45min) para períodos de média demanda, e da DOME CYCLE do Cenário 7 (10h-16h30min) para períodos de baixa demanda. A DOME do Cenário 8 (13h-17h30min) pode ser utilizada em ocasiões específicas em que o médico esteja impedido de trabalhar na parte da manhã.

Com o intuito de avaliar a equidade do indicador de tempo médio de fila para cada um desses cenários, as Figuras 10 e 11 mostram o comportamento do tempo médio de fila por horário agendado. 


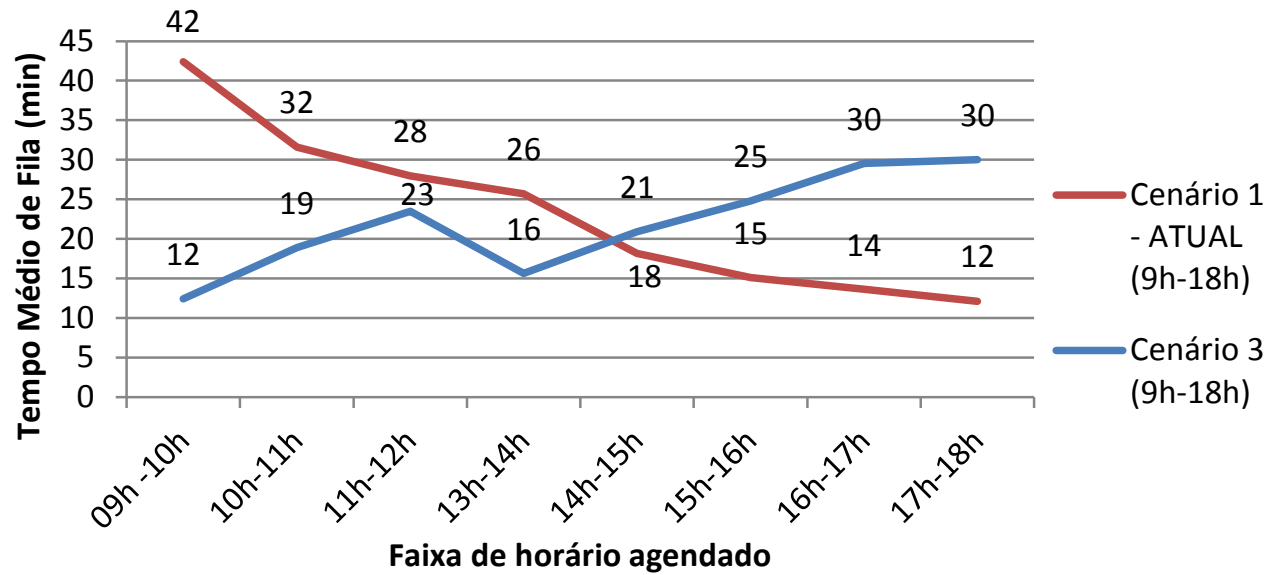

Figura 10 - Comparação do comportamento do tempo médio de fila entre os Cenários 1 e 3 por faixa de horário agendado. Fonte: Elaboração própria.

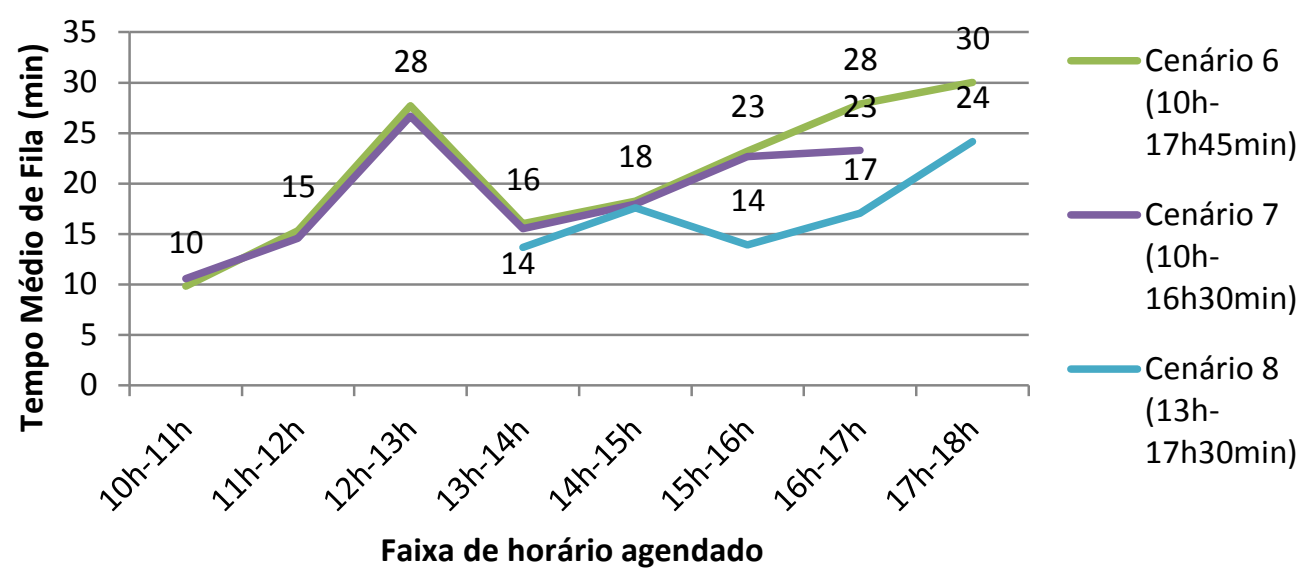

Figura 11 - Comparação do comportamento do tempo médio de fila entre os Cenários 6, 7 e 8 por faixa de horário agendado. Fonte: Elaboração própria.

Pela análise da Figura 10, percebe-se que no Cenário 3, devido à pontualidade do médico, o tempo médio de fila no início do dia não possui valores tão extremos como no cenário atual com a regra ATUAL. Além disso, percebe-se que no Cenário 3 o tempo médio de fila durante todo o dia não ultrapassa 30 minutos, enquanto que no cenário atual ele ultrapassa os 30 minutos nos dois primeiros horários do dia. $\mathrm{Na}$ Figura 11, observa-se que o comportamento do Cenário 6 e 7 são bem semelhantes, já que ambos começam o dia às $10 \mathrm{~h}$, apenas diferindo o horário de término, que no Cenário 7 é mais cedo. Quanto ao Cenário 8, nota-se que o comportamento é diferente, pois o horário de agendamento é apenas a tarde. Além disso, percebe-se 
que a fila média não atinge valores tão altos quanto a dos outros cenários. Isso pode ser explicado pelo menor turno de trabalho e pela não interferência do horário de almoço.

No que tange a comparação entre as políticas de agendamento, conforme os resultados da Seção 5.9, pode-se perceber que, em média, a política DOME CYCLE apresentou o melhor resultado entre as políticas testadas. Esse resultado corrobora com as constatações de Klassen e Yoogalingam (2009) e Cayirli et al. (2012) que concluíram que os intervalos de agendamento ótimos possuíam um comportamento DOME. Além disso, percebe-se que a política desenvolvida neste estudo, a DOME CYCLE, foi superior à política proposta por Klassen e Yoogalingam (2009), a PLATÔ-DOME, e superior à proposta por Cayirli et al. (2012), a DOME UNIVERSAL.

Nota-se também que a política proposta DOME CYCLE não teve bom desempenho apenas no cenário atual (Cenário 1), possivelmente, devido à influência do atraso do médico, que afeta o desempenho das regras que tem como característica colocar mais pacientes no início do dia, como é o caso das políticas que tem padrão DOME (DOME, DOME CYCLE, DOME UNIVERSAL, PLATÔ-DOME) e da política 2BEG (que coloca dois pacientes no primeiro horário), sendo esse o possível motivo da política IBFI ser a melhor política nesse cenário. Em todos os cenários propostos (Cenários 3, 6, 7 e 8), como não é considerado o atraso do médico, a política DOME CYCLE apresenta um bom desempenho, sendo a melhor entre todas as políticas do Cenário 7.

Em relação à DOME UNIVERSAL, percebe-se que a mesma também apresentou um resultado superior às outras, sendo a segunda melhor política, o que está coerente com os resultados de Cayirli et al. (2012), onde essa política foi sugerida e obteve os melhores resultados.

Em relação à política proposta por Klassen e Yoogalingam (2014), a IICR, que havia apresentado resultados superiores à PLATÔ-DOME, percebe-se que, neste presente estudo de caso, esta política não gerou bons resultados e foi inferior à PLATÔ-DOME, diferentemente do que havia sido observador por estes autores. 
No que tange à política de intervalo ajustado DOME UNIVERSAL A proposta por Cayirli e Yang (2014) e a IBFIA, 2BEGA e OFFSET A testadas por Athula Wijewickrama e Takakuwa (2012) e Bhattacharjee e Ray (2016), notou-se no Cenário 3 que os resultados haviam sido inferiores às outras políticas. Esse resultado constata que as políticas mais simples de desenvolvimento e implantação, que é o caso das políticas sem ajuste de horário por classe de paciente, foram superiores às políticas mais complexas que ajustam os horários por classe de paciente. 


\section{6 Conclusão}

A partir das análises dos resultados e discussão, pode-se concluir que o Cenário 3 , que mantém o agendamento de $9 \mathrm{~h}$ às $18 \mathrm{~h}$, e que considera o overbooking de pacientes para compensar o no-show, é a melhor opção em termos de número de atendimentos por dia, proporcionado a partir da utilização da melhor política desse cenário, a OFFSET 1, um aumento de 30\% nos atendimentos, sendo assim recomendado para períodos de alta demanda. Para períodos de média e baixa demanda, recomenda-se, respectivamente, o Cenário 6 com a política PLATÔDOME 1 (10h às 17h45min) e o Cenário 7 com a política DOME CYCLE (10h às 16h:30min).

Em todos os cenários propostos, o nível de serviço melhorou, quando comparado com o do cenário atual (Cenário 1), e apresentou valores satisfatórios do ponto de vista do paciente. Isso pode ser concluído através dos resultados dos indicadores de tempo médio e máximo de fila, que foram menores do que $21 \mathrm{~min}$ e 61 min para todas as políticas propostas em cada cenário, respectivamente. Além disso, o percentual de pacientes até 30min na fila apresentou valores maiores que $72 \%$ para todas as políticas propostas, o que está próximo do valor recomendado na Grã-Bretanha, que é igual a 75\% (Department of Health, 1991).

Um resultado importante relacionado ao aumento de $30 \%$ no número de atendimentos será o consequente aumento no volume de cirurgias bariátricas feitas pelo médico. Apesar desse aumento ser alto, isso não deve ocasionar problemas de capacidade na agenda de cirurgias do médico, uma vez que este possui flexibilidade reservando três dias da semana para realizar as cirurgias. Além disso, nem todos esses pacientes atendidos a mais serão de primeira vez, uma parcela será de retorno operado, o que não garante que serão realizadas novas cirurgias em todos os casos.

No caso da clínica em questão, o sucesso da nova política proposta tem o facilitador de estar sendo aplicada à agenda do próprio dono da clínica, sendo este o 
maior interessado na melhoria do sistema. Caso a agenda fosse de um profissional contratado, poder-se-ia recomendar a utilização de uma remuneração variável para o médico de forma que ele ganhasse mais quanto maior fosse o número de pacientes atendidos.

É importante ressaltar que os cenários propostos consideram a pontualidade do médico, sendo este um fator que está sob o seu domínio, além dele ser o maior interessado na melhoria do sistema de agendamento. $\mathrm{O}$ atraso do médico no cenário atual é explicado pelo fato do médico ficar ocioso no início do dia devido à alta taxa de no-show. Porém, com essa nova política de agendamento proposta, que inclui o uso do overbooking, o número de pacientes agendados será maior do que no cenário atual, o que tende a diminuir a ociosidade do médico no início do dia.

As políticas OFFSET 1, PLATÔ-DOME 1, DOME CYCLE e DOME foram as melhores políticas dentre os cenários propostos. Além disso, pode-se concluir que, na maioria dos cenários, a melhor política teve o aspecto DOME, o que está de acordo com a revisão da literatura, que encontrou em estudos recentes que os intervalos de agendamento ótimos possuem um padrão DOME (Klassen e Yoogalingam, 2009; Cayirli et al., 2012).

Uma contribuição importante desta dissertação foi propor uma nova política de agendamento, a DOME CYCLE, que foi testada em diversos cenários para uma clínica especializada em cirurgia bariátrica do Rio de Janeiro. Essa nova política apresentou um resultado superior ao das principais políticas da literatura, na média dos cenários. Ela tem como característica promover a divisão da DOME tradicional em dois ou mais períodos, a depender do número de pacientes agendados por turno. Essa divisão permite que o efeito da DOME seja mais eficiente para turnos maiores, onde existem muitos pacientes agendados.

A Figura 12 ilustra os horários do turno da tarde da política DOME CYCLE no Cenário 7, sendo esta a melhor política desse cenário, e a Figura 13 ilustra o horário da política DOME para o mesmo cenário. Percebe-se que, devido à divisão da agenda em dois ciclos (13h30min-15h; 15h-16h30min), a política DOME CYCLE permite que no início e final da tarde não cheguem tantos pacientes em intervalos menores quanto na DOME, controlando o crescimento da fila. Além disso, percebe-se também 
que a DOME CYCLE não permite que existam muitos horários com intervalos maiores no meio da tarde, o que reduz a ociosidade nesses horários comparado com a DOME. Além disso, essas figuras demonstram como é simples a implementação das políticas propostas neste estudo, sendo traduzidas em uma agenda com horários fixos para a chegada dos pacientes.

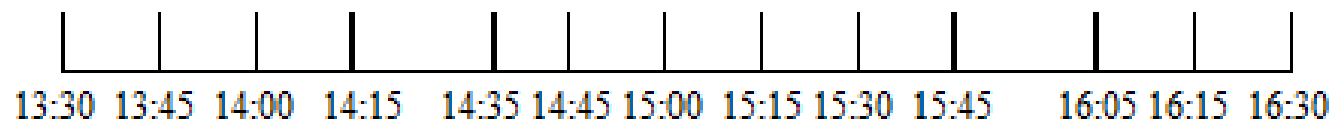

Figura 12 - Horários do turno da tarde da política DOME CYCLE no Cenário 7. Fonte: Elaboração própria.

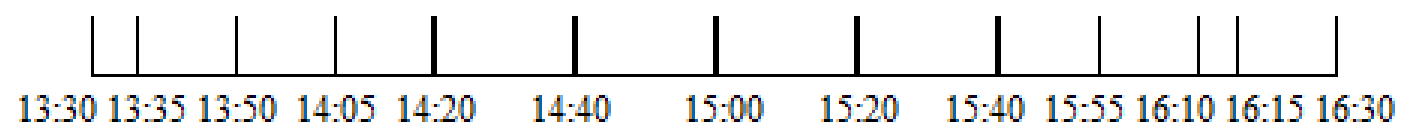

Figura 13 - Horários do turno da tarde da política DOME no Cenário 7. Fonte: Elaboração própria.

Outro aspecto relevante do presente estudo é o número de fatores de complexidade do sistema de saúde que foram considerados na aplicação. Este trabalho considerou sete fatores de complexidade, quais sejam: variação do número de agendamentos por seção, pacientes impontuais, presença de no-shows por classe de paciente, utilização de overbooking, tempos de serviços estocásticos, atrasos e interrupções do serviço, e disciplina de fila por ordem da agenda. Não foi encontrado, até à data, nenhum artigo que apresente todos os fatores que foram considerados nesse trabalho atuando de forma conjunta.

Outra contribuição do presente trabalho foi o desenvolvimento de uma síntese das principais formulações para o cálculo das principais políticas de agendamento da literatura, realizado através de uma revisão sistemática. Além disso, uma formulação para a política IICR, ainda não encontrada na literatura, foi proposta neste estudo.

Por fim, os cenários testados nesse trabalho consideraram o overbooking de pacientes pelo método de redução dos intervalos de agendamento. Para estudos futuros, pretende-se comparar o desempenho dos cenários propostos com uma outra alternativa de overbooking, em que os agendamentos são feitos com dois ou mais 
pacientes em um mesmo slot, sem reduzir os intervalos de agendamento. Para isso, o objetivo é desenvolver um modelo de predição de no-show que leve em consideração a probabilidade de no-shows individuais, de acordo com os dados demográficos e informações de agendamento de cada paciente. A partir da probabilidade de no-show de cada paciente, torna-se possível fazer um overbooking inteligente, que busque adicionar outro paciente no horário onde o paciente agendado tem maior probabilidade de faltar. 
7

\section{Referências bibliográficas}

ATHULA WIJEWICKRAMA, A.; TAKAKUWA, S. Designing outpatient appointment systems with patient characteristics: A case study. International Journal of Healthcare Technology and Management, v. 13, n. 1-3, p. 157-169, 2012.

BABES, M.; SARMA, G. Out-Patient Queues at the Ibn-Rochd Health Center. Journal of the Operational Research Society, v. 42, n. 10, p. 845-855, 1991.

BAILEY, N. A Study of Queues and Appointment Systems in Hospital Outpatient Departments with Special Reference to Waiting Times. Journal of the Royal Statistical Society, v. 14, p. 185-199, 1952.

BARD, J.; SHU, Z.; MORRICE; D., POURSANI, R.; LEYKUM, L. Improving patient flow at a family health clinic. Health care management science, v. 19, n. 2, p. 170-191, 2016.

BHATTACHARJEE, P.; RAY, P. Simulation modelling and analysis of appointment system performance for multiple classes of patients in a hospital: a case study. Operations Research for Health Care, v. 8, p. 71-84, 2016.

BRAILSFORD, S. Advances and challenges in healthcare simulation modeling: tutorial. In: Proceedings of the 39th conference on Winter simulation: 40 years! The best is yet to come. IEEE Press, p. 1436-1448, 2007.

CAYIRLI, T.; VERAL, E.. Outpatient scheduling in health care: a review of literature. Production and operations management, v. 12, n. 4, p. 519-549, 2003.

CAYIRLI, T.; VERAL, E.; ROSEN, H. Assessment of patient classification in appointment system design. Production and Operations Management, v. 17, n. 3, p. 338-353, 2008.

CAYIRLI, T.; VERAL, E.; ROSEN, H.. Designing appointment scheduling systems for ambulatory care services. Health care management science, v. 9, n. 1, p. 47-58, 2006.

CAYIRLI, T.; YANG, K. A universal appointment rule with patient classification for service times, no-shows, and walk-ins. Service Science, v. 6, n. 4, p. 274-295, 2014.

CAYIRLI, T.; YANG, K.; QUEK, S. A Universal Appointment Rule in the Presence of No-Shows and Walk-Ins. Production and Operations Management, v. 21, n. 4, p. 682-697, 2012. 
COX, T.; BIRCHAL, J.; WONG, H. Optimizing the Queuing System for an Ear. Nose and Throat Outpatient Clinic. Journal of Applied Statistics, v. 12, p. 113-126, 1985.

DANTAS, L. Revisão sistemática da literatura sobre no-show em agendamento de consultas. Dissertação de mestrado - Pontifícia Universidade Católica do Rio de Janeiro, Departamento de Engenharia Industrial, 2016.

DELESIE, L. Bridging the gap between clinicians and health managers. European Journal of Operational Research, v. 105, p. 248-256, 1998.

DEPARTMENT OF HEALTH. The Patient's Charter. H. M. S. O., London, U.K, 1991.

EUROPEAN COMISSION (Org.). Special issue on healthcare: Healthy ageing and the future of public healthcare systems. 2009. EUR 24044 EN. Disponível em: $<$ http://ec.europa.eu/research/social-sciences/pdf/efmn-special-issue-onhealthcare_en.pdf $>$. Acesso em: 7 fev. 2015.

GOLDSMITH, J. A Radical Prescription for Hospitals. Harvard Business Review, v. 67, n. 3, p. 104-111, 1989.

GUPTA, D.; DENTON, B.. Appointment scheduling in health care: Challenges and opportunities. IIE transactions, v. 40, n. 9, p. 800-819, 2008.

HALL, R.. Matching Healthcare Resources to Patient Needs. In: Handbook of Healthcare System Scheduling. Springer US, 2012. p. 1-9.

HANS, E.; VAN HOUDENHOVEN, M.; HULSHOF, P.. A framework for healthcare planning and control. In: Handbook of healthcare system scheduling. Springer US, 2012. p. 303-320.

HO, C.; LAU, H. Evaluating the impact of operating conditions on the performance of appointment scheduling rules in service systems. European Journal of Operational Research, v. 112, n. 3, p. 542-553, 1999.

HO, C.; LAU, H. Minimizing total cost in scheduling outpatient appointments. Management science, v. 38, n. 12, p. 1750-1764, 1992.

HUANG, X. Patient attitude towards waiting in an outpatient clinic and its applications. Health Services Management Research, v. 7, n. 1, p. 2-8, 1994.

HULSHOF, P.; KORTBEEKk, N.; BOUCHERIE, R.; HANS, E.; BAKKER, P. Taxonomic classification of planning decisions in health care: a structured review of the state of the art in OR/MS. Operational Research Society, v.1, p. 129-175, 2012.

JERBI, B.; KAMOUN, H.. Multiobjective study to implement outpatient appointment system at Hedi Chaker Hospital. Simulation Modelling Practice and Theory, v. 19, n. 5, p. 1363-1370, 2011.

KHAN, K. S.; KUNZ, R.; KLEIJNEN, J.; ANTES, G. Five steps to conducting a systematic review. Journal of the Royal Society of Medicine, v. 96, n. 3, p. 118$121,2003$. 
KLASSEN, K.; ROHLEDER, T. Scheduling outpatient appointments in a dynamic environment. Journal of operations Management, v. 14, n. 2, p. 83-101, 1996.

KLASSEN, K.; YOOGALINGAM, R. Appointment system design with interruptions and physician lateness. International Journal of Operations \& Production Management, v. 33, n. 4, p. 394-414, 2013.

KLASSEN, K.; YOOGALINGAM, R. Improving performance in outpatient appointment services with a simulation optimization approach. Production and Operations Management, v. 18, n. 4, p. 447-458, 2009.

KLASSEN, K.; YOOGALINGAM, R. Strategies for appointment policy design with patient unpunctuality. Decision Sciences, v. 45, n. 5, p. 881-911, 2014.

KLASSEN, K; ROHLEDER, T. Outpatient appointment scheduling with urgent clients in a dynamic, multi-period environment. International Journal of Service Industry Management, v. 15, n. 2, p. 167-186, 2004.

LAGANGA, L.; LAWRENCE, S. Clinic overbooking to improve patient access and increase provider productivity. Decision Sciences, v. 38, n. 2, p. 251-276, 2007.

LEHANEY, B., CLARKE, S., PAUL, R. A Case of Intervention in an Outpatients Department. Journal of the Operational Research Society, v. 50, n. 9, p. 877-891, 1999.

LINDLEY, D. The Theory of Queues with a Single Server. Proceedings Cambridge Philosophy Society, v. 48, p. 277-289, 1952.

OECD - Organization for Economic Co-operation and Development (2010) Health care systems: Getting more value for money. OECD Economics Department Policy Notes, No. 2.

RISING, E.; BARON, R.; AVERILL, B. A System Analysis of a University Health Service Outpatient Clinic. Operations Research, v. 21, n. 5, p. 1030-1047, 1973.

ROBINSON S. Discrete-event simulation: from the pioneers to the present, what next? The Journal of the Operational Research Society, v. 56, n. 6, p. 619-629, 2005.

ROCKART, J.; HOFMANN, P. Physician and Patient Behavior Under Different Scheduling Systems in a Hospital Outpatient Department. Medical Care, v. 7, n. 6, p. 463-470, 1969.

ROHLEDER, T.; KLASSEN, K. Using client-variance information to improve dynamic appointment scheduling performance. Omega, v. 28, n. 3, p. 293-302, 2000.

SALZARULO, P.; BRETTHAUER, K.; CÔTÉ, M.; SCHULTZ, K. The impact of variability and patient information on health care system performance. Production and Operations Management, v. 20, n. 6, p. 848-859, 2011.

SEPÚLVEDA, J.; BERROETA, C.. Reglas de decisión para la selección de sistemas de citas basadas en características del paciente y de la institución de salud. Revista médica de Chile, v. 140, n. 7, p. 867-872, 2012. 
SHAFER, S.; SMUNT, T. Empirical simulation studies in operations management: context, trends, and research opportunities. Journal of Operations Management, v. 22, n. 4, p. 345-354, 2004.

THOMÉ, A.; SCAVARDA, L.; FERNANDEZ, N.; SCAVARDA A. Sales and operations planning: A research synthesis. International Journal of Production Economics, v. 138, p. 1-13, 2012.

VERGARA, S. Projetos e relatórios de pesquisa em administração. 1 ed. São Paulo: Atlas, 1997. 90p.

VISSERS, J.; WIJNGAARD, J. The outpatient appointment system: Design of a simulation study. European Journal of Operational Research, v. 3, n. 6, p. 459463, 1979.

WESTMAN, G.; ANDERSSON, S.; FREDRIKSSON, P. Waiting Room Time in the Assessment of an Appointment System in Primary Care. Scandinavian Journal of Primary Health Care, v. 5, n. 35, p. 35-40, 1987.

WHITE, D.; FROEHLE, C.; KLASSEN, K.. The effect of integrated scheduling and capacity policies on clinical efficiency. Production and Operations Management, v. 20, n. 3, p. 442-455, 2011.

WHO - World Health Organization. 2014. Disponível em: http://apps.who.int/gho/data/view.main.HEALTHEXPRATIOBRA. Acesso em: 30.ago.2016

YANG, K.; LU, M.; QUEK, S. A New Appointment Rule for a Single-Server, Multiple-Customer Service System," Naval Research Logistics, v. 45, p. 313-326, 1998. 


\section{Apêndice A - Formulações das regras de agendamento}

As regras de agendamento apresentadas por Cayirli et al. (2006) são construídas de acordo com as formulações propostas pelos autores:

Seja $t_{i}$ o horário de agendamento do paciente $i, \mu$ o tempo médio de consulta,

$\beta_{i}$ parâmetros que ajustam quão cedo ou tarde serão os horários de agendamentos comparados com a regra usual IBFI e $k_{i}$ o parâmetro que define quais pacientes que chegarão mais cedo ou mais tarde comparado com a regra IBFI:

- IBFI:

$t_{1}=0$

$t_{i}=t_{i-1}+\mu$, para todo $i>1$

- OFFSET:

$t_{1}=0$

$t_{i}=(i-1) \mu-\beta_{1}\left(k_{1}-i\right) \sigma$, para todo $i \leq k_{1}$

$t_{i}=(i-1) \mu+\beta_{2}\left(i-k_{1}\right) \sigma$, para todo $i>k_{1}$

- DOME:

$t_{1}=0$

$t_{i}=(i-1) \mu-\beta_{1}\left(k_{1}-i\right) \sigma$, para todo $i \leq k_{1}$

$t_{i}=(i-1) \mu+\beta_{2}\left(i-k_{1}\right) \sigma$, para todo $k_{1}<i<k_{2}$

$t_{i}=(i-1) \mu-\beta_{3}\left(i-k_{2}\right) \sigma$, para todo $i \geq k_{2}$

- 2BEG:

$t_{1}=t_{2}=0$

$t_{i}=t_{i-1}+\mu$, para todo $i>2$ 
- MBFI:

$t_{i}=t_{i+1}=(i-1) \mu$, para todo $i=1,3,5,7, \ldots$

- 2BGDM:

$t_{i}=t_{i+1}=(i-1) \mu-\beta_{1}\left(k_{1}-i\right) \sigma$, para todo $i=1$

$t_{i+1}=(i-1) \mu-\beta_{1}\left(k_{1}-i\right) \sigma$, para todo $2 \leq i \leq k_{1}$

$t_{i+1}=(i-1) \mu+\beta_{2}\left(i-k_{1}\right) \sigma$, para todo $k_{1}<i<k_{2}$

$t_{i+1}=(i-1) \mu-\beta_{3}\left(i-k_{2}\right) \sigma$, para todo $i \geq k_{2}$

- MBDM:

$t_{i}=t_{i+1}=(i-1) \mu-\beta_{1}\left(k_{1}-i\right) \sigma$, para todo $i=1,3, \ldots, k_{1}$

$t_{i}=t_{i+1}=(i-1) \mu+\beta_{2}\left(i-k_{1}\right) \sigma$, para todo $k_{1}<i<k_{2}$

$t_{i+1}=(i-1) \mu-\beta_{3}\left(i-k_{2}\right) \sigma$, para todo $i \geq k_{2}$

Quanto aos parâmetros da regra OFFSET, Ho e Lau (1992) recomendaram a utilização de dois conjuntos de parâmetros $\left(\beta_{1}, \beta_{2}, k_{1}\right)$ que tiveram melhor desempenho em seus estudos para uma clínica com $N=10$ pacientes por dia, quais sejam: $(0,15 ; 0,30 ; 5)$ e $(0,25 ; 0,5 ; 5)$. Klassen e Rohleder (1996) identificaram que esses parâmetros definidos por Ho e Lau (1992) resultaram em dias com o horário de final de atendimento excessivamente tarde. Rohleder e Klassen (2000) testaram outros parâmetros para $N=21$ e identificaram que os parâmetros $\beta_{1}=\beta_{2}=0.2 \mathrm{e}$ $k_{1}=12$ tiveram o melhor desempenho. Cayirli et al. (2006) ajustaram o valor dos parâmetros para uma clínica com $N=20$, mantendo $\beta_{1}=0.15$ e $\beta_{2}=0.3$ e utilizando $k_{1}=10$. Bhattacharjee e Ray (2016) utilizaram como parâmetros os valores $(0,15 ; 0,30 ; 9)$ em uma clínica com $N=18$.

Na definição dos parâmetros da regra DOME, Cayirli et al. (2006) apresentam duas restrições que devem ser consideradas: $\beta_{2}<\mu /\left(k_{2}-k_{1}-1\right) \sigma$ e $\beta_{3}<\mu / \sigma$. Em seus testes, o conjunto de parâmetros $\left(\beta_{1}=0,15 ; \beta_{2}=0,3 ; \beta_{3}=0,05 ; k_{1}=\right.$ $5, k_{2}=9$ ) tiveram os melhores resultados para uma clínica com $N=10$. Da mesma forma, para uma clínica com $N=20$, os parâmetros $\left(k_{1}, k_{2}\right)$ foram ajustados para $(10 ; 18)$, respectivamente, mantendo os outros constantes. Bhattacharjee e Ray (2016) 
utilizaram como parâmetros os valores $(0,15 ; 0,40 ; 0,2 ; 6 ; 13)$ em uma clínica com $N=18$.

Salzarulo et al. (2011) desenvolveu a regra PLATÔ-DOME de acordo com a seguinte formulação:

Seja $z_{i}, S, Z, J_{1}$ e $J_{2}$ parâmetros definidos por para determinação dos horários de agendamento:

- PLATÔ-DOME:

- Passo 1:

$z_{i}=Z-\left(J_{1}-i\right) S$, para todo $i<J_{1}$

$z_{i}=Z$, para todo $J_{1} \leq i \leq J_{2}$

$z_{i}=Z-0,5\left(i-J_{2}\right) S$, para todo $i>J_{2}$

- Passo 2:

$t_{i}=0$, para $i=1$

$t_{i}=t_{i-1}+\mu_{i-1}+z_{i} \sigma_{i-1}$, para todo $1<i<N$

Cayirli et al. (2012) definiram a seguinte formulação para o cálculo da regra DOME UNIVERSAL:

- DOME UNIVERSAL:

$t_{i}=\operatorname{Max}\left\{0 ; k(i-1) \mu^{\prime}-\sigma^{\prime} \pi \sqrt{i}\right\}$, para todo $i=1, \ldots, N^{\prime}$

$N^{\prime}=\frac{N}{1-P_{n}+P_{w}}$

$\mu^{\prime}=\left(1-P_{n}+P_{w}\right) \mu$

$\sigma^{\prime 2}=\left(1-P_{n}-P_{w}\right)\left[\sigma^{2}+\left(P_{n}-P_{w}\right)^{2} \mu^{2}\right]+P_{n}\left(1-P_{n}+P_{w}\right)^{2} \mu^{2}$

$+P_{w}\left[2 \sigma^{2}+\left(1+P_{n}-P_{w}\right)^{2} \mu^{2}\right]$

$\pi=\frac{N^{\prime}+i}{N^{\prime}-1}$

$k=\left\{0,9973-0,103\left[0,005765 C R\left(1-P_{n}\right)+\left(C R\left(1-P_{n}\right)\right)^{-0,3481}\right]\right.$

$-0,10699 C V^{1,257}-0,627\left[\left(N^{\prime}\left(1-P_{n}\right)\right)^{-0,8579}\right]$

$-0,007574\left[\left(\left|C R\left(1-P_{w}\right)-2,143\right|\right)^{0,9682}\right.$

$\left.\left.-0,622 C R\left(1-P_{w}\right)\right]+0,004855 C R^{0,8913}\right\}^{-1,898}$

$C V=\sigma / \mu$ 


$$
C R=C_{d} / C_{p}
$$

A partir da regra IICR desenvolvida por Klassen e Yoogalingam (2014), esta dissertação propõe a seguinte uma formulação para o cálculo dessa regra:

Seja $a, b, c, d, e, k_{1}$ e $k_{2}$ parâmetros para determinação dos horários de agendamento:

\section{- IICR:}

$$
\begin{aligned}
t_{i} & =0, \text { para } i=1 \\
t_{i} & =a \mu, \text { para } i=2,4,6, \ldots, k_{1} \\
t_{i} & =b \mu, \text { para } i=3,7,11, \ldots, k_{1} \\
t_{i} & =c \mu, \text { para } i=5,9,13, \ldots, k_{1} \\
t_{i} & =0, \text { para } i=k_{1}+1 \\
t_{i} & =d \mu, \text { para } i=k_{1}+2, k_{1}+5, k_{1}+8, \ldots, k_{2} \\
t_{i} & =0, \text { para } i=k_{1}+3, k_{1}+4, k_{1}+6, k_{1}+7, \ldots, k_{2}+1 \\
t_{i} & =e \mu, \text { para } i=k_{2}+2 \\
t_{i} & =0, \text { para } i=k_{2}+3, k_{2}+4, \ldots, N
\end{aligned}
$$

Segundo Klassen e Yoogalingam (2014), uma das configurações de parâmetros da regra IICR que teve o melhor desempenho foi $(a=0.5, b=1.5, c=2, d=3, e=$ 2.5), sendo $k_{1}$ igual a 10 e $k_{2}$ igual a 18 em uma clínica com $N=24$.

Cayirli e Yang (2014) defiram a seguinte formulação para o cálculo da regra DOME UNIVERSAL A, que considera os mesmos parâmetros da regra DOME UNIVERSAL, com alteração apenas no cálculo do horário de agendamento, que passa a ser separado por classe (A ou B):

- DOME UNIVERSAL A:

$$
\begin{aligned}
& t_{i}=\operatorname{Max}\left\{0 ; k_{A}(i-1) \mu_{A}^{\prime}-\pi \sqrt{i \sigma_{A}^{\prime 2}}\right\}, \text { para todo } i=1, \ldots, N_{A}^{\prime} \\
& \left.t_{i}=k_{A} N_{A}^{\prime} \mu_{A}^{\prime}+k_{B}\left(i-N_{A}^{\prime}-1\right) \mu_{B}^{\prime}-\pi \sqrt{\left(N_{A}^{\prime}+1\right) \sigma_{A}^{\prime 2}+\left(i-N_{A}^{\prime}-1\right) \sigma_{B}^{\prime 2}}\right\}
\end{aligned}
$$

para todo $i=N_{A}^{\prime}+1, \ldots, N^{\prime}$ 
A partir dos trabalhos de Athula Wijewickrama e Takakuwa (2012) e Bhattacharjee e Ray (2016), propõem-se as seguintes formulações para o cálculo das regras IBFI, 2BEG, MBFI e OFFSET com ajuste por classe de paciente:

Seja $\mu_{i}$ e $\sigma_{i}$, respectivamente, a média e o desvio padrão do tempo de serviço do paciente que está sendo agendado no horário $i$, sendo este tempo dependente da classe do paciente marcado:

- IBFIA:

$t_{1}=0$

$t_{i}=t_{i-1}+\mu_{i-1}$, para todo $i>1$

- 2BEGA:

$t_{1}=t_{2}=0$

$t_{i}=t_{i-1}+\mu_{i-1}$, para todo $i>2$

- MBFIA:

$t_{1}=t_{2}=0$

$t_{i}=t_{i+1}=\mu_{i-1}+\mu_{i-2}$, para todo $i=1,3,5,7 \ldots$

- OFFSETA:

$t_{i}=(i-1) \mu_{A}-\beta_{1}\left(k_{1}-i\right) \sigma_{i}$, para todo $i \leq k_{1}$

$t_{i}=(i-1) \mu_{B}+\beta_{2}\left(i-k_{1}\right) \sigma_{i}$, para todo $i>k_{1}$ 


\section{Apêndice B - Regras de sequenciamento}

Klassen e Rohleder (1996) utilizaram a classificação dos pacientes para separar pacientes com diferentes tempos de serviço em dois tipos: de baixa e de alta variância em relação à média geral. A partir dessa classificação, os autores sugeriram sete regras de sequenciamento, quais sejam:

- FCFA: nessa regra não existe sequencia por classe, sendo que o primeiro a ligar é agendado primeiro;

- LVBEG: agenda os pacientes de baixa variância no começo (L) e os de alta $(\mathrm{H})$ no final, mantendo as proporções esperadas de pacientes de cada classe (LLLL...HHHH).

- HVBEG: agenda os pacientes de alta variância no começo e os de baixa no final, mantendo as proporções (HHHH...LLLL).

- LVBND: agenda os pacientes de baixa variância no começo e no final, mantendo as proporções (LLL...HHH...LLL).

- HVBND: agenda os pacientes de alta variância no começo e no final, mantendo as proporções (HHH...LLL...HHH).

- ALTER1: agenda os pacientes alternando as classes, ou seja, alterna um paciente de baixa variância com um de alta (LHLHLH...).

- ALTER5: agenda os pacientes alternando as classes, ou seja, alterna cinco pacientes de baixa variância com cinco de alta (LLLLLHHHHHLLLLL...).

Athula Wijewickrama e Takakuwa (2012) e Bhattacharjee e Ray (2016) simularam a ALTER1 de forma a considerar a diferente proporção entre as classes, colocando o excesso de pacientes da classe de maior proporção no final da seção (LMLMLMLLLL). 
Cayirli et al. (2006) testaram a classificação de pacientes com dados empíricos separando em duas classes com diferentes médias do tempo de serviço, novos e de retorno, propondo o uso de outras regras, quais sejam:

- HMBEG: agenda os pacientes com maior média entre as classes no início e os com menor média no final, mantendo a proporção de cada classe (NNN...RRRR).

- LMBEG: agenda os pacientes com menor média no começo, mantendo as proporções (RRRR...NNN).

- HMBND: agenda os pacientes com maior média no começo e no final, mantendo as proporções (NNN...RRR...NNN).

- LMBND: agenda os pacientes com menor média no começo e no final, mantendo as proporções (RRR...NNN...RRR).

White et al. (2011) propuseram uma alteração na regra ALTER para considerar a proporção de pacientes em cada classe, conforme demonstrado nas duas regras a seguir:

- ALTER-A: agenda os pacientes alternando as classes, mas mantendo a proporção de cada classe, ou seja, se a proporção entre duas classes é de 3 da classe A para 1 da classe $B$, agenda-se alternando 3 pacientes da classe A seguidos de 1 paciente da classe B (AAABAAAB...).

- ALTER-B: agenda os pacientes alternando as classes, mas mantendo a proporção de cada classe, ou seja, se a proporção entre duas classes é de 3 da classe A para 1 da classe $B$, agenda-se alternando 1 paciente da classe $\mathrm{B}$ seguido de 3 pacientes da classe A (BAAABAAA...).

Cayirli e Yang (2014) propuseram três novas regras de sequenciamento que passam a considerar a ocorrência de classes com diferentes médias e desvios padrão do tempo de serviço, quais sejam: 
- LVBEG': agenda os pacientes de baixo desvio padrão ajustado $\left(\sigma^{\prime}\right)$ no começo (L) e os de alto $(\mathrm{H})$ no final, mantendo as proporções esperadas de pacientes de cada classe.

- LMVBEG': agenda os pacientes pela ordem crescente da multiplicação da média ajustada pelo desvio padrão ajustado $\left(\sigma^{\prime} * \mu^{\prime}\right)$, mantendo a proporção de cada classe.

- LCVBEG': agenda os pacientes pela ordem crescente de coeficiente de variação ajustado $\left(\sigma^{\prime} / \mu^{\prime}\right)$, mantendo a proporção de cada classe.

Bhattacharjee e Ray (2016) testaram, inicialmente, a classificação de pacientes em duas classes: pacientes internados e pacientes do ambulatório. Em seguida, os autores fizeram testes separando os mesmos pacientes em seis classes, de acordo com as características dos exames, e propuseram mais duas regras de sequenciamento, quais sejam:

- HPBEG: agenda os pacientes pela ordem decrescente de pontualidade entre as classes mais pontuais no começo, mantendo a proporção de cada classe.

- LCVBEG: agenda os pacientes pela ordem crescente de coeficiente de variação entre as classes, mantendo a proporção de cada classe. 


\section{Apêndice C - Regra para ajuste de intervalo de agendamento}

No estudo de Cayirli et al. (2008), os ajustes foram feitos nos intervalos de agendamento de forma a reconhecer os distintos tempos de serviço de diferentes classes de pacientes. A Figura 12 exemplifica o ajuste feito na regra de agendamento IBFI de forma a reconhecer duas classes de pacientes: novos pacientes (N) e pacientes de retorno (R), com média de tempo de serviço de 30 e 15 minutos, respectivamente. Dessa forma, o primeiro exemplo mostra a regra tradicional IBFI sem ajuste de tempo por classe, apenas sequenciada com os novos pacientes em primeiro (IBFI-HMBEG) e o segundo exemplo mostra a regra IBFI com ajuste de intervalo (IBFIA-HMBEG). Como no exemplo os pacientes novos tem uma média de tempo de serviço maior, na regra IBFIA-HMBEG são atribuídos a eles intervalos maiores (30 $\mathrm{min})$ e aos pacientes de retorno intervalos menores (15 $\mathrm{min})$, em vez de todos terem um único intervalo de agendamento de 21 minutos (que é a média geral) como é feito na regra IBFI- HMBEG.

IBFI-NWBEG
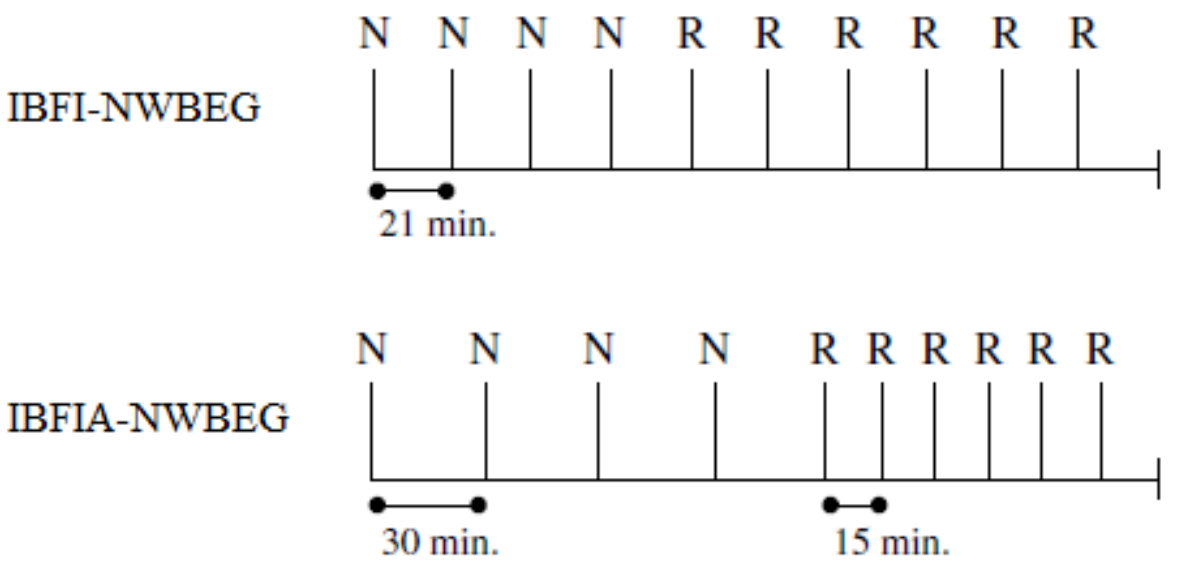

Figura 14 - Exemplo de regra IBFI sem ajuste e com ajustes nos intervalos de agendamento (IBFIA). Fonte: Adaptada de Cayirli et al. (2008). 


\section{Apêndice D - Descrição dos artigos analisados na revisão da literatura}

Tabela 28 - Resumo dos artigos. Fonte: Elaboração própria.

\begin{tabular}{|c|c|c|c|c|c|c|c|}
\hline Artigo & Descrição & $\begin{array}{l}\text { Análise de } \\
\text { sensibilidade }\end{array}$ & Regras testadas & $\begin{array}{l}\text { Melhores } \\
\text { regras }\end{array}$ & Método & $\begin{array}{l}\mathrm{N}^{\circ} \text { de } \\
\text { Fatores }\end{array}$ & $\begin{array}{l}\text { Indicador de } \\
\text { desempenho }\end{array}$ \\
\hline $\begin{array}{l}\text { Ho e } \\
\text { Lau } \\
(1992)\end{array}$ & $\begin{array}{l}\text { Simularam sete regras de agendamento } \\
\text { em } 27 \text { ambientes diferentes. Os autores } \\
\text { concluíram que uma nova regra, } \\
\text { nomeada de OFFSET, teve o melhor } \\
\text { desempenho geral, e obtiveram } \\
\text { também bons resultados com as regras } \\
\text { 2BEG e 4BEG na maioria dos } \\
\text { cenários. }\end{array}$ & $N ; C V ; P_{n}$ & $\begin{array}{l}\text { 2BEG, 3BEG, } \\
\text { 4BEG, OFFSET, } \\
\text { MBFI e outras. }\end{array}$ & $\begin{array}{l}\text { OFFSET, } \\
\text { 2BEG e } \\
4 \mathrm{BEG}\end{array}$ & SED & 3 & $\begin{array}{l}\text { (1) Custo de espera } \\
\text { dos pacientes; ( } 2 \text { ) } \\
\text { custo de ociosidade do } \\
\text { médico. }\end{array}$ \\
\hline $\begin{array}{l}\text { Klassen } \\
\text { e } \\
\text { Rohleder } \\
(1996)\end{array}$ & $\begin{array}{l}\text { Simularam as três melhores regras de } \\
\text { agendamento dos testes de Ho e Lau } \\
\text { (1992) e compararam com sete regras } \\
\text { de sequenciamento. Os testes feitos } \\
\text { não combinaram as regras de } \\
\text { agendamento OFFSET, 2BEG e 4BEG } \\
\text { com as de sequenciamento, apenas } \\
\text { analisaram isoladamente cada política. } \\
\text { Conclui-se que a regra IBFI-LVBEG } \\
\text { foi a melhor em todos os cenários. }\end{array}$ & PCLV е $\mu$ & $\begin{array}{l}\text { OFFSET, 2BEG, } \\
\text { 4BEG e IBFI } \\
\text { combinadas com } \\
\text { FCFA, e IBFI } \\
\text { combinada com } \\
\text { ALTER1, } \\
\text { ALTER5, HVBEG, } \\
\text { HVBND, LVBEG e } \\
\text { LVBND. }\end{array}$ & $\begin{array}{l}\text { IBFI- } \\
\text { LVBEG }\end{array}$ & SED & 4 & $\begin{array}{l}\text { (1) Custo de espera } \\
\text { dos pacientes; (2) } \\
\text { custo de ociosidade do } \\
\text { médico; (3) tempo } \\
\text { médio e máximo do } \\
\text { horário de fim do dia; } \\
\text { (4) \% de urgentes } \\
\text { servidos. }\end{array}$ \\
\hline
\end{tabular}




\begin{tabular}{|c|c|c|c|c|c|c|c|}
\hline Artigo & Descrição & $\begin{array}{l}\text { Análise de } \\
\text { sensibilidade }\end{array}$ & Regras testadas & $\begin{array}{l}\text { Melhores } \\
\text { regras }\end{array}$ & Método & $\begin{array}{l}\mathrm{N}^{\circ} \text { de } \\
\text { Fatores }\end{array}$ & $\begin{array}{l}\text { Indicador de } \\
\text { desempenho }\end{array}$ \\
\hline $\begin{array}{l}\text { Ho e } \\
\text { Lau } \\
(1999)\end{array}$ & $\begin{array}{l}\text { Simularam } 50 \text { regras de agendamento em } \\
27 \text { ambientes diferentes. Os autores } \\
\text { identificaram nove regras que tiveram um } \\
\text { melhor desempenho, sendo a OFFSET a } \\
\text { melhor regra para minimizar o tempo de } \\
\text { espera quando o no-show é baixo (até } \\
10 \% \text { e a regra } 4 \text { BEG a melhor para } \\
\text { minimizar o tempo ocioso, tendo seu } \\
\text { desempenho melhorado à medida que o } \\
\text { no-show aumenta. }\end{array}$ & $\begin{array}{l}\text { Distribuição } \\
\text { estatística do } \\
\text { tempo de } \\
\text { serviço; } \\
N ; C V ; P_{n}\end{array}$ & $\begin{array}{l}50 \text { regras de } \\
\text { agendamento }\end{array}$ & $\begin{array}{l}\text { OFFSET e } \\
\text { 4BEG. }\end{array}$ & SED & 3 & $\begin{array}{l}\text { (1) Custo de espera } \\
\text { dos pacientes; (2) } \\
\text { custo de ociosidade } \\
\text { do médico. }\end{array}$ \\
\hline $\begin{array}{l}\text { Rohleder } \\
\text { e } \\
\text { Klassen } \\
(2000)\end{array}$ & $\begin{array}{l}\text { Testaram a regra de sequenciamento } \\
\text { LVBEG combinada com as regras de } \\
\text { agendamento IBFI e 2BEG, comparando } \\
\text { com as outras regras de agendamento } \\
\text { sequenciadas pela ordem de ligação. } \\
\text { Concluiu-se que a IBFI-LVBEG, seguida } \\
\text { da 2BEG-LVBEG, tiveram os melhores } \\
\text { resultados tanto no cenário sem } \\
\text { preferência de horário quanto com } \\
\text { preferência uniformemente distribuída. }\end{array}$ & $\begin{array}{l}\text { Proporção de } \\
\text { pacientes } \\
\text { com } \\
\text { preferência } \\
\text { de horário, } \\
\text { distribuição } \\
\text { dos horários } \\
\text { preferidos e a } \\
\text { incerteza do } \\
\text { responsável } \\
\text { pelo } \\
\text { agendamento. }\end{array}$ & $\begin{array}{l}\text { IBFI e 2BEG } \\
\text { combinadas com } \\
\text { LVBEG; e 2BEG, } \\
\text { 4BEG, IBFI e } \\
\text { OFFSET } \\
\text { combinadas com } \\
\text { FCFA. }\end{array}$ & $\begin{array}{l}\text { IBFI- } \\
\text { LVBEG e } \\
\text { 2BEG- } \\
\text { LVBEG }\end{array}$ & SED & 5 & $\begin{array}{l}\text { (1) Custo de espera } \\
\text { dos pacientes; (2) } \\
\text { custo de ociosidade } \\
\text { do médico; (3) } \\
\text { tempo médio e } \\
\text { máximo do horário } \\
\text { de fim do dia; (4) \% } \\
\text { de urgentes servidos; } \\
\text { (5) média do tempo } \\
\text { máximo de espera do } \\
\text { paciente; (6) \% de } \\
\text { pacientes que } \\
\text { esperam até } 10 \\
\text { minutos na fila; (7) } \\
\text { \% de pacientes que } \\
\text { receberam seus slots. }\end{array}$ \\
\hline
\end{tabular}




\begin{tabular}{|c|c|c|c|c|c|c|c|}
\hline Artigo & Descrição & $\begin{array}{c}\text { Análise de } \\
\text { sensibilidade }\end{array}$ & Regras testadas & $\begin{array}{l}\text { Melhores } \\
\text { regras }\end{array}$ & Método & $\begin{array}{l}\mathrm{N}^{\circ} \text { de } \\
\text { Fatores }\end{array}$ & $\begin{array}{l}\text { Indicador de } \\
\text { desempenho }\end{array}$ \\
\hline $\begin{array}{l}\text { Klassen } \\
\text { e } \\
\text { Rohleder } \\
(2004)\end{array}$ & $\begin{array}{l}\text { Testaram quatro políticas de } \\
\text { agendamento e verificaram que a melhor } \\
\text { regra é a IBFI-LVBEG, seguida das } \\
\text { regras IBFI-FCFA, 2BEG-LVBEG e } \\
\text { 2BEG-FCFA, sendo } 15.6 \% \text { melhor na } \\
\text { média dos cenários. }\end{array}$ & $N ; P C L V$ & $\begin{array}{l}\text { IBFI-FCFA, } \\
\text { 2BEG-FCFA, } \\
\text { IBFI-LVBEG e } \\
\text { 2BEG-LVBEG. }\end{array}$ & $\begin{array}{l}\text { IBFI- } \\
\text { LVBEG }\end{array}$ & SED & 3 & $\begin{array}{l}\text { (1) Custo de espera } \\
\text { dos pacientes; (2) } \\
\text { custo de ociosidade } \\
\text { do médico; (3) } \\
\text { horário de fim do } \\
\text { dia; (4) utilização } \\
\text { do servidor; (5) } \\
\text { lead-time. }\end{array}$ \\
\hline $\begin{array}{l}\text { Cayirli } \\
\text { et al. } \\
\text { (2006) }\end{array}$ & $\begin{array}{l}\text { Analisaram sete regras de agendamento } \\
\text { em diversos cenários e perceberam que as } \\
\text { regras de intervalo fixo tiveram os } \\
\text { melhores desempenhos gerais. Os autores } \\
\text { também testaram as regras de } \\
\text { sequenciamento utilizando dados } \\
\text { empíricos e separando em duas classes: } \\
\text { novos e de retorno, concluindo que: (i) a } \\
\text { regra FCFA teve o pior desempenho em } \\
\text { todos os cenários; e (ii) as regras } \\
\text { HMBEG, ALTER1 e LMBEG obtiveram } \\
\text { os melhores resultados gerais por ordem } \\
\text { crescente do custo do paciente em relação } \\
\text { ao do médico. }\end{array}$ & $\begin{array}{l}\text { Média da } \\
\text { impontualidade; } \\
\qquad N ; C V ; \\
P_{n} ; P_{w}\end{array}$ & $\begin{array}{l}\text { IBFI, OFFSET, } \\
\text { DOME, 2BEG, } \\
\text { MBFI, 2BGDM } \\
\text { e MBDM } \\
\text { combinadas com } \\
\text { FCFA, ALTER1, } \\
\text { HMBEG, } \\
\text { LMBEG, } \\
\text { HMBND E } \\
\text { LMBND. }\end{array}$ & $\begin{array}{l}\text { 2BEG- } \\
\text { LMBEG teve } \\
\text { o melhor } \\
\text { desempenho } \\
\text { geral, seguida } \\
\text { da 2BEG- } \\
\text { HMBEG, } \\
\text { MBFI- } \\
\text { HMBEG, } \\
\text { 2BEG- } \\
\text { LMBND, } \\
\text { 2BEG- } \\
\text { ALTER1 e } \\
\text { MBFI- } \\
\text { ALTER1. }\end{array}$ & SED & 5 & $\begin{array}{l}\text { (1) Custo de espera } \\
\text { dos pacientes; (2) } \\
\text { custo de ociosidade } \\
\text { do médico; (3) } \\
\text { custo de horas } \\
\text { extras do médico. }\end{array}$ \\
\hline
\end{tabular}




\begin{tabular}{|c|c|c|c|c|c|c|c|}
\hline Artigo & Descrição & $\begin{array}{c}\text { Análise de } \\
\text { sensibilidade }\end{array}$ & Regras testadas & $\begin{array}{c}\text { Melhores } \\
\text { regras }\end{array}$ & Método & $\begin{array}{l}\mathrm{N}^{\mathrm{o}} \text { de } \\
\text { Fatores }\end{array}$ & $\begin{array}{l}\text { Indicador de } \\
\text { desempenho }\end{array}$ \\
\hline $\begin{array}{l}\text { LaGanga } \\
\text { e } \\
\text { Lawrence } \\
(2007)\end{array}$ & $\begin{array}{l}\text { Desenvolveram e simularam uma } \\
\text { regra simples de overbooking baseada } \\
\text { na redução dos intervalos de } \\
\text { agendamento, proporcionalmente com } \\
\text { o aumento da taxa de no-show. } \\
\text { Verificam que essa regra de ajuste } \\
\text { pode ser usada no sentido de aumentar } \\
\text { a utilização do médico. }\end{array}$ & $N^{\prime} ; C V ; P_{n}$ & $\begin{array}{l}\text { IBFI com } \\
\text { overbooking x sem } \\
\text { overbooking }\end{array}$ & $\begin{array}{l}\text { IBFI com } \\
\text { overbooking }\end{array}$ & SED & 4 & $\begin{array}{l}\text { (1) Ganho por } \\
\text { paciente; (2) custo de } \\
\text { espera do paciente; ( } 3 \text { ) } \\
\text { custo de horas extras } \\
\text { do médico. }\end{array}$ \\
\hline $\begin{array}{l}\text { Cayirli et } \\
\text { al. (2008) }\end{array}$ & $\begin{array}{l}\text { Simularam as melhores regras } \\
\text { verificadas por Cayirli et al. }(2006) \text {, } \\
\text { com e sem ajuste de tempo, em } \\
\text { diversos ambientes. Os autores } \\
\text { identificaram que o uso da } \\
\text { classificação de pacientes tinha mais } \\
\text { impacto quanto maior fosse o } \\
\text { percentual de novos pacientes e/ou a } \\
\text { diferença entre a média dos tempos de } \\
\text { serviço de pacientes novos e de } \\
\text { retorno. A regra IBFIA-LMBEG foi a } \\
\text { que teve melhor desempenho nos } \\
\text { indicadores (4) e (5). }\end{array}$ & $\begin{array}{l}\% \text { de novos } \\
\text { pacientes; } \\
\text { relação entre } \\
\text { o tempo } \\
\text { médio de } \\
\text { consulta dos } \\
\text { novos } \\
\text { pacientes e } \\
\text { de retorno; } \\
\quad P_{n} ; P_{w}\end{array}$ & $\begin{array}{l}\text { 2BEG, MBFI e } \\
\text { IBFI com e sem } \\
\text { ajuste de tempo } \\
\text { combinadas com } \\
\text { HMBEG, ALTER1 } \\
\text { e LMBEG. }\end{array}$ & $\begin{array}{l}\text { 2BEGA- } \\
\text { LMBEG, } \\
\text { MBFIA- } \\
\text { LMBEG, } \\
\text { IBFIA- } \\
\text { LMBEG. }\end{array}$ & SED & 5 & $\begin{array}{l}\text { (1) Custo de espera } \\
\text { dos pacientes; (2) } \\
\text { custo de ociosidade do } \\
\text { médico; (3) custo de } \\
\text { horas extras do } \\
\text { médico; (4) equidade } \\
\text { do tempo médio de } \\
\text { fila; (5) \% de } \\
\text { pacientes com tempo } \\
\text { de fila menor que } 30 \\
\text { minutos. }\end{array}$ \\
\hline
\end{tabular}




\begin{tabular}{|c|c|c|c|c|c|c|c|}
\hline Artigo & Descrição & $\begin{array}{c}\text { Análise de } \\
\text { sensibilidade }\end{array}$ & Regras testadas & $\begin{array}{l}\text { Melhores } \\
\text { regras }\end{array}$ & Método & $\begin{array}{l}\mathrm{N}^{o} \text { de } \\
\text { Fatores }\end{array}$ & $\begin{array}{l}\text { Indicador de } \\
\text { desempenho }\end{array}$ \\
\hline $\begin{array}{l}\text { Klassen e } \\
\text { Yoogalingam } \\
\text { (2009) }\end{array}$ & $\begin{array}{l}\text { Desenvolveram um modelo de } \\
\text { otimização estocástica que considera } \\
\text { a variabilidade do tempo de serviço, } \\
\text { validando com outros modelos da } \\
\text { literatura e comparando com as } \\
\text { regras já existentes. Os autores } \\
\text { encontraram resultados melhores do } \\
\text { que os com as regras da literatura e } \\
\text { verificaram que os intervalos de } \\
\text { agendamento ótimos tinham a forma } \\
\text { PLATÔ DOME. Propuseram uma } \\
\text { alteração da DOME para facilitar a } \\
\text { implementação tornando-a em forma } \\
\text { platô. }\end{array}$ & $P_{n}$ & $\begin{array}{l}\text { Solução ótima do } \\
\text { modelo (PLATÔ- } \\
\text { DOME) versus } \\
\text { regras IBFI, MBFI, } \\
\text { 2BEG, 4BEG e } \\
\text { OFFSET }(0.2,7.5 \text {, } \\
\text { 12) }\end{array}$ & $\begin{array}{l}\text { PLATÔ- } \\
\text { DOME }\end{array}$ & PM & 2 & $\begin{array}{l}\text { (1) Custo de espera } \\
\text { dos pacientes; (2) } \\
\text { custo de ociosidade } \\
\text { do médico; (3) custo } \\
\text { de horas extras do } \\
\text { médico. }\end{array}$ \\
\hline $\begin{array}{l}\text { White } \text { et al. } \\
\text { (2011) }\end{array}$ & $\begin{array}{l}\text { Simularam separadamente regras de } \\
\text { agendamento e de sequenciamento } \\
\text { combinadas com políticas de } \\
\text { alocação de recursos para múltiplos } \\
\text { serviços utilizando dados empíricos. } \\
\text { No que tange às políticas de } \\
\text { agendamento, os autores concluíram } \\
\text { que a regra IBFI-LVBEG teve o } \\
\text { melhor desempenho geral. }\end{array}$ & - & $\begin{array}{l}\text { IBFI e PLATÔ } \\
\text { DOME } \\
\text { combinadas com } \\
\text { FCFA, e IBFI } \\
\text { combinadas com } \\
\text { LVBEG, HVBEG, } \\
\text { ALTER-A e } \\
\text { ALTER-B. }\end{array}$ & IBFI-LVBEG & $\begin{array}{l}\text { SED e } \\
\text { EC. }\end{array}$ & 2 & $\begin{array}{l}\text { (1) Média do tempo } \\
\text { de espera dos } \\
\text { pacientes; (2) tempo } \\
\text { de horas extra; ( } 3 \text { ) } \\
\text { utilização do médico. }\end{array}$ \\
\hline
\end{tabular}




\begin{tabular}{|c|c|c|c|c|c|c|c|}
\hline Artigo & Descrição & $\begin{array}{c}\text { Análise de } \\
\text { sensibilidade }\end{array}$ & Regras testadas & $\begin{array}{l}\text { Melhores } \\
\text { regras }\end{array}$ & Método & $\begin{array}{l}\mathrm{N}^{\mathrm{o}} \mathrm{de} \\
\text { Fatores }\end{array}$ & $\begin{array}{l}\text { Indicador de } \\
\text { desempenho }\end{array}$ \\
\hline $\begin{array}{l}\text { Jerbi e } \\
\text { Kamoun } \\
(2011)\end{array}$ & $\begin{array}{l}\text { Estudaram um caso real de } \\
\text { agendamento no Departamento de } \\
\text { Nefrologia do Hospital Hedi Chaker, } \\
\text { na Tunísia. Os autores simularam } \\
\text { regras de agendamento combinadas } \\
\text { com regras de sequenciamento e } \\
\text { utilizaram o resultado da simulação } \\
\text { em um modelo analítico para } \\
\text { encontrar a solução com melhor } \\
\text { resultado geral. }\end{array}$ & - & $\begin{array}{l}\text { 2BEG, IBFI e } \\
\text { MBFI combinadas } \\
\text { com ALTER1, } \\
\text { HMBEG e } \\
\text { LMBEG. }\end{array}$ & $\begin{array}{l}\text { IBFI- } \\
\text { HMBEG }\end{array}$ & $\begin{array}{c}\text { SED, } \\
\text { PM e } \\
\text { EC }\end{array}$ & 3 & $\begin{array}{l}\text { (1) desvio em relação } \\
\text { ao menor tempo médio } \\
\text { de espera do paciente } \\
\text { entre as regras } \\
\text { testadas; (2) desvio em } \\
\text { relação à maior } \\
\text { utilização do médico } \\
\text { entre as regras } \\
\text { testadas. }\end{array}$ \\
\hline $\begin{array}{l}\text { Salzarulo } \\
\text { et al. } \\
\text { (2011) }\end{array}$ & $\begin{array}{l}\text { Propuseram uma formulação para a } \\
\text { regra de agendamento PLATÔ- } \\
\text { DOME testando } 36 \text { configurações } \\
\text { diferentes. Os autores encontraram } \\
\text { dez configurações com melhores } \\
\text { resultados e que poderiam ser } \\
\text { escolhidas de acordo com a relação de } \\
\text { custo entre o médico e o paciente. Os } \\
\text { autores também combinaram essa } \\
\text { regra com regras de sequenciamento e } \\
\text { concluíram que a regra que teve } \\
\text { melhor desempenho geral foi a } \\
\text { LVBEG. }\end{array}$ & $\begin{array}{l}\text { Com } \\
\text { paciente } \\
\text { pontual } \\
\text { versus } \\
\text { impontual; } \\
\text { com versus } \\
\text { sem } \\
\text { interrupção } \\
\text { no serviço. }\end{array}$ & $\begin{array}{l}\text { (1) } 36 \\
\text { configurações da } \\
\text { PLATÔ-DOME ; } \\
\text { (2) combinação da } \\
\text { PLATÔ-DOME } \\
\text { com LVBEG, } \\
\text { ALTER-B e } \\
\text { ALTER1. }\end{array}$ & $\begin{array}{l}\text { (1) } 10 \\
\text { melhores } \\
\text { configurações } \\
\text { da PLATÔ-- } \\
\text { DOME; (2) } \\
\text { LVBEG }\end{array}$ & SED & 4 & $\begin{array}{l}\text { (1) Custo de espera } \\
\text { dos pacientes; ( } 2 \text { ) } \\
\text { custo de ociosidade do } \\
\text { médico. }\end{array}$ \\
\hline
\end{tabular}




\begin{tabular}{|c|c|c|c|c|c|c|c|}
\hline Artigo & Descrição & $\begin{array}{l}\text { Análise de } \\
\text { sensibilidade }\end{array}$ & Regras testadas & $\begin{array}{l}\text { Melhores } \\
\text { regras }\end{array}$ & Método & $\begin{array}{l}\mathrm{N}^{\mathrm{o}} \mathrm{de} \\
\text { Fatores }\end{array}$ & $\begin{array}{l}\text { Indicador de } \\
\text { desempenho }\end{array}$ \\
\hline $\begin{array}{l}\text { Cayirli et al. } \\
\text { (2012) }\end{array}$ & $\begin{array}{l}\text { Propuseram uma nova regra de } \\
\text { agendamento, a DOME } \\
\text { UNIVERSAL, e compararam seu } \\
\text { desempenho com outras regras. Os } \\
\text { autores concluíram que a DOME } \\
\text { UNIVERSAL } 1 \text { teve o melhor } \\
\text { desempenho, seguida da DOME } \\
\text { UNIVERSAL } 2 \text { que teve um } \\
\text { desempenho bem próximo. }\end{array}$ & $\begin{array}{l}N^{\prime} ; C V \\
P_{n} ; P_{w}\end{array}$ & $\begin{array}{l}\text { DOME } \\
\text { UNIVERSAL } 1 \text {, } \\
\text { DOME } \\
\text { UNIVERSAL } 2 \text {, } \\
\text { DOME, IBFI e } \\
\text { OFFSET }(0,15 ; \\
0,30 ; 5)\end{array}$ & $\begin{array}{l}\text { DOME } \\
\text { UNIVERSAL } \\
1 \text { e DOME } \\
\text { UNIVERSAL } \\
2\end{array}$ & SED & 5 & $\begin{array}{l}\text { (1) Custo de } \\
\text { espera dos } \\
\text { pacientes; (2) } \\
\text { custo de } \\
\text { ociosidade do } \\
\text { médico; (3) } \\
\text { custo de horas } \\
\text { extras do } \\
\text { médico. }\end{array}$ \\
\hline $\begin{array}{l}\text { Athula } \\
\text { Wijewickrama } \\
\text { e Takakuwa } \\
\text { (2012) }\end{array}$ & $\begin{array}{l}\text { Simularam regras de agendamento e } \\
\text { de sequenciamento com e sem } \\
\text { ajuste do tempo da consulta por } \\
\text { classe de paciente em um processo } \\
\text { de consulta com dois médicos em } \\
\text { série. Conclui que o ajuste de tempo } \\
\text { baseado no tipo de paciente tem um } \\
\text { desempenho melhor do que o } \\
\text { sistema sem ajuste. }\end{array}$ & $N$ & $\begin{array}{l}\text { 2BEG, 3BEG, } \\
\text { IBFI, MBFI, } \\
\text { OFFSET }(0,15 ; \\
0,30) \text { com e sem } \\
\text { ajuste combinadas } \\
\text { com FCFA, } \\
\text { LMBEG, } \\
\text { HMBEG, } \\
\text { ALTER1, } \\
\text { ALTER5 e } \\
\text { LVBEG. }\end{array}$ & $\begin{array}{l}\text { 2BEGA- } \\
\text { ALTER1, } \\
\text { MBFIA- } \\
\text { ALTER1, } \\
\text { IBFIA- } \\
\text { ALTER1, } \\
\text { OFFSETA- } \\
\text { HMBEG. }\end{array}$ & $\begin{array}{l}\text { SED e } \\
\text { PM }\end{array}$ & 3 & $\begin{array}{l}\text { (1) Custo de } \\
\text { espera dos } \\
\text { pacientes; (2) } \\
\text { custo de } \\
\text { ociosidade do } \\
\text { médico. }\end{array}$ \\
\hline $\begin{array}{l}\text { Sepülveda e } \\
\text { Berroeta } \\
\text { (2012) }\end{array}$ & $\begin{array}{l}\text { Simularam regras de agendamento } \\
\text { combinadas com regras de } \\
\text { sequenciamento com dados } \\
\text { empíricos. }\end{array}$ & $\begin{array}{l}\text { Média da } \\
\text { impontualidade; } \\
\qquad N ; C V ; \\
\quad P_{n} ; P_{w}\end{array}$ & $\begin{array}{l}\text { IBFI, 2BEG e } \\
\text { MBFI combinadas } \\
\text { com ALTER1, } \\
\text { HMBEG e } \\
\text { LMBEG. }\end{array}$ & $\begin{array}{l}\text { Para o } \\
\text { indicador (1): } \\
\text { IBFI- } \\
\text { LMBEG; } \\
\text { 2BEG- } \\
\text { LMBEG; } \\
\text { Para o } \\
\text { indicador (2) } \\
\text { e (3): MBFI- } \\
\text { LMBEG. }\end{array}$ & SED & 6 & $\begin{array}{l}\text { (1) média e } \\
\text { desvio padrão } \\
\text { do tempo de } \\
\text { espera do } \\
\text { paciente; (2) } \\
\text { média do tempo } \\
\text { ocioso; (3) } \\
\text { média do } \\
\text { horário de fim } \\
\text { do dia. }\end{array}$ \\
\hline
\end{tabular}




\begin{tabular}{|c|c|c|c|c|c|c|c|}
\hline Artigo & Descrição & $\begin{array}{c}\text { Análise de } \\
\text { sensibilidade }\end{array}$ & Regras testadas & $\begin{array}{l}\text { Melhores } \\
\text { regras }\end{array}$ & Método & $\begin{array}{l}\mathrm{N}^{\circ} \text { de } \\
\text { Fatores }\end{array}$ & $\begin{array}{l}\text { Indicador de } \\
\text { desempenho }\end{array}$ \\
\hline $\begin{array}{l}\text { Klassen e } \\
\text { Yoogalingam } \\
\text { (2013) }\end{array}$ & $\begin{array}{l}\text { Avaliaram o efeito do atraso do } \\
\text { médico e da interrupção do serviço } \\
\text { no sistema de agendamento. } \\
\text { Verificou que a solução ótima dos } \\
35 \text { cenários testados tem o aspecto } \\
\text { PLATÔ-DOME. }\end{array}$ & $\begin{array}{l}\text { Média do } \\
\text { atraso do } \\
\text { médico; \% de } \\
\text { interrupção } \\
\text { do serviço; } \\
\quad \sigma ; C R\end{array}$ & - & $\begin{array}{l}\text { PLATÔ- } \\
\text { DOME. }\end{array}$ & $\mathrm{PM}$ & 3 & $\begin{array}{l}\text { (1) Custo de espera } \\
\text { dos pacientes; (2) } \\
\text { custo de ociosidade } \\
\text { do médico; (3) custo } \\
\text { de horas extras do } \\
\text { médico. }\end{array}$ \\
\hline $\begin{array}{l}\text { Klassen e } \\
\text { Yoogalingam } \\
\text { (2014) }\end{array}$ & $\begin{array}{l}\text { Propuseram uma nova regra de } \\
\text { agendamento que teve o melhor } \\
\text { desempenho em seus testes, a IICR. } \\
\text { Os autores compararam essa regra } \\
\text { com outras regras da literatura e } \\
\text { concluíram que esta tem o melhor } \\
\text { resultado, seguida pela PLATÔ- } \\
\text { DOME. Conclui que o no-show, o } \\
\text { atraso do médico e as interrupções, } \\
\text { não mudam a escolha da melhor } \\
\text { regra IICR. }\end{array}$ & $\begin{array}{l}\text { Média e } \\
\text { variância da } \\
\text { impontualidade } \\
\text { do paciente; } \\
\text { média do } \\
\text { atraso do } \\
\text { médico; \% de } \\
\text { interrupções } \\
\text { entre } \\
\text { consultas; } \\
\quad P_{n} ; \text { CR }\end{array}$ & $\begin{array}{l}\text { Solução "ótima" } \\
\text { do modelo (IICR) } \\
\text { versus DOME, } \\
\text { PLATÔ-DOME, } \\
\text { 2BEG. }\end{array}$ & $\begin{array}{l}\text { IICR e } \\
\text { PLATÔ- } \\
\text { DOME. }\end{array}$ & $\mathrm{PM}$ & 5 & $\begin{array}{l}\text { (1) Custo de espera } \\
\text { dos pacientes; (2) } \\
\text { custo de ociosidade } \\
\text { do médico; (3) custo } \\
\text { de horas extras do } \\
\text { médico. }\end{array}$ \\
\hline
\end{tabular}




\begin{tabular}{|c|c|c|c|c|c|c|c|}
\hline Artigo & Descrição & $\begin{array}{c}\text { Análise de } \\
\text { sensibilidade }\end{array}$ & Regras testadas & Melhores regras & Método & $\begin{array}{l}\mathrm{N}^{\circ} \text { de } \\
\text { Fatores }\end{array}$ & $\begin{array}{l}\text { Indicador de } \\
\text { desempenho }\end{array}$ \\
\hline $\begin{array}{l}\text { Cayirli e } \\
\text { Yang } \\
\text { (2014) }\end{array}$ & $\begin{array}{l}\text { Propuseram uma adaptação na regra } \\
\text { de agendamento DOME } \\
\text { UNIVERSAL para considerar a } \\
\text { classificação de pacientes. Os autores } \\
\text { compararam essa regra (com e sem } \\
\text { ajuste) com outras regras (com } \\
\text { ajuste), verificando que a DOME } \\
\text { UNIVERSAL com ajuste teve o } \\
\text { melhor desempenho. Os autores } \\
\text { também testaram as regras de } \\
\text { sequenciamento de acordo com } \\
\text { quatro possíveis tipos de } \\
\text { classificação. Os autores propuseram } \\
\text { outras regras de sequenciamento e } \\
\text { mostraram que a regra LCVBEG' } \\
\text { teve o melhor desempenho. }\end{array}$ & $\sigma ; \mathrm{CR}$ & $\begin{array}{l}\text { (1) DOME } \\
\text { UNIVERSAL com } \\
\text { e sem ajuste de } \\
\text { tempo, IBFIA, } \\
\text { 2BEGA. (2) } \\
\text { LVBEG', } \\
\text { LMVBEG' e } \\
\text { LCVBEG'. }\end{array}$ & $\begin{array}{l}\text { (1) DOME } \\
\text { UNIVERSAL com } \\
\text { ajuste de tempo; } \\
\text { (2) LCVBEG'. }\end{array}$ & SED & 4 & $\begin{array}{l}\text { (1) Custo de } \\
\text { espera dos } \\
\text { pacientes; (2) } \\
\text { custo de } \\
\text { ociosidade do } \\
\text { médico; (3) } \\
\text { custo de horas } \\
\text { extras do } \\
\text { médico. }\end{array}$ \\
\hline $\begin{array}{l}\text { Bhattachar } \\
\text { jee e Ray } \\
(2016)\end{array}$ & $\begin{array}{l}\text { Estudaram um caso real de } \\
\text { agendamento em um hospital da } \\
\text { Índia, simulando regras de } \\
\text { agendamento combinadas com dois } \\
\text { tipos de regras de sequenciamento, ou } \\
\text { por classe de pacientes inpatients (IP) } \\
\text { e outpatients (OP), ou por tipo de } \\
\text { exame. }\end{array}$ & $\begin{array}{l}\text { Variância da } \\
\text { impontualidade } \\
\text { do paciente; } \\
\quad P_{n} ; P_{w}\end{array}$ & $\begin{array}{l}\text { IBFI, IBFIA, } \\
\text { 2BEG, 2BEGA, } \\
\text { MBFI, MBFIA, } \\
\text { OFFSET }(0,15 ; \\
0,30 ; 9) \text { e DOME } \\
(0,15 ; 0,40 ; 0,2 ; 6 \text {; } \\
\text { 13) combinadas } \\
\text { com HMBEG, } \\
\text { LMBEG, } \\
\text { ALTER1, } \\
\text { HMBND, } \\
\text { LMBND ou com } \\
\text { HPBEG e } \\
\text { LCVBEG. }\end{array}$ & $\begin{array}{l}\text { OFFSET-LMBEG, } \\
\text { DOME-ALTER1, } \\
\text { 2BEGA-LMBEG, } \\
\text { OFFSET-LMBEG, } \\
\text { IBFIA-HPBEG, } \\
\text { DOME-HPBEG e } \\
\text { IBFIA-LCVBEG. }\end{array}$ & $\begin{array}{l}\text { SED e } \\
\text { EC }\end{array}$ & 5 & $\begin{array}{l}\text { (1) Custo de } \\
\text { espera dos } \\
\text { pacientes; (2) } \\
\text { custo de } \\
\text { ociosidade do } \\
\text { médico; (3) } \\
\text { custo de horas } \\
\text { extras do } \\
\text { médico. }\end{array}$ \\
\hline
\end{tabular}




\begin{tabular}{|c|c|c|c|c|c|c|c|}
\hline Artigo & Descrição & $\begin{array}{c}\text { Análise de } \\
\text { sensibilida } \\
\text { de }\end{array}$ & Regras testadas & Melhores regras & Método & $\begin{array}{l}\mathrm{N}^{\mathrm{o}} \mathrm{de} \\
\text { Fatores }\end{array}$ & $\begin{array}{l}\text { Indicador de } \\
\text { desempenho }\end{array}$ \\
\hline $\begin{array}{l}\text { Bard } e t \\
\text { al. }(2016)\end{array}$ & $\begin{array}{l}\text { Estudaram um caso real de agendamento e } \\
\text { uma clínica de Cuidados Primários nos } \\
\text { Estados Unidos. Os autores simularam } \\
\text { regras de agendamento e propuseram a de } \\
\text { melhor desempenho (OFFSET). } \\
\text { Posteriormente, testaram a combinação da } \\
\text { OFFSET com diferentes regras de fila parc } \\
\text { acomodar os pacientes adiantados e } \\
\text { atrasados. A regra FCFS foi comparada } \\
\text { com variações de regra de fila baseada na } \\
\text { ordem de agendamento, tanto para os } \\
\text { pacientes adiantados quanto para os } \\
\text { atrasados. }\end{array}$ & $C V ; P_{n}$ & $\begin{array}{l}\text { (1) IBFI, 2BEG, } \\
\text { MBFI, OFFSET, } \\
\text { DOME e MBDM; (2) } \\
\text { FCFS, SEM } \\
\text { ANTECIPAÇÃO e } \\
\text { COM } \\
\text { ANTECIPAÇÃO; (3) } \\
\text { FCFS, FINAL DA } \\
\text { SEÇÃO, FINAL DA } \\
\text { FILA). }\end{array}$ & $\begin{array}{l}\text { (1) OFFSET, } \\
\text { DOME e IBFI; } \\
\text { (2) COM } \\
\text { ANTECIPAÇÃ } \\
\text { O; (3) FINAL } \\
\text { DA FILA. }\end{array}$ & $\begin{array}{l}\text { SED e } \\
\text { EC }\end{array}$ & 5 & $\begin{array}{l}\text { (1) Tempo total do } \\
\text { paciente na clínica; (2) } \\
\text { média do horário de } \\
\text { fim do dia. }\end{array}$ \\
\hline
\end{tabular}

PCLV = Percentual de pacientes com baixa variância; $C V=$ Coeficiente de variação do tempo de serviço; $\mu=$ média do tempo de serviço; $\sigma=$ desvio padrão do tempo de serviço; $P_{n}=$ taxa de noshow; $P_{w}=$ taxa de walkin; $N=n^{\circ}$ de pacientes agendados; $N^{\prime}=n^{\circ}$ de pacientes agendados ajustado; $C R=$ razão de custo do médico sobre o custo do paciente; SED = Simulação de eventos discretos; $P M=$ Programação matemática; $E C=$ Estudo de caso 


\section{Apêndice E - Teste estatístico do no-show por dia da semana}

Tabela 29 - Teste de significância da variação do no-show por dia da semana. Fonte: Elaboração própria.

\begin{tabular}{|c|c|c|c|c|c|c|c|c|}
\hline \multirow[b]{2}{*}{ Horário } & \multicolumn{3}{|c|}{ Frequencia Observada } & \multicolumn{3}{|c|}{ Valor Esperado } & \multirow{2}{*}{$\begin{array}{c}\text { Estatística } \\
\text { de teste } \\
\text { No-show } \\
\left(\mathrm{X}^{2}\right)\end{array}$} & \multirow{2}{*}{$\begin{array}{c}\text { Estatística } \\
\text { de teste } \\
\text { Show } \\
\left(\mathrm{X}^{2}\right)\end{array}$} \\
\hline & $\begin{array}{l}\text { No- } \\
\text { show }\end{array}$ & Show & $\begin{array}{c}\text { Tamanho } \\
\text { da } \\
\text { amostra }\end{array}$ & $\begin{array}{l}\text { No- } \\
\text { show }\end{array}$ & Show & $\begin{array}{c}\text { Tamanho } \\
\text { da } \\
\text { amostra }\end{array}$ & & \\
\hline $\begin{array}{l}\text { segunda- } \\
\text { feira }\end{array}$ & 187 & 482 & 669 & 173 & 496 & 669 & 1.13 & 0.39 \\
\hline quarta-feira & 151 & 487 & 638 & 165 & 473 & 638 & 1.19 & 0.41 \\
\hline \multirow[t]{2}{*}{ Total } & 338 & 969 & 1,307 & 338 & 969 & 1,307 & 2.32 & 0.81 \\
\hline & & & & & & & $\begin{array}{c}\mathrm{T} \\
\text { (calculado) } \\
\mathrm{T} \\
\text { (tabelado) } \\
\text { p-valor }\end{array}$ & $\begin{array}{r}3.84 \\
0.077\end{array}$ \\
\hline
\end{tabular}




\section{Apêndice F - Teste estatístico do no-show por classe de paciente}

Tabela 30 - Teste de significância da variação do no-show por classe de paciente. Fonte: Elaboração própria.

\begin{tabular}{|c|c|c|c|c|c|c|c|}
\hline Horário & $\begin{array}{l}\text { Fre } \\
\text { No- } \\
\text { show }\end{array}$ & encia $\mathrm{Ob}$ & $\begin{array}{l}\text { ervada } \\
\text { Tamanho } \\
\text { da } \\
\text { amostra }\end{array}$ & No-show & serado & $\begin{array}{c}\text { Estatística } \\
\text { de teste } \\
\text { No-show } \\
\left(\mathrm{X}^{2}\right)\end{array}$ & $\begin{array}{c}\text { Estatística } \\
\text { de teste } \\
\text { Show }\left(\mathrm{X}^{2}\right)\end{array}$ \\
\hline $1^{a} \mathrm{Vez}$ & 209.00 & 479.00 & 688.00 & 179.79 & 508.21 & 4.75 & 1.68 \\
\hline Marcação & 13.00 & 49.00 & 62.00 & 16.20 & 45.80 & 0.63 & 0.22 \\
\hline $\begin{array}{l}\text { Retorno Não } \\
\text { Operado }\end{array}$ & 76.00 & 312.00 & 388.00 & 101.39 & 286.61 & 6.36 & 2.25 \\
\hline $\begin{array}{l}\text { Retorno } \\
\text { Operado }\end{array}$ & 54.00 & 155.00 & 209.00 & 54.62 & 154.38 & 0.01 & 0.00 \\
\hline \multirow[t]{4}{*}{ Total } & 352.00 & 995.00 & 1347.00 & 352.00 & 995.00 & 11.75 & 4.16 \\
\hline & & & & & & $\begin{array}{c}\mathrm{T} \\
\text { (calculado) }\end{array}$ & 15.90 \\
\hline & & & & & & $\begin{array}{c}\mathrm{T} \\
\text { (tabelado) }\end{array}$ & 7.81 \\
\hline & & & & & & p-valor & 0.001 \\
\hline
\end{tabular}




\section{Apêndice G - Ajuste do no-show de cada horário pela proporção de pacientes}

Tabela 31 - Ajuste do no-show de cada horário pela proporção de pacientes. Fonte: Elaboração própria.

\begin{tabular}{cccccc}
\hline Horário & $\begin{array}{c}\text { Proporção } \\
\text { Primeira } \\
\text { Vez }\end{array}$ & $\begin{array}{c}\text { Proporção } \\
\text { Marcação }\end{array}$ & $\begin{array}{c}\text { Proporção } \\
\text { Retorno } \\
\text { Não } \\
\text { Operado }\end{array}$ & $\begin{array}{c}\text { Proporção } \\
\text { Retorno } \\
\text { Operado }\end{array}$ & $\begin{array}{c}\text { No-show esperado } \\
\text { (Soma em classe de } \\
\text { \% proporção * } \\
\text { \% no-show) }\end{array}$ \\
\hline 9h-10h & $47.96 \%$ & $4.08 \%$ & $22.45 \%$ & $25.51 \%$ & $26.41 \%$ \\
$10 \mathrm{~h}-11 \mathrm{~h}$ & $45.05 \%$ & $4.47 \%$ & $34.82 \%$ & $15.65 \%$ & $25.49 \%$ \\
$11 \mathrm{~h}-12 \mathrm{~h}$ & $47.04 \%$ & $5.59 \%$ & $28.95 \%$ & $18.42 \%$ & $25.89 \%$ \\
$13 \mathrm{~h}-14 \mathrm{~h}$ & $38.89 \%$ & $4.44 \%$ & $33.33 \%$ & $23.33 \%$ & $25.30 \%$ \\
$14 \mathrm{~h}-15 \mathrm{~h}$ & $53.78 \%$ & $3.59 \%$ & $26.29 \%$ & $16.33 \%$ & $26.46 \%$ \\
$15 \mathrm{~h}-16 \mathrm{~h}$ & $60.32 \%$ & $3.17 \%$ & $26.59 \%$ & $9.92 \%$ & $26.76 \%$ \\
$16 \mathrm{~h}-17 \mathrm{~h}$ & $51.38 \%$ & $6.32 \%$ & $32.02 \%$ & $10.28 \%$ & $25.86 \%$ \\
$17 \mathrm{~h}-18 \mathrm{~h}$ & $56.92 \%$ & $5.13 \%$ & $29.74 \%$ & $8.21 \%$ & $26.31 \%$ \\
$18 \mathrm{~h}-19 \mathrm{~h}$ & $75.00 \%$ & $0.00 \%$ & $20.31 \%$ & $4.69 \%$ & $27.97 \%$ \\
\hline \% no-show & $30.38 \%$ & $20.97 \%$ & $19.59 \%$ & $25.84 \%$ & \\
\hline
\end{tabular}




\section{Apêndice H - Teste estatístico do no-show por horário do dia}

Tabela 32 - Teste de significância da variação do no-show por horário do dia. Fonte: Elaboração própria.

\begin{tabular}{|c|c|c|c|c|c|c|c|}
\hline \multirow{2}{*}{ Horário } & \multicolumn{3}{|c|}{ Frequencia Observada } & \multicolumn{2}{|c|}{$\mathrm{N}^{\circ}$ esperado } & \multirow{2}{*}{$\begin{array}{c}\text { Estatística } \\
\text { de teste } \\
\text { No-show } \\
\left(\mathrm{X}^{2}\right)\end{array}$} & \multirow{2}{*}{$\begin{array}{c}\text { Estatística } \\
\text { de teste } \\
\text { Show } \\
\left(X^{2}\right)\end{array}$} \\
\hline & $\begin{array}{c}\text { No- } \\
\text { shows }\end{array}$ & Shows & $\begin{array}{c}\text { Tamanho } \\
\text { da } \\
\text { amostra }\end{array}$ & $\begin{array}{c}\text { No- } \\
\text { shows }\end{array}$ & Shows & & \\
\hline $9 \mathrm{~h}-10 \mathrm{~h}$ & 20.00 & 54.00 & 74.00 & 19.55 & 54.45 & 0.01 & 0.00 \\
\hline $10 \mathrm{~h}-11 \mathrm{~h}$ & 50.00 & 174.00 & 224.00 & 57.09 & 166.91 & 0.88 & 0.30 \\
\hline $11 \mathrm{~h}-12 \mathrm{~h}$ & 41.00 & 185.00 & 226.00 & 58.52 & 167.48 & 5.24 & 1.83 \\
\hline $13 \mathrm{~h}-14 \mathrm{~h}$ & 15.00 & 52.00 & 67.00 & 16.95 & 50.05 & 0.23 & 0.08 \\
\hline $14 \mathrm{~h}-15 \mathrm{~h}$ & 64.00 & 126.00 & 190.00 & 50.28 & 139.72 & 3.75 & 1.35 \\
\hline $15 \mathrm{~h}-16 \mathrm{~h}$ & 52.00 & 138.00 & 190.00 & 50.84 & 139.16 & 0.03 & 0.01 \\
\hline $16 h-17 \mathrm{~h}$ & 48.00 & 133.00 & 181.00 & 46.81 & 134.19 & 0.03 & 0.01 \\
\hline $17 \mathrm{~h}-18 \mathrm{~h}$ & 42.00 & 109.00 & 151.00 & 39.73 & 111.27 & 0.13 & 0.05 \\
\hline $18 \mathrm{~h}-19 \mathrm{~h}$ & 20.00 & 24.00 & 44.00 & 12.31 & 31.69 & 4.81 & 1.87 \\
\hline Total & 352.00 & 995.00 & $1,347.00$ & 352.08 & 994.92 & 15.10 & 5.49 \\
\hline & & & & & & $\begin{array}{c}\mathrm{T} \\
\text { (calculado) } \\
\mathrm{T} \\
\text { (tabelado) } \\
\text { p-valor }\end{array}$ & $\begin{array}{l}15.51 \\
0.004\end{array}$ \\
\hline
\end{tabular}




\section{Apêndice I - Teste estatístico do no-show por horário do dia (retirando faixa de 18h-19h)}

Tabela 33 - Teste de significância da variação do no-show por horário do dia, com exceção do horário de 18h-19h. Fonte: Elaboração própria.

\begin{tabular}{|c|c|c|c|c|c|c|c|}
\hline Horário & No-shows & ncia Obs & $\begin{array}{l}\text { ada } \\
\text { Tamanho } \\
\text { da } \\
\text { amostra }\end{array}$ & $\begin{array}{r}\mathrm{N}^{\circ} \\
\text { No- } \\
\text { shows }\end{array}$ & Shows & $\begin{array}{c}\text { Estatística } \\
\text { de teste } \\
\text { No-show } \\
\left(\mathrm{X}^{2}\right)\end{array}$ & $\begin{array}{l}\text { Estatística de } \\
\text { teste Show }\left(\mathrm{X}^{2}\right)\end{array}$ \\
\hline $9 \mathrm{~h}-10 \mathrm{~h}$ & 20.00 & 54.00 & 74.00 & 19.55 & 54.45 & 0.01 & 0.00 \\
\hline $10 \mathrm{~h}-11 \mathrm{~h}$ & 50.00 & 174.00 & 224.00 & 57.09 & 166.91 & 0.88 & 0.30 \\
\hline $11 \mathrm{~h}-12 \mathrm{~h}$ & 41.00 & 185.00 & 226.00 & 58.52 & 167.48 & 5.24 & 1.83 \\
\hline $13 \mathrm{~h}-14 \mathrm{~h}$ & 15.00 & 52.00 & 67.00 & 16.95 & 50.05 & 0.23 & 0.08 \\
\hline $14 \mathrm{~h}-15 \mathrm{~h}$ & 64.00 & 126.00 & 190.00 & 50.28 & 139.72 & 3.75 & 1.35 \\
\hline $15 \mathrm{~h}-16 \mathrm{~h}$ & 52.00 & 138.00 & 190.00 & 50.84 & 139.16 & 0.03 & 0.01 \\
\hline 16h-17h & 48.00 & 133.00 & 181.00 & 46.81 & 134.19 & 0.03 & 0.01 \\
\hline $17 \mathrm{~h}-18 \mathrm{~h}$ & 42.00 & 109.00 & 151.00 & 39.73 & 111.27 & 0.13 & 0.05 \\
\hline Total & 332.00 & 971.00 & $1,303.00$ & 339.77 & 963.23 & 10.29 & 3.63 \\
\hline & & & & & & $\begin{array}{c}\mathrm{T} \\
\text { (calculado) } \\
\mathrm{T} \\
\text { (tabelado) }\end{array}$ & $\begin{array}{l}13.92 \\
14.07\end{array}$ \\
\hline & & & & & & p-valor & 0.053 \\
\hline
\end{tabular}




\section{Apêndice $\mathrm{J}$ - Formulação da regra proposta (DOME CYCLE)}

A formulação da regra DOME CYCLE é explicada a seguir. Seja $t_{i}$ o horário de agendamento do paciente $i, \mu$ o tempo médio de consulta, $\beta_{i}$ parâmetros que ajustam quão cedo ou tarde serão os horários de agendamentos comparados com a regra usual IBFI, $k_{i}$ o parâmetro que define quais pacientes que chegarão mais cedo ou mais tarde comparado com a regra IBFI e $P$ o tamanho do período. $\mathrm{O}$ valor de $P$ pode ser calculado dividindo o $N$ em duas ou mais partes. Neste estudo, verificou-se que é interessante separar em ciclos de forma que cada ciclo tenha menos de 10 pacientes agendados. Ou seja, se existem 16 pacientes, deve-se dividir o ciclo em duas partes, mas se existem 24 , deve-se dividir o ciclo em três partes.

\section{- DOME CYCLE:}

Período 1:

$t_{1}=0$

$t_{i}=(i-1) \mu-\beta_{1}\left(k_{1}-i\right) \sigma$, para todo $i \leq k_{1}$

$t_{i}=(i-1) \mu+\beta_{2}\left(i-k_{1}\right) \sigma$, para todo $k_{1}<i<k_{2}$

$$
t_{i}=(i-1) \mu-\beta_{3}\left(i-k_{2}\right) \sigma \text {, para todo } k_{2} \leq i \leq P
$$

A partir do primeiro paciente agendado em cada período, o próximo ciclo começa e o valor de $i$ retorna para 1 .

Outros períodos:

$$
\begin{aligned}
& t_{i}=(i-1) \mu-\beta_{1}\left(k_{1}-i\right) \sigma, \text { para todo } i \leq k_{1} \\
& t_{i}=(i-1) \mu+\beta_{2}\left(i-k_{1}\right) \sigma, \text { para todo } k_{1}<i<k_{2} \\
& t_{i}=(i-1) \mu-\beta_{3}\left(i-k_{2}\right) \sigma, \text { para todo } i \geq k_{2}
\end{aligned}
$$

